University of Tennessee Health Science Center

UTHSC Digital Commons

$12-2015$

\title{
Optimization of Lead Spectinamide Compounds as Novel Anti- tuberculosis Agents with a Pharmacometric Approach
}

\author{
Ashit Rasendu Trivedi \\ University of Tennessee Health Science Center
}

Follow this and additional works at: https://dc.uthsc.edu/dissertations

Part of the Medicinal and Pharmaceutical Chemistry Commons, and the Pharmaceutics and Drug Design Commons

\section{Recommended Citation}

Trivedi, Ashit Rasendu , "Optimization of Lead Spectinamide Compounds as Novel Anti-tuberculosis Agents with a Pharmacometric Approach" (2015). Theses and Dissertations (ETD). Paper 399. http://dx.doi.org/10.21007/etd.cghs.2015.0323.

This Dissertation is brought to you for free and open access by the College of Graduate Health Sciences at UTHSC Digital Commons. It has been accepted for inclusion in Theses and Dissertations (ETD) by an authorized administrator of UTHSC Digital Commons. For more information, please contact jwelch30@uthsc.edu. 


\title{
Optimization of Lead Spectinamide Compounds as Novel Anti-tuberculosis Agents with a Pharmacometric Approach
}

\author{
Abstract \\ In an effort to combat the global Tuberculosis pandemic, Dr.Richard E. Lee and his group at St.Jude \\ Children's Research Hospital designed a novel series of anti-tuberculosis agents, spectinamides - semi- \\ synthetic analogs of spectinomycin. Spectinamides are a potent inhibitor of mycobacterial ribosomes \\ and overcome efflux mediated drug resistance in $\mathrm{M}$. tb. Spectinamides have shown an excellent in vitro \\ activity, which makes them well suited for further lead optimization and preclinical development. We \\ hypothesized that through pharmacokinetic (PK) and pharmacodynamics (PD) model-based dosing \\ optimization studies, we could strategically guide the selection and refinement of more potent and \\ effective anti-TB spectinamides. Biopharmaceutical in vitro screening demonstrated that spectinamides \\ in general have low plasma protein binding and are stable against hepatic microsomal metabolism. In \\ vivo pharmacokinetic studies in rats revealed that the kidneys are the major route of elimination for \\ spectinamides in their unchanged form. Radiolabeled biodistribution studies showed $84.7 \%$ of \\ radioactivity accumulated $70 \%$ in urine, $12.6 \%$ in feces, and the remainder in the blood and other major \\ organs. The unaccounted for residual $15.3 \%$ likely distributed into the epidermis and other surface tissue. \\ In multiple-dose accumulation studies, the Cmax of radiolabeled compound after the 1 st dose and the 8th \\ dose of twice-daily dosing regimen was similar: $3.39 \mu \mathrm{Ci} / \mathrm{mL}$ and $3.55 \mu \mathrm{Ci} / \mathrm{mL}$, suggesting no relevant \\ accumulation of parent drug and metabolites. The concentration of radiolabeled compound was three \\ times more in lungs and spleen as compared to whole blood, suggesting good tissue penetration. \\ Macrophage uptake studies showed that Lee 1329, Lee1445 and Lee 1599 had significantly higher \\ macrophage uptake than spectinomycin and streptomycin. Lee 1329 showed 6-fold and 2.2-fold higher \\ uptake than streptomycin and spectinomycin, respectively. Based on the results of the in vitro \\ experiments and preliminary PK/PD studies in rats, Lee 1599 was selected as the lead candidate \\ compound. To predict PK/PD indices of antimicrobial efficacy, we performed model-based dosing \\ optimization studies with Lee 1599. We used an in vitro PK/PD model system to simulate the rat PK \\ conditions while evaluating antibacterial activities to predict effective dosing regimens for further in vivo \\ efficacy studies. Our results have shown that Lee 1599 exhibits dose-dependent bactericidal effect. Lee \\ 1599 showed up to 4 -log reductions in bacterial counts at 100mg QD dosing. The PK/PD indices \\ demonstrated that Lee 1599 elicits a concentration- and time-dependent killing with AUC/MIC as the \\ optimal index. The model was put through numerical simulations to predict the effect of Lee 1599 in mice \\ at various dosing regimens. The in vitro PK/PD simulated profile has suggested that high doses with \\ frequent dosing intervals may demonstrate optimum in vivo efficacy. Consequently, we aimed to \\ determine the pharmacodynamic interaction between Lee 1599 and existing anti-tuberculosis agent. We \\ selected rifampicin as a model compound and applied a parametric approach to quantitatively assess the \\ pharmacodynamic drug interaction between Lee 1599 and rifampicin. The three dimensional surface \\ response assay demonstrated that there is an additive effect between both the agents as opposed to the \\ conventional checkerboard assay, which suggested synergism between these agents. The results of \\ surface response assay were validated using an in vitro PK/PD model for combination agents and in vivo \\ efficacy trials, which showed an additive effect between Lee 1599 and rifampicin. Thus, quantitative \\ assays such as the surface response assay seem to provide more reliable information on \\ pharmacodynamic interactions as opposed to qualitative methods such as checkerboard assay. In \\ conclusion, we have successfully supported the further development of spectinamides using a \\ pharmacometric approach. We have identified a lead candidate compound Lee 1599 using an iterative \\ PK/PD approach for its pre-clinical drug development. The application of PK/PD knowledge is essential \\ for translating the in vitro screening assay findings to the in vivo stage, thus accelerating the drug \\ development process. The results of the above studies can be used as a roadmap for the optimization of \\ anti-infective agents in the early drug discovery and pre-clinical developmental phase.
}




\section{Document Type \\ Dissertation \\ Degree Name \\ Doctor of Philosophy (PhD) \\ Program \\ Pharmaceutical Sciences \\ Research Advisor \\ Bernd Meibohm, Ph.D., FCP}

\section{Keywords}

Anti-infectives, Modeling, Pharmacodynamics, Pharmacokinetics, Pharmacometrics, Simulations

\section{Subject Categories}

Medicinal and Pharmaceutical Chemistry | Medicine and Health Sciences | Pharmaceutics and Drug Design | Pharmacy and Pharmaceutical Sciences 


\title{
OPTIMIZATION OF LEAD SPECTINAMIDE COMPOUNDS AS NOVEL ANTI-
} TUBERCULOSIS AGENTS WITH A PHARMACOMETRIC APPROACH

\author{
A Dissertation \\ Presented for \\ The Graduate Studies Council \\ The University of Tennessee \\ Health Science Center
}

\author{
In Partial Fulfillment \\ Of the Requirements for the Degree \\ Doctor of Philosophy \\ From The University of Tennessee
}

By

Ashit Rasendu Trivedi

December 2015 
Chapter 1 (C) 2013 by Informa Healthcare.

All other material (C) 2015 by Ashit Rasendu Trivedi.

All rights reserved. 


\section{DEDICATION}

It is not the destination; it is about the journey... 


\section{ACKNOWLEDGEMENTS}

Although the journey for the doctor of philosophy degree was certainly lengthy, adventurous and eventful, there are number of people that I want to acknowledge and express my gratitude for making it beautiful and memorable. Firstly, I would like to thank and appreciate my mentor Dr. Bernd Meibohm who believed me and provided me with a wonderful opportunity of working with him under his direct supervision. It would not have been easier for me to learn and accomplish multiple things without your support and guidance. My committee members: Dr. Richard Lee, Dr. Ryan Yates, Dr. David Rogers and Dr. Julian Hurdle have played an instrumental role in my academic and scientific progress towards my PhD degree. I want to thank Dr. Richard Lee especially for allowing me to work on spectinamide project without which my research work would not have been possible. Special thanks to Dr. Richard Lee's lab members: Robin Lee, Dr. David Bruhn, Marcus Maddox and Dr. Jiuyu Liu for teaching me microbiology skills, giving me the compounds for performing all research work and MIC data; our collaborators Dr. Anne Leanarts and her team for providing in vivo data to support and navigate my research findings. I am also grateful to Dr. Neeraj Gupta, Director in Clinical Pharmacology at Takeda (Millennium) Pharmaceuticals, Cambridge who offered me with an internship position and contributed to my scientific and career development.

Secondly, I wish to extend the appreciation to my previous and current lab members (also my friends) for being my support system and helping me troubleshoot the research problems during the course of my research work. These amazing people are Dr. Nageshwar Budha, Dr. Pavan Kumar Vaddady, Dr. Satyendra Suryawanshi, Dr. Yi Zhang, Wararat Limothai, Dr. Margaret Thomson, Dr. Lei Diao, Dr. Dorababu Madhura, Chetan Rathi, Dr. Sumit Rawal, Dr. Josiah Ryman, Karoline Kromke and Sophie Krauel. My sincere thanks to the staff members Jennifer Stabenow, Dr. Jan Peters, Samuel Woods, Robert Benson and John Shelton of Regional Biocontainment Lab for making my life easier by providing us a space to carry out the microbiology experiments and for extending their technical support at any given point of time. I also wish to acknowledge Brenda Thornton, Corliss Finlay and Benita Williams in the Department of Pharmaceutical Science for providing administrative aid. A special note of appreciation to my friends and colleagues Jordan Toutounchian, Jeffrey Pressly, Dileep Janagam, Diwa Koirala, Shajila Siricilla, Dr. Nivesh Mittal, Dr. Sarah Whaley, Dr. Andrew Nishimoto and Beth Ladner Berkow.

It was not an easy task for me to leave behind old good friends and settle in Memphis without any known person. It was possible to move forward only because of my dear friends Varun, Ramya, Nikunj, Dipti, Pallavi, Satyajeet, Spurthi and Vishwanath who encouraged and supported me at every step during my graduate studies. I also met new people here in Memphis and they definitely became good friends over the period of five years making me feel home. Thanks a lot Vaibhav, Viraj, Sumana, Rajashree, Kavisha, Kiraat, Satya and Saini for some great memories that we will cherish together in years to come. 
None of the above things would have been possible without my dedicated parents who taught me everything and supported me with every decision and correcting me whenever I was wrong. Thanks mummy and papa for this awesome upbringing and my sister, Sneha for entertaining me every single day over the phone and making me feel I am home with them in India. 


\begin{abstract}
In an effort to combat the global Tuberculosis pandemic, Dr.Richard E. Lee and his group at St.Jude Children's Research Hospital designed a novel series of antituberculosis agents, spectinamides - semi-synthetic analogs of spectinomycin. Spectinamides are a potent inhibitor of mycobacterial ribosomes and overcomes efflux mediated drug resistance in $M . t b$.

Spectinamides have shown an excellent in vitro activity, which makes them well suited for further lead optimization and preclinical development. We hypothesized that through pharmacokinetic (PK) and pharmacodynamics (PD) model-based dosing optimization studies, we could strategically guide the selection and refinement of more potent and effective anti-TB spectinamides.

Biopharmaceutical in vitro screening demonstrated that spectinamides in general have low plasma protein binding and are stable against hepatic microsomal metabolism. In vivo pharmacokinetic studies in rats revealed that the kidneys are the major route of elimination for spectinamides in their unchanged form. Radiolabeled biodistribution studies showed $84.7 \%$ of radioactivity accumulated $70 \%$ in urine, $12.6 \%$ in feces, and the remainder in the blood and other major organs. The unaccounted for residual $15.3 \%$ likely distributed into the epidermis and other surface tissue. In multiple-dose accumulation studies, the $\mathrm{C}_{\max }$ of radiolabeled compound after the $1 \mathrm{st}$ dose and the 8 th dose of twice-daily dosing regimen was similar: $3.39 \mu \mathrm{Ci} / \mathrm{mL}$ and $3.55 \mu \mathrm{Ci} / \mathrm{mL}$, suggesting no relevant accumulation of parent drug and metabolites. The concentration of radiolabeled compound was three times more in lungs and spleen as compared to whole blood, suggesting good tissue penetration. Macrophage uptake studies showed that Lee 1329, Lee1445 and Lee 1599 had significantly higher macrophage uptake than spectinomycin and streptomycin. Lee 1329 showed 6-fold and 2.2-fold higher uptake than streptomycin and spectinomycin, respectively.
\end{abstract}

Based on the results of the in vitro experiments and preliminary $\mathrm{PK} / \mathrm{PD}$ studies in rats, Lee 1599 was selected as the lead candidate compound. To predict PK/PD indices of anti-microbial efficacy, we performed model-based dosing optimization studies with Lee 1599. We used an in vitro PK/PD model system to simulate the rat PK conditions while evaluating antibacterial activities to predict effective dosing regimens for further in vivo efficacy studies. Our results have shown that Lee 1599 exhibits dose-dependent bactericidal effect. Lee 1599 showed up to 4-log reductions in bacterial counts at $100 \mathrm{mg}$ QD dosing. The PK/PD indices demonstrated that Lee 1599 elicits a concentration- and time-dependent killing with AUC/MIC as the optimal index. The model was put through numerical simulations to predict the effect of Lee 1599 in mice at various dosing regimens. The in vitro $\mathrm{PK} / \mathrm{PD}$ simulated profile has suggested that high doses with frequent dosing intervals may demonstrate optimum in vivo efficacy.

Consequently, we aimed to determine the pharmacodynamic interaction between Lee 1599 and existing anti-tuberculosis agent. We selected rifampicin as a model 
compound and applied a parametric approach to quantitatively assess the pharmacodynamic drug interaction between Lee 1599 and rifampicin. The three dimensional surface response assay demonstrated that there is an additive effect between both the agents as opposed to the conventional checkerboard assay, which suggested synergism between these agents. The results of surface response assay were validated using an in vitro PK/PD model for combination agents and in vivo efficacy trials, which showed an additive effect between Lee 1599 and rifampicin. Thus, quantitative assays such as the surface response assay seem to provide more reliable information on pharmacodynamic interactions as opposed to qualitative methods such as checkerboard assay.

In conclusion, we have successfully supported the further development of spectinamides using a pharmacometric approach. We have identified a lead candidate compound Lee 1599 using an iterative PK/PD approach for its pre-clinical drug development. The application of PK/PD knowledge is essential for translating the in vitro screening assay findings to the in vivo stage, thus accelerating the drug development process. The results of the above studies can be used as a roadmap for the optimization of anti-infective agents in the early drug discovery and pre-clinical developmental phase. 


\section{TABLE OF CONTENTS}

\section{CHAPTER 1. APPLICATION OF PHARMACOMETRICS IN THE CLINICAL DRUG DEVELOPMENT OF ANTI-INFECTIVES ...................................1}

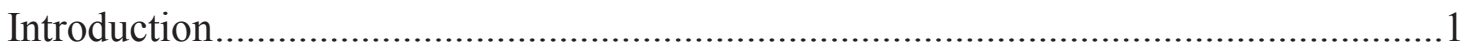

Pharmacometrics in Anti-infective Drug Development .................................................

Prerequisites for the Application of Pharmacometrics ...................................................

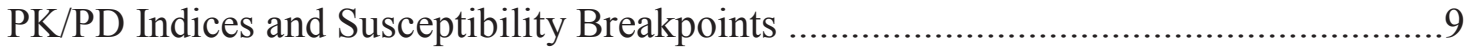

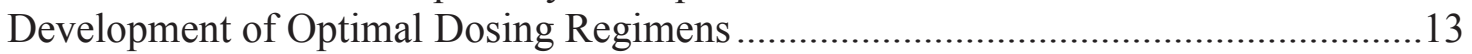

Optimization of Clinical Studies and Clinical Applications...........................................15

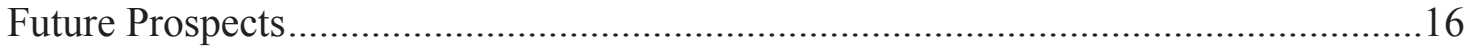

CHAPTER 2. CENTRAL HYPOTHESIS .....................................................................19

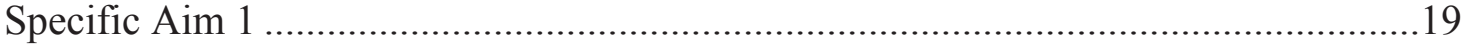

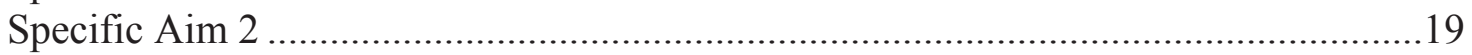

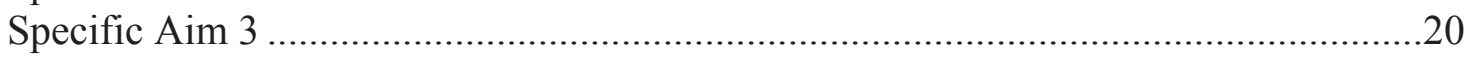

\section{CHAPTER 3. PHARMACOKINETICS AND BIODISTRIBUTION OF A} NOVEL SERIES OF ANTI-TUBERCULOSIS AGENTS: SPECTINAMIDES.......21

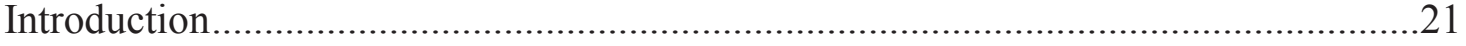

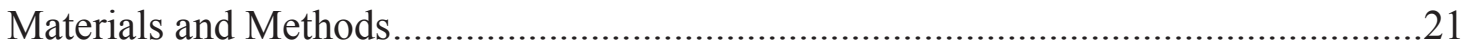

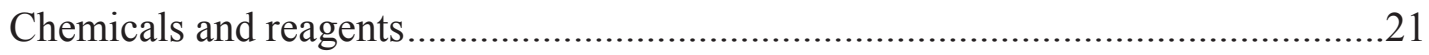

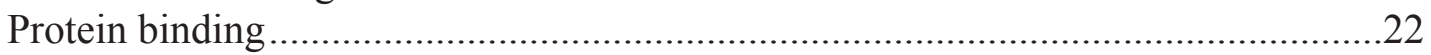

Formulation preparation and administration .......................................................22

Pharmacokinetic studies...................................................................................22

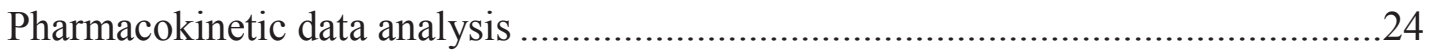

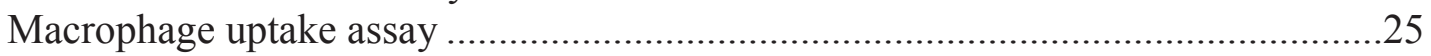

Sample preparation and LC-MS/MS analysis .....................................................25

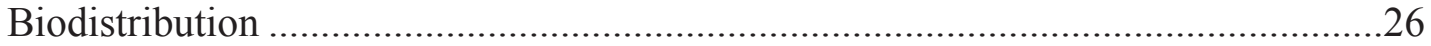

Sample preparation of biological samples for ${ }^{3} \mathrm{H}-1329 \ldots \ldots \ldots \ldots \ldots \ldots \ldots \ldots \ldots \ldots \ldots \ldots \ldots \ldots \ldots . . .26$

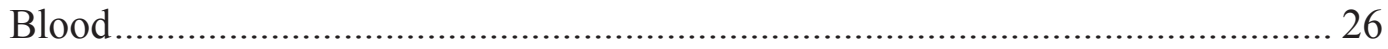

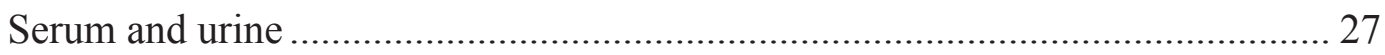

Organs and muscle tissue ................................................................................. 27

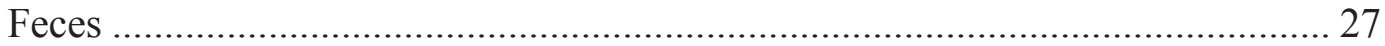

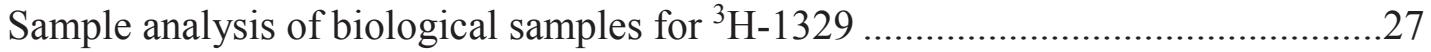

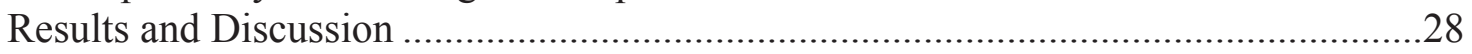

Biopharmaceutical properties of spectinamides …………...................................28

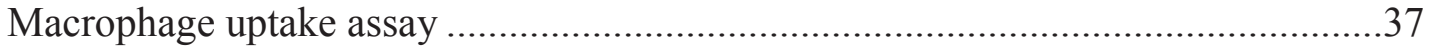

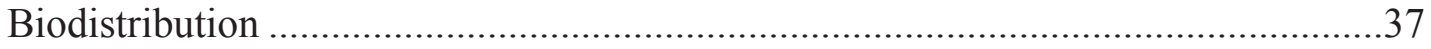

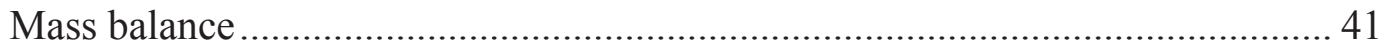

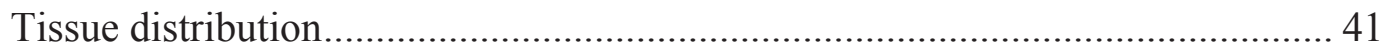

Pharmacokinetic profile of radioactivity in serum............................................... 41

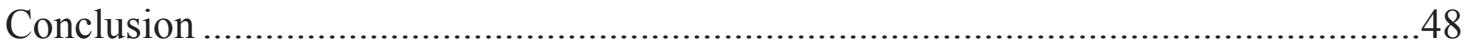




\section{CHAPTER 4. A PHARMACOMETRICS-BASED APPROACH USING IN VITRO PK/PD MODELING TO DEVELOP DOSING REGIMENS FOR IN VIVO STUDIES FOR A NOVEL SPECTINAMIDE ANTI-TUBERCULOSIS

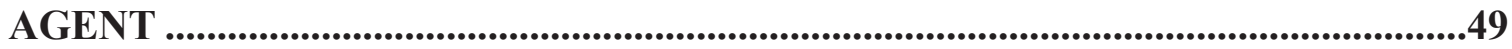

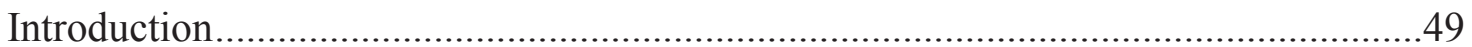

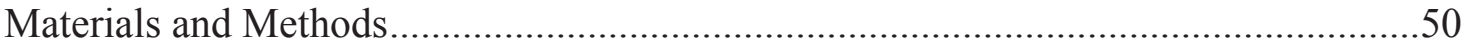

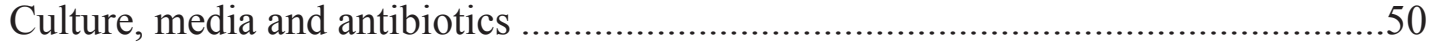

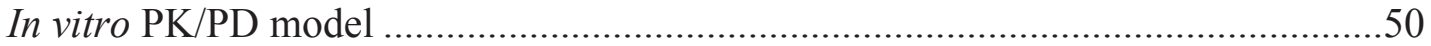

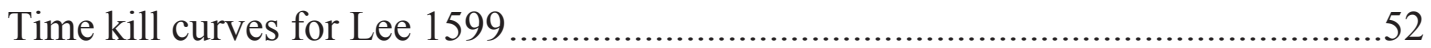

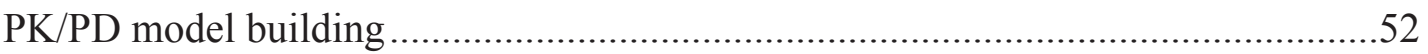

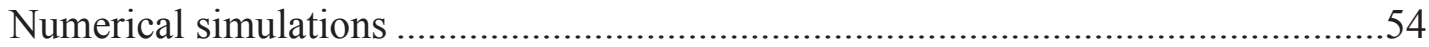

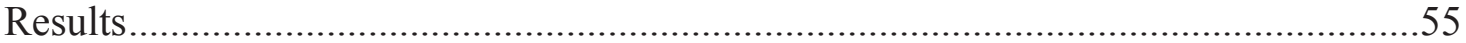

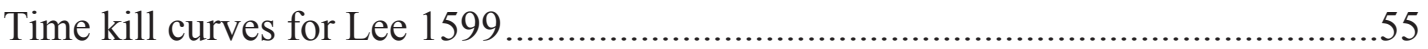

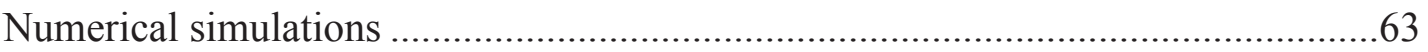

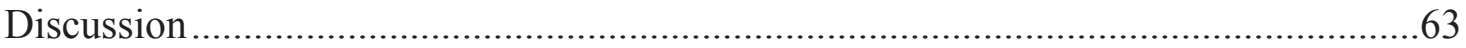

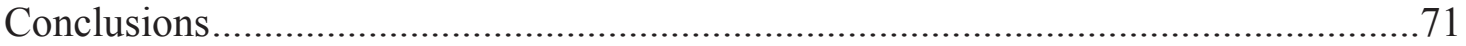

\section{CHAPTER 5. APPLICATION OF PHARMACOMETRIC TOOLS FOR IDENTIFYING PHARMACODYNAMIC INTERACTIONS IN ANTIBIOTIC

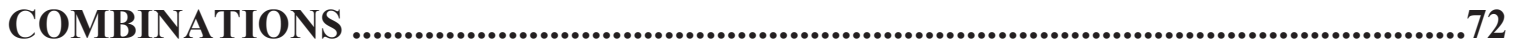

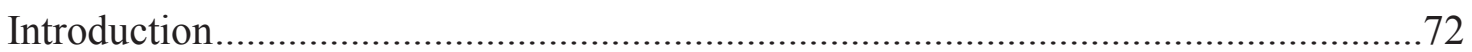

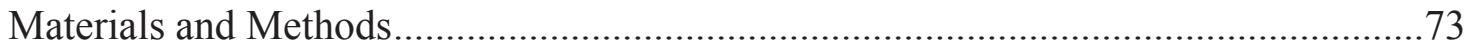

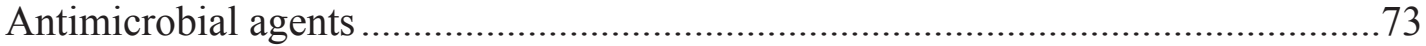

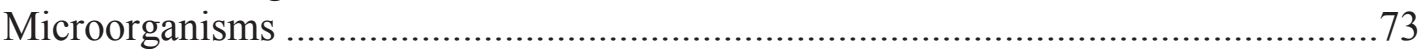

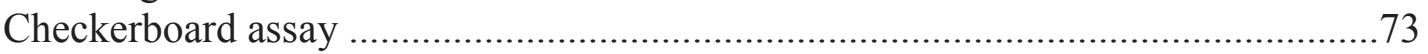

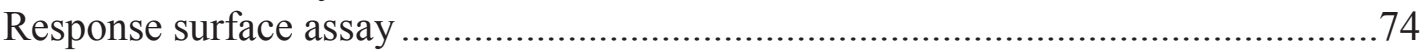

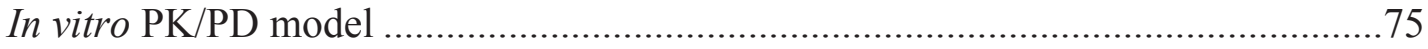

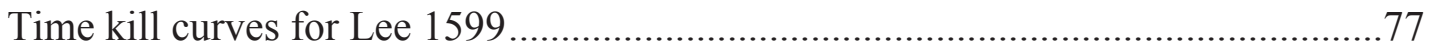

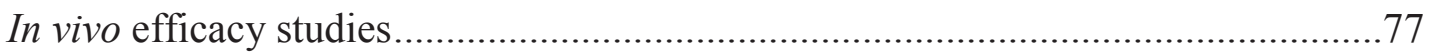

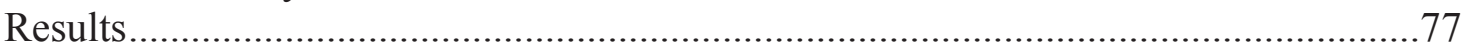

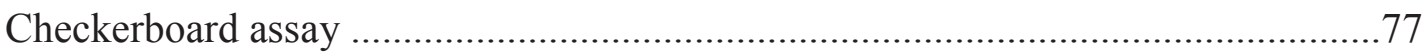

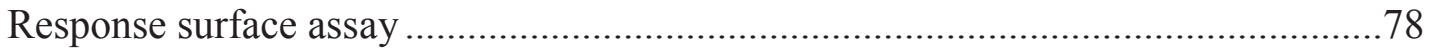

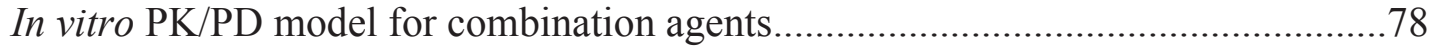

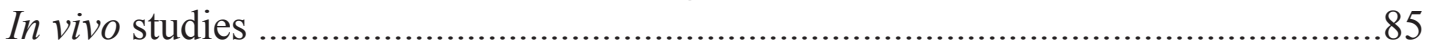

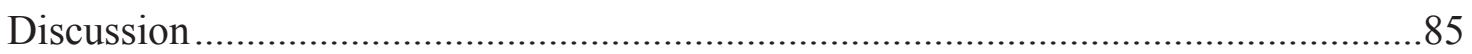

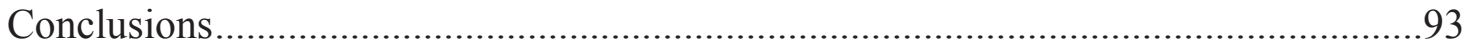

CHAPTER 6. SUMMARY ...............................................................................................94

LIST OF REFERENCES ..............................................................................................96

VITA 


\section{LIST OF TABLES}

Table 1-1. Examples of the application of pharmacometrics analyses for antiinfectives.

Table 3-1. Physico-chemical properties and pharmacokinetic parameters for spectinamides after intravenous administration at $10 \mathrm{mg} / \mathrm{kg}$ dose

Table 3-2. Mean concentration of drug uptake into J774A.1 murine macrophage cell line at $24 \mathrm{~h}$ for two different doses.

Table 3-3. Tissue distribution and recovery of radioactivity (mean $(\% \mathrm{CV})$ ) following IV administration of ${ }^{3} \mathrm{H}-1329$ at $0.9 \mathrm{mg} / \mathrm{kg}$ BID for 4.5 days in rats.

Table 3-4. Serum pharmacokinetic parameters after the 1st and 8th intravenous dose of $0.9 \mathrm{mg} / \mathrm{kg}^{3} \mathrm{H}-1329$ (values are expressed as mean $(\% \mathrm{CV})$ ).

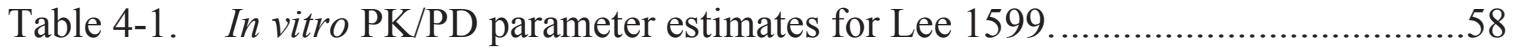

Table 4-2. Empirical PK/PD indices based on day 4 data.

Table 5-1. Checkerboard assay results to determine pharmacodynamic interaction between Lee 1599 and RIF.

Table 5-2. Results of three dimensional surface response assay.

Table 5-3. Summary of results of pharmacodynamics interactions from different methods.

Table 5-4. Comparison of \%AUC ratios (the \%AUC were normalized with AUC of control group). 


\section{LIST OF FIGURES}

Figure 1-1. Illustration of interplay of pharmacology, microbiology, physiology, disease and their association with pharmacometric evaluations in the clinical development and application of anti-infectives.

Figure 1-2. Illustration of the $\mathrm{PK} / \mathrm{PD}$ indices at steady state during multiple dosing:

(i) $\mathrm{T}>\mathrm{MIC}$ : Time above MIC (ii) $\mathrm{Cmax} / \mathrm{MIC}$ (iii) $\mathrm{AUC} / \mathrm{MIC}$.

Figure 3-1. Chemical structure of lead spectinamides with MIC values.

Figure 3-2. Measured plasma concentration-time profiles (mean $\pm \mathrm{SEM})$ after intravenous $(10 \mathrm{mg} / \mathrm{Kg})$ and oral $(100 \mathrm{mg} / \mathrm{Kg})$ administration of Lee 1544 in rats.

Figure 3-3. Measured plasma concentration-time profiles (mean \pm SEM) after intravenous $(10 \mathrm{mg} / \mathrm{Kg})$ and oral $(100 \mathrm{mg} / \mathrm{Kg})$ administration of Lee 1599 in rats.

Figure 3-4. Measured plasma concentration-time profiles (mean \pm SEM) after intravenous $(10 \mathrm{mg} / \mathrm{Kg})$ and oral $(100 \mathrm{mg} / \mathrm{Kg})$ administration of Lee 1601 in rats.

Figure 3-5. Measured plasma concentration-time profiles (mean \pm SEM) after intravenous $(10 \mathrm{mg} / \mathrm{Kg})$ and oral $(100 \mathrm{mg} / \mathrm{Kg})$ administration of Lee 1603 in rats.

Figure 3-6. Measured plasma concentration-time profiles (mean \pm SEM) after intravenous $(10 \mathrm{mg} / \mathrm{Kg})$ and oral $(100 \mathrm{mg} / \mathrm{Kg})$ administration of Lee 1661 in rats.

Figure 3-7. Measured plasma concentration-time profiles (mean $\pm \mathrm{SEM}$ ) after intravenous $(10 \mathrm{mg} / \mathrm{Kg})$ administration of Lee 1666 in rats.

Figure 3-8. Measured plasma concentration-time profiles (mean $\pm \mathrm{SEM}$ ) after intravenous $(10 \mathrm{mg} / \mathrm{Kg})$ administration of spectinomycin in rats.

Figure 3-9. Mean average concentrations ( \pm SEM) of drug uptake into J774A.1 murine macrophage cell line at $24 \mathrm{~h}$.

Figure 3-10. Fold differences in drug uptake in J774A.1 murine macrophage cell line. ...40

Figure 3-11. Mass balance and percentage distribution of Lee 1329-T at $1 \mathrm{~h}$ post $9^{\text {th }}$ dose of $0.9 \mathrm{mg} / \mathrm{kg}$.

Figure 3-12. Amount of radioactivity (mean \pm SD) excreted in urine after each dosing interval $\left(0.9 \mathrm{mg} / \mathrm{kg}{ }^{3} \mathrm{H}-1329\right.$, BID for 4.5 days $)$. 
Figure 3-13. Fold difference (mean $\pm \mathrm{SD}$ ) in tissue distribution of radioactivity compared to amount in whole blood (after normalizing the distributions to $\mu \mathrm{Ci} / \mathrm{mL}$ or $\mu \mathrm{Ci} / \mathrm{mg}$ of blood or tissue).

Figure 3-14. Comparison of single and multiple dose pharmacokinetics showing average $( \pm \mathrm{SD})$ serum concentration-time profiles of radioactivity after the 1 st dose and 8 th dose during multiple dosing with $0.9 \mathrm{mg} / \mathrm{kg}^{3} \mathrm{H}-$ 1329 given intravenously every $12 \mathrm{~h}$.

Figure 4-1. A representation of working unit of an in vitro PK/PD model.

Figure 4-2. Schematic representation of PK/PD model to describe the rate of change in the number of bacteria in the in vitro $\mathrm{PK} / \mathrm{PD}$ model system.

Figure 4-3. Timekill effect of Lee 1599 against M. bovis BCG ( $\mathrm{N}_{0}$ : 6-7 log $\mathrm{CFU} / \mathrm{mL}$ ) with observed $\log \mathrm{CFU} / \mathrm{mL}$ plotted against time for different dosing regimens.

Figure 4-4. Timekill effect of Lee 1599 against M. bovis $\mathrm{BCG}\left(\mathrm{N}_{0}: 7-8 \log \right.$ $\mathrm{CFU} / \mathrm{mL}$ ) with observed $\log \mathrm{CFU} / \mathrm{mL}$ plotted against time for different dosing regimens.

Figure 4-5. Panels showing goodness of fit plots for the Lee 1599 PK/PD model fit (A.) DV vs PRED (B.) DV vs IPRED (C.) PRED vs CWRES (D.) TIME vs CWRES.

Figure 4-6. Plots showing measured (DV is observed data), individual predictions IPRED (black lines) and population predictions (red lines) for M. bovis BCG CFU/mL over time for the Lee 1599 PK/PD model.

Figure 4-7. Relationship between PK/PD indices and microbial kill on Day 4 after treatment.

Figure 4-8. Schematic representation of PK/PD model used for simulations. .64

Figure 4-9. Time kill curves calculated from 1000 numerical simulations for once daily dosing regimen of Lee 1599 in mice.

Figure 4-10. Time kill curves calculated from 1000 numerical simulations for twice daily dosing regimen of Lee 1599 in mice. .66

Figure 4-11. Time kill curves calculated from 1000 numerical simulations for thrice daily dosing regimen of Lee 1599 in mice.

Figure 4-12. Time kill curves calculated from 1000 numerical simulations for once daily (5 days a week) dosing regimen of Lee 1599 in mice. 
Figure 4-13. Time kill curves calculated from 1000 numerical simulations for twice daily (5 days a week) dosing regimen of Lee 1599 in mice.

Figure 5-1. A representation of in vitro PK/PD model set up for dynamic time-kill studies.

Figure 5-2. Model fits of bacterial burden at 24h in static time kill studies for Lee 1599 (A) and RIF (B) to obtain the parameter estimates such as $\mathrm{E}_{0}$, Emax and $\mathrm{EC}_{50}$ .80

Figure 5-3. Observed effect of combination agent Lee 1599 and RIF.... .81

Figure 5-4. Model predicted effect of the combination compound Lee 1599 and RIF...82

Figure 5-5. In vitro PK/PD dynamic time kill study for Lee 1599, RIF and its combination with different doses.

Figure 5-6. The bacterial log reduction with different doses using an in vitro PK/PD dynamic time kill experiment. .86

Figure 5-7. In vivo efficacy trial data showing bacterial burden reduction (log $\mathrm{CFU} / \mathrm{mL}$ ) in the lungs of $M$. $t b$ infected mice, $\mathrm{N}=6$ for Lee 1599 and Lee $1599+\mathrm{RIF}, \mathrm{N}=5$ for RIF.

Figure 5-8. Comparison of $\%$ AUC ratios after the $\%$ AUC were normalized with AUC of control group indicating higher the \%AUC ratio, greater the bacterial killing. 


\section{LIST OF ABBREVIATIONS}

\begin{tabular}{|c|c|}
\hline $\mathrm{ABC}$ & ATP binding cassette \\
\hline AIC & Akaike information criterion \\
\hline ATCC & American type culture collection \\
\hline AUC & Area under the curve \\
\hline $\mathrm{AUC}_{\mathrm{ss}, 0-24}$ & Area under the curve at steady state plasma concentration \\
\hline BAL & Bronchoalveolar lavage fluid \\
\hline BCG & Bacillus calmette-guérin \\
\hline $\mathrm{BIC}$ & Bayesian information criterion \\
\hline BID & Twice daily \\
\hline CAP & Community acquired pneumonia \\
\hline CFU & Colony forming unit \\
\hline CKD & Chronic kidney disease \\
\hline $\mathrm{CL}$ & Clearance \\
\hline $\mathrm{CL}_{\mathrm{Cr}}$ & Creatinine clearance \\
\hline $\mathrm{CL}_{\mathrm{r}}$ & Renal clearance \\
\hline CLSI & Clinical laboratory standards institute \\
\hline $\mathrm{C}_{\max }$ & Maximum plasma concentration \\
\hline CSF & Cerebrospinal fluid \\
\hline CVVHDF & Continuous venovenous hemodiafiltration \\
\hline DI & Deionized water \\
\hline DMEM & Dulbecco's modified eagle's medium \\
\hline DPBS & Dulbecco's phosphate-buffered saline \\
\hline DPM & Disintegrations per minute \\
\hline EBA & Early bactericidal activity \\
\hline ELF & Epithelial lining fluid \\
\hline EMA & European medicines agency \\
\hline $\mathrm{F}$ & Oral bioavailability \\
\hline $\mathrm{f}_{\mathrm{e}}$ & Fraction excreted unchanged in the urine \\
\hline FICI & Fractional inhibitory concentration index \\
\hline $\mathrm{fup}_{\mathrm{u}}$ & fraction unbound in plasma \\
\hline GFR & Glomerular filtration rate \\
\hline HAART & Highly active antiretroviral therapy \\
\hline HDA & High dose aerosol \\
\hline HFIM & Hollow fiber infection model \\
\hline HIV & Human immunodeficiency virus \\
\hline $\mathrm{IC}_{50}$ & Concentration required to produce half-maximal effect \\
\hline II & Interaction index \\
\hline$I_{\max }$ & Maximum bacterial kill rate \\
\hline IV & Intravenous \\
\hline LC-MS/MS & Liquid chromatography-mass spectrometry \\
\hline LDA & Low dose aerosol \\
\hline $\mathrm{M} \& \mathrm{~S}$ & Modeling and simulations \\
\hline MDR & Multi drug resistant \\
\hline
\end{tabular}




\begin{tabular}{ll} 
MIC & Minimum inhibitory concentration \\
MPC & Mutant prevention concentration \\
MRSA & Methicillin-resistant Staphylococcus aureus \\
MRT & Mean residence time \\
$M . t b$ & Mycobacterium Tuberculosis \\
NAT2 & N-acetyl transferase-2 \\
NCA & Non compartmental analysis \\
NDA & New drug applications \\
OD & Optical density \\
PB & Protein binding \\
PBPK & Physiologically based PK and PK/PD modeling \\
PCP & Pneumocystis carinii pneumonia \\
PD & Pharmacodynamic \\
PK & Pharmacokinetic \\
PK/PD & Pharmacokinetics/Pharmacodynamics \\
PO & Per oral \\
PTA & Pharmacodynamic target attainment \\
Q6h & Once every 6 hours \\
Q8h & Once every 8 hours \\
QD & Once daily \\
RIF & Rifampicin \\
RSE & Residual standard error \\
SEM & Standard error of mean \\
SNP & Single nucleotide polymorphisms \\
SP & Spectinomycin \\
ST & Streptomycin \\
TB & Tuberculosis \\
TID & Thrice daily \\
TR-TB & Totally drug resistant tuberculosis \\
US FDA & United states food and drug administration \\
USP & United states pharmacopoeia \\
VPC & Visual predictive check \\
V & Volume of distribution at steady state \\
VUP & Volume under the plane \\
WHO & World health organization \\
XDR & Extremely drug resistant \\
\%SCLSI & CLSI susceptibility breakpoints \\
\%SPD & Between-subject variability to define PD derived breakpoints \\
-2LL & -2 log likelihood \\
& \\
\hline
\end{tabular}




\section{CHAPTER 1. APPLICATION OF PHARMACOMETRICS IN THE CLINICAL DRUG DEVELOPMENT OF ANTI-INFECTIVES*}

\section{Introduction}

With the increased emergence of anti-infective resistance in recent years, much focus has recently been drawn to the development of new anti-infectives and the optimization of treatment regimens and combination therapies for established antimicrobials. In this context, the field of pharmacometrics using quantitative numerical modeling and simulation techniques has in recent years emerged as an invaluable tool in the pharmaceutical industry, academia and regulatory agencies to facilitate the integration of preclinical and clinical development data and to provide a scientifically based framework for rationale dosage regimen design and treatment optimization. The following chapter highlights the usefulness of pharmacometric analyses in anti-infective drug development and applied pharmacotherapy with select examples.

\section{Pharmacometrics in Anti-infective Drug Development}

The increased emergence of multidrug resistant (MDR) microbial strains in recent years and the resulting complications in the clinical care for infected patients is a strong reminder for the urgent need to develop new anti-infective agents. As the battle against drug-resistant microorganisms rages on in clinical centers around the globe, the development of novel single agent and combination therapies against microbial infections has challenged research scientists in the pharmaceutical industry and academia as well as clinicians and other healthcare providers to seek a multi-disciplinary approach; one that encompasses microbiology, clinical expertise, and drug development sciences. Pharmacometrics has in this context arisen as a formidable tool to bridge and link between key concepts in these disciplines and to provide a rationale, scientific framework throughout the drug development continuum as well as in clinical applications $[1,2]$. There are case studies which suggest that basing optimization of treatment on pharmacometric assessments improves the risk-management of MDR pathogens in the clinical realm by minimizing the failures and mistakes associated with inappropriate or careless use of antibiotic therapies $[3,4]$.

Pharmacometrics is the scientific discipline that uses mathematical models based on biology, pharmacology, physiology, and disease for quantifying the interactions between drugs and patients (Figure 1-1). Data and information from various sources are bridged together and quantitatively related to each other. Computer-based modeling and simulation of pharmacokinetic (PK) and pharmacodynamic (PD) data (denoted as PK/PD $\mathrm{M} \& S$ ) usually forms the basis for a pharmacometric analysis, but is frequently

* Adapted with permission. Ashit Trivedi, Richard E. Lee, and Bernd Meibohm. (2013). Applications of pharmacometrics in the clinical development and pharmacotherapy of anti-infectives. Expert Review of Clinical Pharmacology, 6(2), 159-170. 


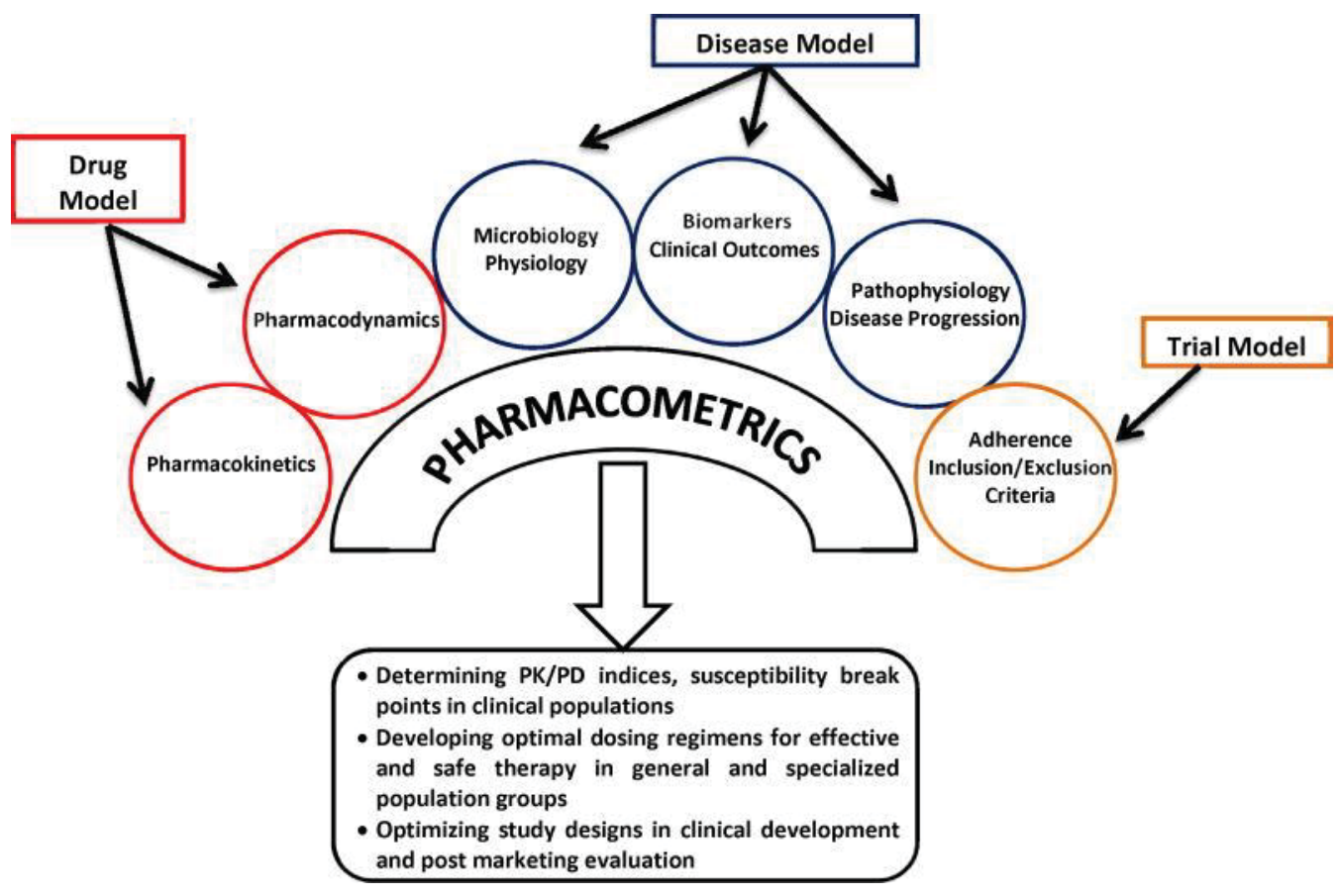

Figure 1-1. Illustration of interplay of pharmacology, microbiology, physiology, disease and their association with pharmacometric evaluations in the clinical development and application of anti-infectives. 
supplemented by models characterizing important other aspects of drug efficacy and/or safety in a given situation, such as disease progression, adherence to therapy or bacterial growth and infection [5]. PD measures used in pharmacometrics are frequently biomarkers, but can also be surrogate endpoints or clinical endpoints.

Pharmacometrics is aimed at establishing models that provide guidance and decision support in drug development such as trials design, efficacy comparisons, dosage regimen optimization and endpoint analysis, but also in supporting regulatory decisions and improving clinical care in specific patient populations [6,7]. Its purpose is thereby to reduce cost and shorten development time by optimizing the clinical assessment of efficacy and safety.

An increased application of pharmacometric methodologies in drug development and applied pharmacotherapy has in the last decade been strongly promoted by industry, academia and especially regulatory agencies, with specific emphasis from the U.S. Food and Drug Administration [8,9]. Pharmacometrics has been extensively used in the development and application of novel antibiotics [10-12]. In addition, increasing emphasis is more recently being placed on dose selection of approved antibiotics already in clinical use, with heavy reliance on quantitative benefit-risk evaluations [13].

This chapter aims to provide an overview on the usefulness and utility of pharmacometrics and in specific modeling and simulation approaches (M\&S) in antiinfective drug development and clinical application (Table 1-1), and will highlight these in examples on the application of $M \& S$ approaches in three specific areas:

1. The determination of PK/PD indices and susceptibility breakpoints indicative of anti-microbial activity in clinical populations.

2. The development of optimal dosing regimens for effective and safe anti-microbial therapy in both general and specialized population groups, such as pediatric patients.

3. The optimization of key attributes of study design in clinical development and postmarketing evaluations.

\section{Prerequisites for the Application of Pharmacometrics}

One of the major prerequisites for the application of M\&S in clinical drug development and applied pharmacotherapy is the availability of a mathematical framework that captures the dose-exposure relationship for the antibiotic in relevant tissues of interest (i.e. the plasma and tissue pharmacokinetics), the growth characteristics of the pathogen and its relevant subpopulations in the in vivo environment (microbiology), and the dynamic interplay between pathogen and antibiotic exposure with regard to pathogen survival, death, latency or resistance (pharmacodynamics). 
Table 1-1. Examples of the application of pharmacometrics analyses for anti-infectives.

\begin{tabular}{|c|c|c|c|c|c|c|c|}
\hline Drug & Organism & Disease & Target site & $\begin{array}{c}\text { Objective for } \\
\text { performing } \\
\text { pharmacometrics } \\
\text { analysis }\end{array}$ & Outcome & Population & Ref. \\
\hline Biapenem & $\begin{array}{l}\text { Gram positive } \\
\text { and gram } \\
\text { negative } \\
\text { anaerobes }\end{array}$ & $\begin{array}{l}\text { Continuous } \\
\text { venovenous } \\
\text { hemodiafiltration } \\
\text { (CVVHDF) }\end{array}$ & $\begin{array}{l}\text { Plasma and } \\
\text { filtrate- } \\
\text { dialysate }\end{array}$ & $\begin{array}{l}\text { Determine } \\
\text { appropriate dosage } \\
\text { recommendation } \\
\text { for patients on } \\
\text { CVVHDF }\end{array}$ & $\begin{array}{l}300 \mathrm{mg} \text { BID, } \\
\text { intravenous ( } 2 \mathrm{~h} \\
\text { infusion) }\end{array}$ & $\begin{array}{l}\text { Adult Japanese } \\
\text { (mean } 65.1 \mathrm{yr} \text { ), } \\
\mathrm{N}=7\end{array}$ & {$[14]$} \\
\hline Cefditoren & $\begin{array}{l}\text { Streptococcus } \\
\text { pneumoniae }\end{array}$ & $\begin{array}{l}\text { Lower respiratory } \\
\text { tract infections }\end{array}$ & $\begin{array}{l}\text { Plasma and } \\
\text { BAL }\end{array}$ & $\begin{array}{l}\text { PD profiling \& } \\
\text { determining PTA } \\
\text { (Dose: } 400 \mathrm{mg} \text { QD, } \\
\text { oral) }\end{array}$ & $\begin{array}{l}\text { PTA with } 33 \% \\
\mathrm{~T}>\mathrm{MIC} \text { is }<80 \% \text { for } \\
\mathrm{MIC}=0.06 \mathrm{mg} / \mathrm{L}\end{array}$ & $\begin{array}{l}\text { Adult Caucasian } \\
(35-78 \text { yr) } N=24\end{array}$ & {$[15]$} \\
\hline Cefepime & $\begin{array}{l}\text { Streptococcus } \\
\text { pneumoniae }\end{array}$ & $\begin{array}{l}\text { Extracerebral } \\
\text { infections }\end{array}$ & $\begin{array}{l}\text { Serum and } \\
\text { CSF }\end{array}$ & $\begin{array}{l}\text { PD profiling \& } \\
\text { determining PTA } \\
\text { (2g BID, } 0.5 \mathrm{~h} \text { IV } \\
\text { infusion) }\end{array}$ & $\begin{array}{l}\text { PTA in CSF with } \\
50 \% \mathrm{~T}>\mathrm{MIC} \text { is } \\
91.8 \%, 100 \% \\
\mathrm{~T}>\mathrm{MIC} \text { is } 82 \%\end{array}$ & $\begin{array}{l}\text { Adult females } \\
\text { (mean } 58.9 \mathrm{yr} \text { ) } \\
\mathrm{N}=7\end{array}$ & {$[16]$} \\
\hline \multirow[t]{2}{*}{ Ceftobiprole } & $\begin{array}{l}\text { Staphylococcus } \\
\text { aureus }\end{array}$ & $\begin{array}{l}\text { Staphylococcal } \\
\text { pneumonia }\end{array}$ & $\begin{array}{l}\text { ELF, serum, } \\
\text { BAL }\end{array}$ & $\begin{array}{l}\text { PD profiling \& } \\
\text { determining PTA } \\
\text { (500mg, TID, 2h } \\
\text { IV infusion) }\end{array}$ & $\begin{array}{l}\text { PTA with } \mathrm{T}>\mathrm{MIC} \text { is } \\
15 \% \text { for } 1-\log _{10} \\
\mathrm{CFU} / \mathrm{g} \text { reduction; } \\
25 \% \text { for } 2-\log _{10} \\
\mathrm{CFU} / \mathrm{g} \text { reduction }\end{array}$ & $\begin{array}{l}\text { Adults }(>18 \mathrm{yr}) \\
\mathrm{N}=25\end{array}$ & {$[17]$} \\
\hline & $\begin{array}{l}\text { Staphylococcus } \\
\text { aureus, } \\
\text { Streptococcus } \\
\text { pneumoniae }\end{array}$ & $\begin{array}{l}\text { Nosocomial } \\
\text { pneumonia }\end{array}$ & Skin, Plasma & $\begin{array}{l}\text { PD profiling \& } \\
\text { determining PTA } \\
\& \text { renal dose } \\
\text { adjustments ( } 500 \\
\text { mg BID, } 1 \mathrm{~h} \\
\text { infusion; 500mg } \\
\text { TID, 2h infusion) }\end{array}$ & $\begin{array}{l}\text { With } 500 \mathrm{mg} \text {, BID: } \\
\text { PTA of } 30 \% \text { and } \\
50 \% \text { T }>\text { MIC } \\
\text { exceeded } 90 \% \text {. With } \\
500 \\
\text { lmg, TID: PTA of } \\
40 \% \text { and } 60 \% \\
\text { T>MIC exceeded } \\
90 \% \text {. } \\
500 \mathrm{mg}, \text { BID is } \\
\text { optimal dose for } \\
\text { CL }{ }_{\text {Cr }} \leq 50 \mathrm{~mL} / \mathrm{min}\end{array}$ & Adults, $\mathrm{N}=150$ & {$[18]$} \\
\hline
\end{tabular}


Table 1-1. (Continued).

\begin{tabular}{|c|c|c|c|c|c|c|c|}
\hline Drug & Organism & Disease & Target site & $\begin{array}{c}\text { Objective for } \\
\text { performing } \\
\text { pharmacometrics } \\
\text { analysis }\end{array}$ & Outcome & Population & Ref. \\
\hline Ceftriaxone & $\begin{array}{l}\text { Streptococcus } \\
\text { pneumoniae }\end{array}$ & $\begin{array}{l}\text { Extracerebral } \\
\text { infections }\end{array}$ & $\mathrm{CSF}$ & $\begin{array}{l}\text { PD profiling \& } \\
\text { determining PTA } \\
(2 \mathrm{~g} \mathrm{BID}, 0.5 \mathrm{~h} \\
\text { infusion) }\end{array}$ & $\begin{array}{l}\text { PTA is } 76 \% \text { for } \\
50 \% \mathrm{~T}>\mathrm{MIC} \text { in } \\
\mathrm{CSF} \text {; } \\
\mathrm{PTA} \text { is } 65 \% \text { for } \\
100 \% \mathrm{~T}>\mathrm{MIC} \text { in } \\
\mathrm{CSF}\end{array}$ & $\begin{array}{l}\text { Adult females } \\
\text { (mean age } 58.9 \\
\text { yr) } \mathrm{N}=7\end{array}$ & {$[16]$} \\
\hline \multirow[t]{2}{*}{ Garenoxacin } & $\begin{array}{l}\text { Streptococcus } \\
\text { pneumoniae }\end{array}$ & $\begin{array}{l}\text { Community- } \\
\text { acquired } \\
\text { pneumonia (CAP) }\end{array}$ & Serum, ELF & $\begin{array}{l}\text { Evaluate exposure- } \\
\text { response } \\
\text { relationship by } \\
\text { population PK/PD }\end{array}$ & $\begin{array}{l}f^{\mathrm{AUC}_{0-24} / \mathrm{MIC}_{90}>} \\
200 \\
400 \mathrm{mg} \mathrm{QD}, \text { Oral } \\
\text { dosing is safe and } \\
\text { adequate for } \\
\text { efficacy }\end{array}$ & $\begin{array}{l}\text { Adults }(\geq 18 \mathrm{yr}) \\
\mathrm{N}=580\end{array}$ & {$[19,20]$} \\
\hline & $\begin{array}{l}\text { Streptococcus } \\
\text { pneumonia, } \\
\text { Staphylococcus } \\
\text { aureus, } \\
\text { Klebsiella } \\
\text { pneumonia, } \\
\text { Moraxella } \\
\text { catarrhalis, } \\
\text { Haemophilus } \\
\text { influenzae }\end{array}$ & $\begin{array}{l}\text { Pneumonia, } \\
\text { secondary } \\
\text { infection of } \\
\text { chronic respiratory } \\
\text { diseases, } \\
\text { bronchitis, } \\
\text { sinusitis, } \\
\text { otis media, } \\
\text { laryngopharyngitis, } \\
\text { tonsillitis }\end{array}$ & & $\begin{array}{l}\text { Determine PTA in } \\
\text { serum and ELF }\end{array}$ & $\begin{array}{l}\text { PTA }>95 \% \text { for } \\
\text { fAUC }_{0-24} / \mathrm{MIC}_{90} \text { is } \\
100 \text { (serum) and } \\
120 \text { (ELF) }\end{array}$ & $\begin{array}{l}\text { Adult Japanese } \\
(\geq 18 \mathrm{yr}) \mathrm{N}=136\end{array}$ & [21] \\
\hline Gatifloxacin & $\begin{array}{l}\text { Streptococcus } \\
\text { pneumoniae }\end{array}$ & $\begin{array}{l}\text { Community- } \\
\text { acquired } \\
\text { pneumonia (CAP) }\end{array}$ & N/A & $\begin{array}{l}\text { PD profiling \& } \\
\text { determining PTA } \\
\text { at } 400 \mathrm{mg} \text { QD, oral } \\
\text { (young) and } 200 \\
\text { mg QD, oral } \\
\text { (elderly) }\end{array}$ & $\begin{array}{l}\text { PTA for } \mathrm{AUC}_{0-} \\
24 / \mathrm{MIC}_{\text {all }} \geq 30 \text { is } \\
92.3 \% \text { in young; } \\
91.4 \% \text { in elderly }\end{array}$ & $\begin{array}{l}\text { Adults } \\
\text { Young }(<65 \mathrm{yr}) \\
\text { Elderly }(>65 \mathrm{yr}) \\
\mathrm{N}=183\end{array}$ & [22] \\
\hline Gemifloxacin & $\begin{array}{l}\text { Streptococcus } \\
\text { pneumoniae }\end{array}$ & $\begin{array}{l}\text { Community- } \\
\text { acquired } \\
\text { pneumonia (CAP) }\end{array}$ & Serum, ELF & $\begin{array}{l}\text { PD profiling \& } \\
\text { PTA in serum and } \\
\text { ELF } \\
(320 \mathrm{mg} Q D, \text { oral })\end{array}$ & $\begin{array}{l}\text { PTA }(>95 \% \text {, or } \\
>99 \%[23]) \text { for } \\
f^{2} C_{0-24} / \mathrm{MIC}_{90} \text { is } \\
100 \text { (ELF) and } \\
78.3-88 \text { (Serum) }\end{array}$ & N/A & {$[20,23]$} \\
\hline
\end{tabular}




\section{Table 1-1. (Continued).}

\begin{tabular}{|c|c|c|c|c|c|c|c|}
\hline Drug & Organism & Disease & Target site & $\begin{array}{c}\text { Objective for } \\
\text { performing } \\
\text { pharmacometrics } \\
\text { analysis }\end{array}$ & Outcome & Population & Ref. \\
\hline \multirow[t]{2}{*}{ Levofloxacin } & $\begin{array}{l}\text { Escherichia coli, } \\
\text { Chlamydia }\end{array}$ & Prostatitis & $\begin{array}{l}\text { Prostatic } \\
\text { tissue }\end{array}$ & $\begin{array}{l}\text { Determine } \\
\text { penetration at site } \\
\text { of action (500mg } \\
\text { QD) }\end{array}$ & $\begin{array}{l}\mathrm{AUC}_{\text {prostrate }} / \mathrm{AUC}_{\text {plasma }} \\
\text { is } 2.96\end{array}$ & $\begin{array}{l}\text { Adult (47-94 yr) } \\
\mathrm{N}=22\end{array}$ & {$[24]$} \\
\hline & $\begin{array}{l}\text { Organisms } \\
\text { causing } \\
\text { Pneumonia }\end{array}$ & $\begin{array}{l}\text { Nosocomial } \\
\text { pneumonia }\end{array}$ & Plasma, ELF & $\begin{array}{l}\text { Determine } \\
\text { penetration ratio in } \\
\text { ELF (500mg QD; } \\
750 \mathrm{mg} \text { QD) }\end{array}$ & $\begin{array}{l}\mathrm{AUC}_{\mathrm{ELF}} / \mathrm{AUC}_{\mathrm{plasma}} \text { is } \\
1.16\end{array}$ & $\begin{array}{l}\text { Adult ( }>18 \text { yr) } \\
\mathrm{N}=24\end{array}$ & {$[25]$} \\
\hline Metronidazole & $\begin{array}{l}\text { Bacteroides } \\
\text { fragilis }\end{array}$ & $\mathrm{N} / \mathrm{A}$ & $\begin{array}{l}\text { Plasma and } \\
\text { urine }\end{array}$ & $\begin{array}{l}\text { PD profiling \& } \\
\text { determining PTA } \\
\text { at 500mg, TID; } \\
\text { 1000mg QD; } \\
\text { 1500mg QD }\end{array}$ & $\begin{array}{l}\text { PTA for AUC/MIC } \\
\geq 70 \text { is } 99 \%\end{array}$ & $\begin{array}{l}\text { Adults males, } \\
\mathrm{N}=18 \text { ( } 10 \\
\text { healthy, } 8 \\
\text { patients })\end{array}$ & {$[26]$} \\
\hline Moxifloxacin & $\begin{array}{l}\text { Streptococcus } \\
\text { pneumoniae }\end{array}$ & $\begin{array}{l}\text { Community- } \\
\text { acquired } \\
\text { pneumonia } \\
\text { (CAP) }\end{array}$ & Serum, ELF & $\begin{array}{l}\text { PD profiling \& } \\
\text { determining PTA } \\
\text { ( } 400 \mathrm{mg} \text { QD, } 1 \mathrm{~h} \\
\text { infusion) }\end{array}$ & $\begin{array}{l}\text { PTA }(>95 \%) \text { for } \\
f^{A U C} C_{0-24} / \mathrm{MIC}_{90} \text { is } \\
120(\mathrm{ELF}) \text { and } 78.3- \\
88(\text { Serum); } \\
\mathrm{C}_{\max } / \mathrm{MIC}_{90}>10, \\
\text { AUC/MIC }_{90} \sim 100\end{array}$ & $\begin{array}{l}\text { Adults }(18-80 \\
\text { yr) } N=16\end{array}$ & {$[20,27]$} \\
\hline Norvancomycin & $\begin{array}{l}\text { Staphylococcus } \\
\text { aureus }\end{array}$ & $\begin{array}{l}\text { Gram-positive } \\
\text { bacterial } \\
\text { infections }\end{array}$ & Serum & $\begin{array}{l}\text { PD profiling \& } \\
\text { prediction of CL } \\
\text { estimates in } \\
\text { population (400mg } \\
\text { QD, intravenous) }\end{array}$ & $\begin{array}{l}95 \% \text { cured clinical } \\
\text { outcome with } \mathrm{AUC}_{0-} \\
{ }_{24} / \mathrm{MIC} \text { of } 579.9 \\
\mathrm{CL}=2.54\left(\mathrm{CL}_{\mathrm{Cr}} / 50\right) \text { in } \\
\text { patients with renal } \\
\text { dysfunction } \\
\mathrm{CL}=6.0(\mathrm{Body} \\
\text { Weight } / 60)^{0.52} \text { in } \\
\text { healthy subjects }\end{array}$ & Adult, $\mathrm{N}=166$ & {$[28]$} \\
\hline
\end{tabular}


Table 1-1. (Continued).

\begin{tabular}{|c|c|c|c|c|c|c|c|}
\hline Drug & Organism & Disease & Target site & $\begin{array}{c}\text { Objective for } \\
\text { performing } \\
\text { pharmacometrics } \\
\text { analysis } \\
\end{array}$ & Outcome & Population & Ref. \\
\hline $\begin{array}{l}\text { Oseltamivir and } \\
\text { Oseltamivir carboxylate } \\
\text { (OC) }\end{array}$ & $\begin{array}{l}\text { Influenza A } \\
\text { (H1N1 virus) }\end{array}$ & $\begin{array}{l}\text { Influenza A } \\
\text { and B }\end{array}$ & Serum & $\begin{array}{l}\text { To determine } \\
\text { dosing in neonates } \\
\text { and infants }\end{array}$ & $\begin{array}{l}3 \mathrm{mg} / \mathrm{kg}, \mathrm{BID}, \text { Oral } \\
\text { in infants } 1.7 \mathrm{mg} / \mathrm{kg} \text {, } \\
\text { BID, Oral in } \\
\text { neonates }\end{array}$ & $\begin{array}{l}\text { Adult males } \\
\mathrm{N}=6 ; \\
\text { Infants }(<2 \mathrm{yr}) \\
\mathrm{N}=43 ; \\
\text { Neonates }(1.5- \\
17.5 \text { weeks }) \\
\mathrm{N}=20\end{array}$ & $\begin{array}{l}{[29,} \\
30]\end{array}$ \\
\hline $\begin{array}{l}\text { Piperacillin/Tazobactam } \\
\text { (combination) }\end{array}$ & $\begin{array}{l}\text { Escherichia } \\
\text { coli, S. aureus, } \\
\text { Klebsiella } \\
\text { pneumonia, } \\
\text { Pseudomonas } \\
\text { aeruginosa, } \\
\text { Bacteroides } \\
\text { fragilis, } \\
\text { Acinetobacter } \\
\text { baumannii }\end{array}$ & $\begin{array}{l}\text { Gram-negative } \\
\text { bacterial } \\
\text { infections }\end{array}$ & Serum & $\begin{array}{l}\text { To determine } \\
\text { PK/PD parameters } \\
\text { \& in vivo } \\
\text { effectiveness with } \\
\text { doses } 3.375 \mathrm{~g}, \\
\text { Q4h, Q6h; } \\
4.5 \mathrm{~g}, \mathrm{Q} 6 \mathrm{~h}, \mathrm{Q} 8 \mathrm{~h} \\
\text { (intravenous, } 0.5 \mathrm{~h} \\
\text { infusion) }\end{array}$ & $\begin{array}{l}\mathrm{T}>\mathrm{MIC} \text { is }>60 \% \text { for } \\
\text { all doses }\end{array}$ & $\begin{array}{l}\text { Adult males } \\
\mathrm{N}=12\end{array}$ & $\begin{array}{l}{[31,} \\
32]\end{array}$ \\
\hline Rifampin & $\begin{array}{l}\text { Mycobacterium } \\
\text { tuberculosis }\end{array}$ & Tuberculosis & $\begin{array}{l}\text { Plasma, ELF, } \\
\text { BAL, } \\
\text { Alveolar } \\
\text { Cells (ACs) }\end{array}$ & $\begin{array}{l}\text { Determine } \\
\text { pulmonary PK/PD } \\
\text { in lungs \& } \\
\text { evaluate } \\
\text { recommended } \\
\text { dose }(600 \mathrm{mg}, \mathrm{QD} \text {, } \\
\text { oral) }\end{array}$ & $\begin{array}{l}\mathrm{C}_{\max } / \mathrm{MIC} \geq 175 \text { are } \\
95 \% \text { (ACs), } 48.8 \% \\
\text { (plasma), } 35.9 \% \\
(\mathrm{ELF}) ; \mathrm{AUC} \mathrm{C}_{0-} \\
\text { 24/MIC } \geq 271 \text { is } \\
100 \% \text { (plasma); } \\
\text { Higher doses ( } 1200 \\
\text { mg) required as } \\
\text { pulmonary } \\
\text { concentration is too } \\
\text { low with } \\
\text { recommended } \\
\text { dosing }\end{array}$ & Adults, $\mathrm{N}=40$ & [33] \\
\hline
\end{tabular}


Table 1-1. (Continued).

\begin{tabular}{|c|c|c|c|c|c|c|c|}
\hline Drug & Organism & Disease & Target site & $\begin{array}{c}\text { Objective for } \\
\text { performing } \\
\text { pharmacometrics } \\
\text { analysis }\end{array}$ & Outcome & Population & Ref. \\
\hline Telavancin & $\begin{array}{l}\text { Staphylococcus } \\
\text { aureus }\end{array}$ & $\begin{array}{l}\text { Health care } \\
\text { associated } \\
\text { pneumonia }\end{array}$ & Plasma and ELF & $\begin{array}{l}\text { To determine } \\
\text { penetration in ELF } \\
\text { with } 10 \mathrm{mg} / \mathrm{kg} \text { QD } \\
\text { (intravenous, } 1 \mathrm{~h} \\
\text { infusion) }\end{array}$ & $\begin{array}{l}\mathrm{AUC}_{\mathrm{ELF}} / \mathrm{AUC}_{\mathrm{plasma}} \\
\text { is } 0.73\end{array}$ & $\begin{array}{l}\text { Adult } \\
\text { Caucasians, } \\
\mathrm{N}=20\end{array}$ & {$[34]$} \\
\hline Vancomycin & $\begin{array}{l}\text { Staphylococcus } \\
\text { aureus }\end{array}$ & $\begin{array}{l}\text { Ventilator- } \\
\text { associated } \\
\text { pneumonia }\end{array}$ & $\begin{array}{l}\text { Plasma, } \\
\text { Bronchoalveolar } \\
\text { lavage fluid, } \\
\text { ELF }\end{array}$ & $\begin{array}{l}\text { To determine } \\
\text { penetration in ELF } \\
\text { with } 1000 \mathrm{mg} \text { BID } \\
\text { (intravenous) }\end{array}$ & $\begin{array}{l}\mathrm{AUC}_{\mathrm{ELF}} / \mathrm{AUC}_{\mathrm{plasma}} \\
\text { is } 0.675 \\
\mathrm{AUC} / \mathrm{MIC} \geq 400\end{array}$ & $\begin{array}{l}\text { Adults }(>18 \\
\mathrm{yr}) \\
\mathrm{N}=10\end{array}$ & {$[35]$} \\
\hline Voriconazole & Candida strains & $\mathrm{N} / \mathrm{A}$ & Plasma & $\begin{array}{l}\text { To investigate the } \\
\text { effect of } \\
\text { concomitant } \\
\text { fluconazole on } \\
\text { Voriconazole PK }\end{array}$ & $\begin{array}{l}\text { Coadministration } \\
\text { is not } \\
\text { recommended, } \\
\text { Monitor for } \\
\text { adverse events if } \\
\text { voriconazole is } \\
\text { sequentially } \\
\text { administered after } \\
\text { fluconazole }\end{array}$ & $\begin{array}{l}\text { Adult males } \\
(21-55 \mathrm{yr}) \\
\mathrm{N}=10\end{array}$ & {$[36]$} \\
\hline
\end{tabular}


Relevant PK and PD parameters may be derived from a variety of sources, including preclinical and clinical pharmacokinetic studies, studies assessing tissue concentration-time courses with techniques such as imaging or microdialysis, in vitro MIC data, in vitro time-kill curves, disease pathology, and microbiologic characteristics of the pathogen/infective agent itself $[37,38]$. These data can be combined with knowledge about the between- and within-subject variability in relevant PK parameters as well as microbiologic differences among different pathogen strains. Since betweensubject variability is oftentimes a major complicating factor in drug development and pharmacotherapy, the potential impact of M\&S approaches is usually higher the larger is the between-subject variability. The resulting models help identify optimal drug concentrations necessary to achieve at the target site to be efficacious in overcoming an infection (i.e. bacterial eradication) and minimizing bacterial resistance, and the corresponding dosing regimens that provide a high likelihood of therapeutic success in a specific target population $[10,39]$. Once this basic framework has been established, additional factors including human physiological, biochemical, and genetic variability and differences to preclinical species that complicate the translation of preclinical results to the clinic and of data from controlled clinical studies to clinical practice may be considered and implemented in the modeling framework.

\section{PK/PD Indices and Susceptibility Breakpoints}

Susceptibility breakpoints, or critical antimicrobial concentrations, are valuable parameters in assessing the degree of drug susceptibility and/or resistance to an antimicrobial pharmacotherapy. Breakpoints refer to antibiotic concentrations or exposures that separate bacterial strains where there is a high likelihood of treatment success from those bacteria where treatment is more likely to fail. Historically, pharmacokinetic exposure parameters such as the area-under-the-plasma-concentrationtime-curve (AUC) or the maximum or peak concentration (Cmax) have been the gold standard for monitoring drug action under the assumption that plasma concentration are indicative of target site concentrations and that a defined and fixed target site exposure is necessary for drug action. For antimicrobial pharmacotherapy, however, target site exposure is not sufficient to predict efficacy since the susceptibility of the microorganism to the target site concentration is variable among different microorganisms and strains and may change over time in the event of for example resistance development.

Susceptibility of a microorganism to an antibiotic is frequently described by its minimum inhibitory concentration (MIC), an in vitro parameter that quantifies growth inhibition to a static antibiotic concentration. Combination of the pharmacodynamic parameter MIC with pharmacokinetic exposure parameters such as AUC or Cmax allows defining PK/PD indices that are hybrid parameters that integrate $\mathrm{PK}$ and $\mathrm{PD}$ information related to target exposure and microbial sensitivity, and can be used to derive PK/PD breakpoints.

Dependent on the predominant mechanism of action of the antibiotic, the following three

PK/PD indices (as shown in Figure 1-2) have been found useful in characterizing in vivo. 


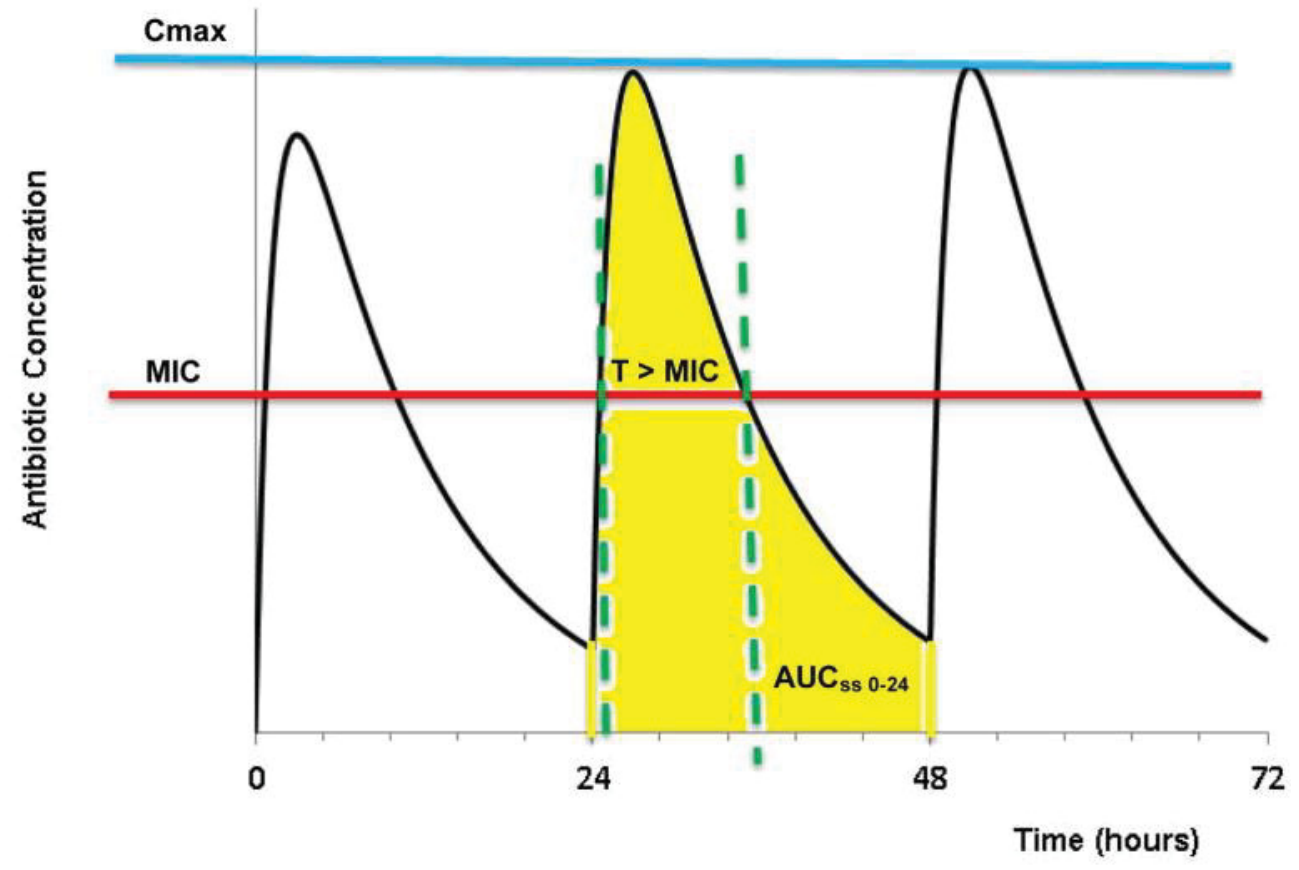

Figure 1-2. Illustration of the PK/PD indices at steady state during multiple dosing: (i) T>MIC: Time above MIC (ii) $\mathrm{Cmax} / \mathrm{MIC}$ (iii) $\mathrm{AUC} / \mathrm{MIC}$. 
1. $\mathrm{T}>\mathrm{MIC}$ : Time $\mathrm{T}$ of exposure of microorganisms to plasma concentrations exceeding its MIC.

2. Cmax/MIC: Ratio of peak plasma concentration to MIC.

3. AUC/MIC: Ratio of area under plasma concentration curve to MIC.

These indices are frequently used to classify the pattern of killing activity for antimicrobials, concentration-dependent vs. time-dependent. Antibiotics for which T > MIC best describes their antimicrobial activity follow time-dependent killing with minimal persistent effects that requires a maximum duration of exposure above MIC for maximum activity. Antibiotics for which Cmax/MIC best describes their antimicrobial activity follow concentration-dependent killing with prolonged persistent effects that require a maximum peak antibiotic concentration for maximum activity. Antibiotics for which AUC/MIC best describes their antimicrobial activity exhibit both time-dependent and concentration-dependent killing with moderately persistent effects that require a combination of high concentration and long duration above MIC for maximum activity. The AUC in these indices is calculated at pharmacokinetic steady state over $24 \mathrm{~h}$ (AUCss, $0-24$ ) and is usually derived from Bayesian parameter estimates from population PK analysis approaches.

As indicated in these relationships, the MIC is consistently used as a denominator or 'normalization factor'. The integration of drug exposure (PK) and the actual drug activity based on microbial sensitivity (PD) allows to develop generalized breakpoints with which multiple drugs can be evaluated for efficacy related to both their PK and PD parameters [40-42]. The efficacy is the desired clinical effect that a particular drug is producing and is the combined effect of PK and PD and other, for example patientrelated, factors. The term 'efficacy' cannot be interchanged for PD. Thus, breakpoints are often used as a valuable tool in drug development and applied pharmacotherapy to optimize dosing regimens of an antibiotic for the treatment of a specific pathogen and to minimize the increase of resistant strains with optimal dosing.

It should be stressed, however, that many antibiotics are bound to variable degree to proteins in plasma and tissue, and that only the free, unbound concentration at the target site is pharmacologically active and exerts the antimicrobial activity. Since MIC is frequently determined with no or limited binding proteins present, it usually represents an unbound concentration [43]. Thus, PK/PD indices also need to be based in free drug exposures rather than total concentrations to avoid any bias introduced by considering protein binding only in the PD parameter MIC, but not the PK parameters AUC and Cmax. Consequently, $f \mathrm{~T}>\mathrm{MIC}, f \mathrm{Cmax} / \mathrm{MIC}$, and $f \mathrm{AUC} / \mathrm{MIC}$ based on free drug concentrations are now usually applied as appropriate PK/PD indices [40-42, 44].

PK/PD indices assessed in M\&S studies can be used to assess and compare the likelihood of achieving effective target exposure for different antibiotics and thus prioritize compounds for the treatment of specific infections. Noreddin et al. used this approach by applying simulation studies to determine the probability of target attainment 
in serum and epithelial lining fluid (ELF) defined as a $f \mathrm{AUC}_{0-24} / \mathrm{MIC}_{90}$ ratio of 30 , with bacterial eradication as efficacy endpoint, for standard clinical regimens of azithromycin, clarithromycin, and telithromycin against $S$. pneumonia strains with different susceptibility [45].

Another example for establishing PK/PD indices by M\&S is the case of isoniazid which displays a multimodal elimination pattern in the population based on single nucleotide polymorphisms (SNPs) in the gene encoding for N-acetyl transferase-2 (NAT2). Since the allelic frequency of these genetic variants differs among different ethnic groups, these groups differ in the number of "slow" and "fast" acetylators based on NAT2 phenotype. Thus, standard recommended doses would obviously result in different bactericidal activities among different populations. In vitro models showed that AUC024/MIC is associated with both microbial death and emergence of resistance for isoniazid. Based on this approach, $M \& S$ was used to predict the bactericidal effects of different doses of drug in various ethnic populations, accounting for the multimodal elimination of isoniazid. The model allowed to predict the dose with highest early bactericidal activity (EBA) and this dose was used in subsequent clinical studies [46].

Based on susceptibility breakpoints microorganisms are classified as susceptible, intermediate and resistant based on predefined. The identification of susceptibility breakpoints is being performed using standard tests implemented by the Clinical Laboratory Standards Institute (CLSI) by examining MIC distributions across different strains of a bacterial species. MIC values are measured using Mueller-Hinton broth, as recommended by CLSI guidelines [42, 47]. While these test methodologies achieve a precise estimate of breakpoints in vitro, the major challenge lies in the ability for clinical translation. Since target site exposure and microbial susceptibility will vary among different individuals with different infection sites and different pathogen populations, susceptibility breakpoints are inherently variable in a clinical population [40]. Thus, in vitro derived breakpoints have to be interpreted as point estimates in a breakpoint distribution with a confidence interval that presents itself in the clinic [48]. M\&S approaches using clinical data may contribute to derive and increase the exactness or confidence in the derived breakpoints.

Multiple studies have indicated inconsistencies between the probability of PD target attainment (PTA) and susceptibility as per CLSI defined breakpoints. DeRyke et al. demonstrated that CLSI susceptibility breakpoints (\%SCLSI) overestimated probability for achieving bactericidal exposure for antibiotics such as ciprofloxacin, levofloxacin and piperacillin-tazobactam against gram negative bacteria such as P.aeruginosa, $A$. baumannii, E. coli and Klebsiella spp. [48]. To overcome this limitation, the authors used Monte-Carlo simulations based on published PK data and their between-subject variability to define PD derived breakpoints (\%SPD). This \%SPD accounts for betweensubject variability in human pharmacokinetics as well as exposure differences resulting from different dosing regimens. In this approach, \%SPD was defined as the highest MIC at which at least $90 \%$ of the population achieve the targeted bactericidal exposure, and bactericidal exposure was defined as $f \mathrm{~T}>\mathrm{MIC}$ (time of free concentration above MIC) of $40 \%$ for carbapenems, $50 \%$ for cephalosporins and the piperacillin component of the 
piperacillin-tazobactam combination, and 125 for the AUC/MIC ratio of fluoroquinolones. The analysis indicated that although there was a general lack of agreement between PTA and \%SPD or \%SCLSI, only \%SCLSI overestimated the ability of the investigated dosing regimens to achieve bactericidal exposures. In contrast, \% SPD often underestimated PTA, a deviation clinically far less concerning than overestimation. The underestimation of PTA using \%SPD leads to an overestimation of dose in a particular subject (which is preferable), but the general overestimation of doses for a population can lead to an increase in bacterial resistance. Based on the performed simulations, the authors suggest pathogen and dosing regimen specific breakpoints as a more appropriate way to classify bacteria as susceptible [48].

\section{Development of Optimal Dosing Regimens}

One of the top priorities in antibiotic pharmacotherapy is to optimize the duration of therapy with proper dosing regimens that are effective and safe, and minimize the occurrence of bacterial resistance. However, these goals are often requiring opposing measures and can often not be achieved simultaneously. The concept of clinical utility can help in optimizing these goals. Clinical utility allows to quantify and optimize "tradeoffs" between multiple factors such as efficacy, safety, microbiology, and usage of drugs [49]. Pharmacometrics allows the integration of clinical utility with M\&S, where "tradeoffs" can be derived and explored mathematically.

The clinical efficacy (i.e. bacterial eradication) of drugs such as garenoxacin, telithromycin and doripenem is more than $90 \%$. With such high efficacy it is challenging to design dosing regimens on the basis of efficacy and safety at varying doses. Population based pharmacokinetic M\&S using Monte Carlo simulations helped in deciding on a dosage regimen by taking into account the between-subject variability in PK parameters and varying MIC distributions by various clinical isolates. This approach helped in determining the optimal dose for garenoxacin (400mg) on the basis of:

1. Selecting AUC0-24/MIC as an appropriate $\mathrm{PK} / \mathrm{PD}$ index derived from in vivo efficacy data

2. Performing Monte Carlo Simulations using population PK parameters, MIC distributions and mutant prevention concentration (MPC)

3. Determining a recommended dose based on probability of target attainment

4. Validation of the recommended dose based on PK/PD data acquired from phase III studies for respiratory tract infection [21].

Design of dosing regimens is especially challenging for patients who are critically ill with severe bacterial infections, and who have renal failure and are on continuous venovenous hemodiafiltration (CVVHDF). In the event of renal failure, dosing regimen needs of individual patients can be adjusted by assessing the impact of kidney 
dysfunction on the disposition of drugs [50]. For example the PK and PD properties of biapenem change when a patient is on CVVHDF. Ikawa et al. performed PK M\&S to determine $\mathrm{PD}$ exposure of $\mathrm{T}>\mathrm{MIC}_{4 \mu \mathrm{g} / \mathrm{mL}}$ and suggested that for $\mathrm{T}>\mathrm{MIC}_{4 \mu \mathrm{g} / \mathrm{mL}}$ for $30 \%$ of the dosing interval biapenem dosage should be $300 \mathrm{mg}$ BID, $600 \mathrm{mg} \mathrm{BID}$, or $600 \mathrm{mg}$ BID for dialysate flow rates of $1.4 \mathrm{~L} / \mathrm{h}, 2.8 \mathrm{~L} / \mathrm{h}$, or $5.6 \mathrm{~L} / \mathrm{h}$, respectively [14]. As the dialysate flow rate increased, $\mathrm{T}>\mathrm{MIC}_{4 \mu \mathrm{g} / \mathrm{mL}}$ decreased. The $600 \mathrm{mg}$ BID dose was the optimum to reach $\mathrm{T}>\mathrm{MIC}_{4 \mu \mathrm{g} / \mathrm{mL}}$ of $30 \%$ for both dialysate flow rates of $2.8 \mathrm{~L} / \mathrm{h}$ and $5.6 \mathrm{~L} / \mathrm{h}$. These simulations illustrate that low doses or increased dosing intervals should not be recommended for patients who are on CVVHDF or renal replacement technique.

Since critically ill patients often have altered drug distribution and elimination, they may experience inadequate dosing with antibiotics and may thus be at a much higher risk of infections with antibiotic resistant organisms [51]. For doripenem, a carbapenem, $\mathrm{T}>\mathrm{MIC}$ for $35 \%$ of the dosing interval has been the recommendation in patients with normal kidney function. Since doripenem is primarily excreted in unchanged form into the urine, PK-based Monte Carlo simulations were performed to develop dosing recommendations for patients with renal impairment. For mild-stage 2 chronic kidney disease $(\mathrm{CKD})$ patients with a creatinine clearance $\left(\mathrm{CL}_{\mathrm{Cr}}\right)>60 \mathrm{~mL} / \mathrm{min}, 500 \mathrm{mg}$ should be infused over $1 \mathrm{~h}$ every $8 \mathrm{~h}$ for bacteria with $\mathrm{MIC} \leq 1 \mu \mathrm{g} / \mathrm{mL}$; however, in the more severe stage $3 \mathrm{CKD}$ patients with $\mathrm{CL}_{\mathrm{Cr}} \sim 30-50 \mathrm{~mL} / \mathrm{min}$, an infusion of $250 \mathrm{mg}$ of doripenem over $1 \mathrm{~h}$ every $8 \mathrm{~h}$ for bacteria with $\mathrm{MIC} \leq 2 \mu \mathrm{g} / \mathrm{mL}$ is recommended. For patients with severe renal impairment with a $\mathrm{CL}_{\mathrm{Cr}}$ of $10-29 \mathrm{~mL} / \mathrm{min}, 250 \mathrm{mg}$ was recommended to be infused over longer durations, $4 \mathrm{~h}$ instead of $1 \mathrm{~h}$, every $12 \mathrm{~h}$ for $\mathrm{MIC} \leq 2 \mu \mathrm{g} / \mathrm{mL}$. This is consistent with the time-dependent ( $>\mathrm{MIC}$ ) killing pattern of carbapenems. Dosing strategies like this can only be achieved from PK/PD M\&S where the creatinine clearance builds the parameter framework for achieving set exposure levels, as PK studies in critically ill patients would be extremely difficult to perform [52].

In order to be efficacious, an antibiotic needs to reach the site of infection in therapeutically effective concentrations. In patients with severe lung infections, the concentration of antibiotics in ELF is an essential measure to decide on an optimal dosage regimen [25]. It has been reported recently that methicillin-resistant S. aureus (MRSA) is the likely culprit in causing more than $25 \%$ of all ventilator-associated pneumonias in intensive care unit patients [53]. A population PK model with Monte Carlo simulations was employed to determine the range of ELF exposure relative to that in plasma. It was determined that vancomycin penetrates ELF at approximately $50 \%$ of plasma concentrations [35]. Under the assumption that the PK/PD in ELF is similar to the AUC/MIC of $\geq 400$ used in plasma, the M\&S exercise showed that target attainment is expected to be suboptimal for MRSA with MICs in excess of $1 \mathrm{mg} / \mathrm{L}$ under current dosing regimens. A similar approach was used for PD profiling of cefditoren and telavancin against penicillin-susceptible and penicillin-intermediate $S$. pneumonia [15] and methicillin-resistant S. aureus, respectively [34].

The MIC value for an antibiotic varies depending on which organism it acts upon. Carbapenems require higher MIC to be effective against $\mathrm{P}$. aeruginosa as compared to other bacteria. The antibacterial efficacy of four commonly used dosage regimen for 
doripenem was determined using an integrated PK/PD M\&S approach based on in vitro time-kill data and human PK data. The simulations indicated time-dependent antimicrobial activity of doripenem, in which the 250mg TID regimen had a higher bactericidal effect than did 500mg BID [54].

While dosage regimens for most antibiotics can be derived by PK/PD-based M\&S as outlined in the presented examples, the therapeutic concentration obtained from those recommendations may be insufficient to safeguard optimum clinical efficacy and bacterial clearance from the site of infection, especially if they are based on studies in healthy individuals rather than patients. Hence, it is of utmost importance to take into account the disposition (PK) and target site accessibility of antibiotics in diseased individuals having abnormal physiological conditions such as renal dysfunction. Along these lines, it is often preferred to use in these PK/PD M\&S evaluations drug resistant bacteria that constitute a worst case scenario. An example for such an approach is the dose optimization of norvancomycin against methicillin-resistant rather than non-resistant Staphylococcus isolates for patients with different physiological and pathological conditions in the Chinese population. The optimized norvancomycin dosing recommendations were $800-1000 \mathrm{mg}$ BID for patients with normal renal function, $800 \mathrm{mg}$ QD or BID for patients with mild renal dysfunction ( $\mathrm{CL}_{\mathrm{Cr}}>50$ to $\leq 85 \mathrm{~mL} / \mathrm{min}$ ), $800 \mathrm{mg}$ QD to 2.5days for patients with modest renal dysfunction ( $\mathrm{CL}_{\mathrm{Cr}}>10$ to $\leq 50 \mathrm{~mL} / \mathrm{min}$ ), and $600 \mathrm{mg}$ over 5 -11 days or $800 \mathrm{mg}$ over 6-13days for patients with severe renal dysfunction $\left(\mathrm{CL}_{\mathrm{Cr}}>5\right.$ to $\left.\leq 10 \mathrm{~mL} / \mathrm{min}\right)[28]$.

\section{Optimization of Clinical Studies and Clinical Applications}

Over the last decade, it has become obvious in many examples that fine tuning of phase II/III clinical trials as well as post-marketing studies a priori is essential to reduce cost and optimize study performance and outcomes. PK/PD based M\&S has played a major role in this process by integrating observations and data obtained from preclinical studies in animals and phase I studies in healthy volunteers as well as phase IIa studies in patients. The factors taken into consideration for mathematical modeling are often:

1. MIC distribution patterns in clinical isolates

2. The range of individual PK parameters in the target patient population

3. Identified PD targets from efficacy studies in animals

4. The degree of protein binding.

The combination of microbiological, preclinical and clinical PK and PD data in mathematical models is essential in designing target antibiotic exposures. M\&S with such data is not only beneficial for single drug therapy but also for the evaluation of multiple concurrently used antibiotics and their potential additive or synergistic effects [41]. 
There is a sustained need for monitoring the PK/PD of antibiotics even after their approval and marketing. Rifampin is widely used for treatment of tuberculosis since several decades, but there is only limited data on rifampin concentrations in the lungs. Using an M\&S based simulation study, Goutelle et al. found that the existing dosage regimen $(600 \mathrm{mg} /$ day) for rifampin is suboptimal in most patients. This could be a potential contributing factor for the increasing number of tuberculosis infections with multi drug-resistant and extremely drug-resistant strains. The authors suggest considering higher doses $(1200 \mathrm{mg} /$ day) of rifampin for an increase in pulmonary concentrations, thereby keeping in mind the toxicity and tolerability of such high doses in patients [33].

M\&S may also be useful in developing strategies to minimize the effect of drugdrug interactions. Voriconazole and fluconazole are two widely used antifungal drugs with similar mechanism of action, but a strong drug-drug interaction when immediately switching between the two agents. Fluconazole is the most commonly used antifungal agent but unlike voriconazole it does not have anti-aspergillosis coverage sometimes necessitating a clinical switch. Fluconazole is a CYP2C19 inhibitor and its presence inhibits voriconazole metabolism causing substantial voriconazole-related adverse effects. Physiologically based PK modeling was used to determine the time lag required between the two therapies to avoid potential toxicity, but also minimize the time period without effective antifungal exposure which is essential in the event of serious fungal infections. The PK simulations demonstrated that a time lag of at least $24 \mathrm{~h}$ is required to switch from fluconazole to voriconazole in order to avoid relevant interactions [36].

The use of M\&S is not only restricted to optimizing dosing regimen and efficacy of treatment, but can also be used for building up clinical treatment guidelines. Goldie et al. constructed a population model of HIV infection to answer lifetime cost, life expectancy, quality-adjusted life expectancy, and quality-adjusted life years in patients receiving highly active antiretroviral therapy (HAART) and Pneumocystis carinii pneumonia (PCP) prophylaxis. The simulation exercises were performed to compare different criteria of CD4 cell counts for discontinuing primary PCP prophylaxis in patients with CD4 cell count increases receiving HAART and second-line PCP prophylaxis (such as dapsone, atovaquone, and aerosolized pentamidine) due to intolerance to trimethoprim-sulfamethoxazole. The outcome of the exercise showed that treatment is cost-effective when PCP prophylaxis is discontinued with CD4 count $>300 / \mu \mathrm{L}$, and that in patients intolerant to trimethoprim-sulfamethoxazole dapsone therapy is more cost-effective than atovaquone [55].

\section{Future Prospects}

The application of pharmacometric analyses using PK/PD based M\&S approaches has in the recent decade developed into one of the most essential tools for interpreting and integrating large and diverse pools of preclinical and clinical data and translating them into an informative knowledgebase [5]. It is expedient not only for industry professionals to promote internal decision making at critical drug development steps, but is also increasingly utilized by regulatory authorities for compiling and analyzing data for 
approval and labeling. A recent survey shows that during the last decade, the drug approval and labeling decisions of more than $60 \%$ of submissions for New Drug Applications (NDA) to the US FDA were influenced by pharmacometric analyses. For $30 \%$ of the submissions during this period, FDA reviewers performed independent pharmacometric analysis [13]. For example, among anti-infectives, an appropriate dosing regimen of micafungin for the treatment of esophageal candidiasis was selected based on an exposure-response analysis by FDA personnel. The FDA reviewers utilized the phase II and III study data to model the relationship between dose and effectiveness, which led them to recommend approval of the $150 \mathrm{mg}$ over the $100 \mathrm{mg}$ micafungin dose due to similar maximum efficacy, but a $15 \%$ lower rate of relapse [9].

Another prime example for use of $\mathrm{M} \& \mathrm{~S}$ in regulatory decision making is the pharmacometrics-based dose selection of levofloxacin for post exposure treatment of inhalational anthrax in children. The available data from two PK studies on 47 adults at different doses $(500 \mathrm{mg} / \mathrm{kg}$ and $750 \mathrm{mg} / \mathrm{kg})$ and 90 pediatric patients who received a dose of $7 \mathrm{mg} / \mathrm{kg}$ were used to develop an integrated population PK model. The model was then utilized to derive dosing recommendations for pediatric patients that match adult exposure after a $500 \mathrm{mg} / \mathrm{kg}$ dose with regard to AUC, and maximum and minimum concentration during multiple dosing at steady state. Based solely on this M\&S approach, a dose regimen of $8 \mathrm{mg} / \mathrm{kg}$ BID for children $<50 \mathrm{~kg}$ and $\geq 6$ months of age and 500mg QD for children weighing $\geq 50 \mathrm{~kg}$ was recommended and included in the labeling information $[56]$.

The US FDA and the European Medicines Agency (EMA) both acknowledge the impact of $\mathrm{M} \& \mathrm{~S}$ on regulatory approvals, but assess the investigational plans and scientific information differently. FDA seems to prefer to conduct pharmacometric reviews including independent data analyses for all the submitted applications irrespective of whether the sponsor submitted an analysis or not. In contrast, EMA seems to consider a pharmacometric assessment only if it is included in the submission by the sponsor. EMA might ask for additional pharmacometric analyses, but these should be conducted by the sponsor. European regulatory bodies are especially encouraging and emphasizing the use of M\&S for drugs in pediatrics and for anti-infectives [57-59]. Irrespective of these different philosophies in the review process, the emphasis and demand of M\&S based pharmacometric analyses in drug approval will likely further increase the application of M\&S throughout the drug development process [8, 30, 60].

More recently, physiologically based $\mathrm{PK}$ and $\mathrm{PK} / \mathrm{PD}$ modeling (PBPK) is gaining more widespread application, predominantly because of improvements in the associated M\&S methodologies and the availability of more robust and user-friendly software tools [61-63]. It is predicted that the use of PBPK will increase over the next years for identifying the effects of intrinsic and extrinsic factors modifying drug efficacy and safety in patients. PBPK will play a significant role in predicting and deciphering drugdrug interactions and will be the basis for $M \& S$ in special population such as pediatric patients or in critically-ill patients [63]. 
Evidently, pharmacometric analyses have proven their merits in myriad ways during the entire process of drug development. However, there is always room for improvements for more accurate and precise estimates resulting in more confident predictions. This fine-tuning can likely be accomplished by a more prospective integration of M\&S approaches in each individual development phase, including goaloriented and intelligent sample and data collection that specifically addresses and supports pharmacometric analyses. Some of the questions that need to be addressed relate to the transfer of knowledge from controlled studies to clinical practice: PK parameter estimates are generally derived from healthy subjects. How can we assure that PK/PD predictions are accurate in patients with variable physiologic function and variable sites and types of infection? How can we account for patients with multiple disease conditions? How will their confounding illnesses or polypharmacy affect drug exposure for the considered anti-infective? How will variability in the strains of microorganisms and their response to the survival stress elicited by the anti-infective such as latency and resistance development affect treatment outcome? A more systematic and intensive assessment of antibiotic concentrations at the site of action such as ELF over the time course of therapy might help to provide some of the needed answers. Techniques such as microdialysis have been proven of substantial value in assessing active drug concentrations in target tissues not as easily accessible as ELF [64, 65].

In summary, more complex $\mathrm{M} \& \mathrm{~S}$ models will likely be established in the future that integrate all therapeutic considerations when treating microbial infections. Using precise estimates of PK and PD parameters as well as their distributions in populations of patients and microorganisms, including their potential interdependencies, will help in facilitating more realistic and thus also even more clinically meaningful predictions for the in silico evaluation and development of optimal antibiotic dosing regimens, including combination therapies. To combat the growing bacterial resistance, we need to rapidly increase the available number of effective antibiotics in our armamentarium by relatively fast, safe, smart and inexpensive clinical development programs. We believe that $M \& S$ based pharmacometric approaches hold great promise in facilitating this process and thus may serve as a key technology for the development of future generations of antiinfectives. 


\section{CHAPTER 2. CENTRAL HYPOTHESIS}

Among the most deadly infectious microorganisms, tuberculosis is a second greatest killer worldwide [66]. According to WHO [67], tuberculosis kills approximately 1.5 million people annually and it was estimated that 480,000 patients developed multidrug resistant TB (MDR-TB) in 2013 alone. The existing drug therapies requires treatment spans of 4-24 months and efficacy is hindered severely by poor adherence to dosing regiments and drug adverse effects. This alarming situation undoubtedly calls for the urgent need for the development of novel and more effective treatment options to defeat TB $[68,69]$. The primary goal for current anti-tuberculosis drug development efforts is to shorten the treatment regimen and circumvent drug-resistance mechanisms.

Our group has designed a novel semi-synthetic series of spectinomycin analogs, or spectinamides. All compounds in this series were initially screened using in vitro assays. The results from these preliminary studies aided in refining the chemical structure of lead compounds and improved their drug-likeness properties for clinical readiness. The lead optimization process comprised in vitro and in vivo pharmacological, biopharmaceutical, pharmacokinetic (PK) and pharmacodynamic (PD) profiling of candidate compounds $[70,71]$. Using a pharmacometric approach, we integrated the PK and PD properties of spectinamides to better characterize the interplay and interdependencies between drug concentration and drug efficacy in models of disease. We hypothesized that a pharmacometrics-directed quantitative approach for integrated $\mathrm{PK} / \mathrm{PD}$ characterization is useful for antibiotic lead characterization and highly predictive of in vivo antibacterial efficacy.

\section{Specific Aim 1}

In this Aim 1 (Chapter 3), we investigated the biopharmaceutics and pharmacokinetic properties of select spectinamide agents to determine lead candidate compounds and provide the basis for pharmacometrics-directed PK/PD assessments. An important aspect in the efficacy and safety of novel drug candidates is the extent of distribution and potential accumulation in tissues. In this context, intracellular uptake into macrophages is a prerequisite for antibiotic activity against $M$. $t b$ residing inside infected macrophages. To address these questions, we also evaluated the biodistribution profile of a radio-labeled spectinamide and cellular uptake of spectinamides into murine macrophages.

\section{Specific Aim 2}

In Aim 2, we further evaluated the PK/PD relationships of lead compound, Lee 1599 using an in vitro PK/PD model system which characterizes a dose-response relationship in order to facilitate a rational dose-selection for in vivo efficacy trials (Chapter 4). While PD assessments under static conditions such as MIC determinations 
provided only a point estimate of anti-bacterial activity. A more effective way of determining the appropriate dosing regimen with optimum efficacy and with high correlation between in vitro and in vivo efficacy is through an integrated PK/PD model approach. An in vitro PK/PD model is a convenient tool to predict the efficacy, dosing regimen of single or combination drug candidates and PK/PD indices (concentration and/or time dependent killing) based on dynamic time-kill curves for supporting in vivo studies. To test this hypothesis we determined the time-kill effect of Lee 1599 at various dosing regimens against $M$. bovis BCG as model organism. With this data, we developed a PD model to describe Lee 1599 mediated bacterial killing. Based on these in silico simulations, we were able to predict the optimal dosing regimen for in vivo efficacy studies.

\section{Specific Aim 3}

In Aim 3 (Chapter 5), we expanded the pharmacometrics-directed quantitative $\mathrm{PK} / \mathrm{PD}$ assessment of Lee 1599 to combination therapies with rifampicin as model compound. Traditionally, qualitative methods such as the checkerboard assay have been widely used to evaluate possible pharmacodynamic interaction between two agents. We applied a three dimensional surface response assay as quantitative pharmacometric tool for characterizing the interaction between Lee 1599 and rifampicin and compared them to the checkerboard assay. We validated the results of both assays by expanding our previously applied with an in vitro PK/PD model (Chapter 3) to drug combination therapy and by a comparison to results of in vivo studies in a mouse model of $M$. $t b$ infection. 


\section{CHAPTER 3. PHARMACOKINETICS AND BIODISTRIBUTION OF A NOVEL SERIES OF ANTI-TUBERCULOSIS AGENTS: SPECTINAMIDES}

\section{Introduction}

Tuberculosis (TB) is a global pandemic that has a mortality rate of approximately 1.5 million people per year. The existing drug therapy requires treatment for a span of 424 months. The flaws of this treatment regimen become very apparent once it is administered to patient populations, as it is lengthy and complicated resulting in poor patient adherence. As a result, many patients discontinue therapy before complete eradication of the disease, which subsequently may lead to the development of drug resistant strains such as multi drug resistant (MDR), extremely drug resistant (XDR) and totally drug resistant tuberculosis (TR-TB) [67, 68, 72-76].

With the help of a structure based design process, novel semisynthetic analogs of spectinomycin called spectinamides were recently discovered. Spectinamides inhibit protein synthesis by selectively binding to the head domain of the $30 \mathrm{~S}$ ribosomal subunit and blocking its translocation [77]. They have also exhibited overcoming an intrinsic resistance mechanism by avoiding the tap efflux pump Rv1258c in $M$. $t b$. Rv1258c is an efflux pump belonging to the ABC (ATP-binding cassette) transporters and is known to play an important role in mediating the efflux of different chemical classes and antibiotics [78-80]. While spectinomycin is a substrate for Rv1258c resulting in no relevant activity against $M$. $t b$, the structural modification in spectinamides renders them unsuitable as Rv1258c substrate. Thus, the potency of the spectinamide series is a product of high affinity for the mycobacterial ribosome and the avoidance of Rv1258c efflux pumps [81].

The primary goal of this chapter is to gain knowledge of the preclinical pharmacokinetics of the select compounds in the spectinamide series. We also investigated the biodistribution properties of a spectinamide lead, Lee 1329, using a radioisotope technique, as well as uptake into macrophages. Knowledge about the extent and pattern of biodistribution are crucial PK characteristics that may determine the efficacy and safety profile of drug candidates.

\section{Materials and Methods}

\section{Chemicals and reagents}

All tested spectinamides were synthesized in the laboratory of Dr. Richard.E. Lee at St.Jude Children's Research Hospital, Memphis, TN, including Lee 1329 (3'-dihydro3'-deoxy-4(R)-(pyridin-2-yl) acetylamino spectinomycin), Lee 1544 (3'-Dihydro-3'deoxy-4(R)-(4-chloropyridin-2-yl) acetylamino spectinomycin), Lee 1599 (3'-Dihydro3'-deoxy-3'(R)- (5-chloropyridin-2-yl)acetylamino spectinomycin Trihydrobromide), 3'- 
Dihydro-3'-deoxy-3'(R)- (4-(4-chlorophenyl)pyridin-2-yl))acetylamino spectinomycin Trihydrobromide (Lee 1601), 3'-Dihydro-3'-deoxy-3'(R)- (2-(pyridin-2-ylamino)thiazol4-yl)acetylamino spectinomycin Terahydrobromide (Lee 1603), 3'-Dihydro-3'-deoxy3'(R)- (4-chloro-5-fluoropyridin-2-yl)acetylamino spectinomycin Trihydrobromide (Lee 1661), 3'-Dihydro-3'-deoxy-3'(R)- (1-methyl-1H-benzo[d]imidazol-2-yl)acetylamino spectinomycin Trihydrobromide (Lee 1663) as shown in Figure 3-1. Acetonitrile, methanol, HPLC grade water, formic acid and ammonium formate were purchased from Fisher Scientific (Pittsburgh, PA). Drug free rat plasma was purchased from Innovative Research (Novi, MI).

\section{Protein binding}

The plasma protein binding is determined using equilibrium dialysis with ready to use RED device inserts from Thermo Scientific (Rockford, IL) in base plates containing plasma and buffer chamber for analysis. High and low concentrations $(500 \mathrm{ng} / \mathrm{mL}$ and $5 \mu \mathrm{g} / \mathrm{mL}$ ) of test compounds are prepared in rat plasma. $200 \mu \mathrm{L}$ of the plasma sample was added to the central compartment and $350 \mu \mathrm{L}$ of blank isotonic phosphate buffer, $\mathrm{pH} 7.4$ to the peripheral compartment of dialysis base plate. The base plate is covered with sealing tape and incubated at $37^{\circ} \mathrm{C}$ at approximately $100 \mathrm{rpm}$ on an orbital shaker for $4 \mathrm{~h}$ to achieve equilibrium. The drug concentration is determined using an LC-MS/MS assay. The free fraction of the drug is calculated as ratio of the concentrations in the buffer and in plasma. The results are expressed in terms of \%-bound to plasma proteins.

\section{Formulation preparation and administration}

Spectinamides $(10 \mathrm{mg} / \mathrm{kg}$ and $100 \mathrm{mg} / \mathrm{kg})$ were formulated in plasmalyte solution and sterilized by filtration ( 0.2 micron syringe filter). The IV doses were administered via femoral vein catheter followed by flushing the catheter with locking solution. A group of 5 rats were dosed for each compound and dose level.

\section{Pharmacokinetic studies}

The PK studies are performed on catheterized (jugular vein alone for oral study (PO) and jugular vein and femoral vein for intravenous (IV) study) male Sprague-Dawley rats weighing approximately $225 \mathrm{~g}$ ( 8 -10 weeks old). The animals were housed in the animal facility with $12 \mathrm{~h}$ of light/dark cycle with food and water available ad libitum at University of Tennessee Health Science Center following protocol number 13-4263A. the protocol was approved by the Institutional Animal Care and Use Committee at University of Tennessee Health Science Center. Test compounds were administered for IV and PO studies at a dose of $10 \mathrm{mg} / \mathrm{kg}$ and $100 \mathrm{mg} / \mathrm{kg}$, respectively. Serial blood samples were collected pre-dose and at predetermined intervals until $72 \mathrm{~h}$. Plasma was separated immediately by centrifugation at $10,000 \mathrm{rpm}, 4^{\circ} \mathrm{C}$ for $10 \mathrm{~min}$ and stored at $-80^{\circ} \mathrm{C}$ until analysis. Plasma and urine samples were analyzed for drug concentrations by 


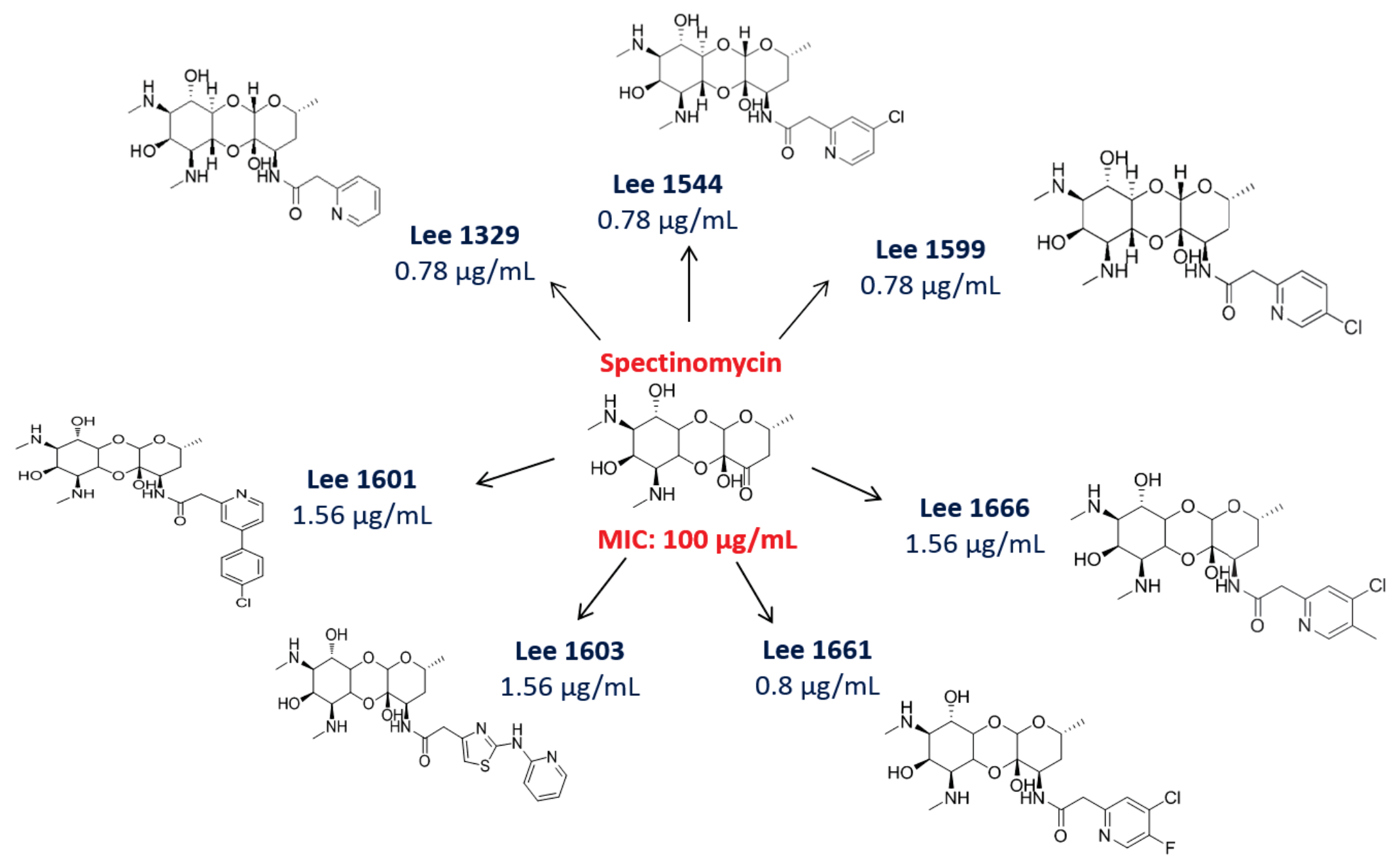

Figure 3-1. Chemical structure of lead spectinamides with MIC values. 
LC-MS/MS analysis. Blood samples $(250 \mu \mathrm{L})$ were collected at $0.25,0.5,0.75,1.0,1.5$, 2.0, 4.0, 6.0, 8.0, 12.0, 24.0, 36.0 and 48.0h after drug administration. Urine samples were collected at intervals of $0-6,6-12,12-24,24-36$ and $36-48 \mathrm{~h}$ post-dose and stored at $20^{\circ} \mathrm{C}$ until analysis.

\section{Pharmacokinetic data analysis}

The concentration-time profiles for both PO and IV administration were analyzed by non-compartmental analysis. The IV concentration-time profiles were also analyzed by nonlinear regression analysis using a 2-compartment open model with bolus input and first order output. The area under curve $\left(A U C_{i n f}\right)$ from time zero to infinity was calculated using the trapezoidal rule by extrapolating to time infinity. Mean residence time (MRT), defined as the average amount of time a drug particle remaining in a compartment of a system upon IV administration was calculated using

$$
M R T=\frac{A U M C_{\text {inf }}}{A U C_{i n f}}
$$

where $\mathrm{AUMC}_{\mathrm{inf}}$ is the area under the moment curve when the concentration-time curve is extrapolated to infinity. The systemic clearance (CL) was calculated using the equation

$$
C L=\frac{\operatorname{Dose}_{i v}}{A U C_{i n f, i v}}
$$

where Dose $_{\text {iv }}$ and $\mathrm{AUC}_{\text {inf,iv }}$ are the IV dose and area under the plasma concentration-time curve from time 0 to infinity, respectively. An estimate of volume of distribution at steady state $\left(\mathrm{V}_{\mathrm{ss}}\right)$ was obtained from IV data using

$$
V_{S S}=M R T * C L
$$

Oral bioavailability (F) was calculated using

$$
F=\frac{A U C_{\text {inf }, \text { oral }} * \text { Dose }_{\text {iv }}}{A U C_{\text {inf }, i v} * \text { Dose }_{\text {oral }}}
$$

where Dose oral, $_{\text {, Dose }}$ iv, $\mathrm{AUC}_{\text {inf, iv }}$, and $\mathrm{AUC}_{\text {inf,oral }}$ are the oral and IV doses and the corresponding areas under the plasma concentration-time curves from time zero to infinity, respectively. Urinary excretion parameters were calculated from the cumulative dose excreted unchanged in urine and the fraction unbound in plasma (fup). Glomerular filtration rate (GFR) was taken from the physiologic parameters published by Davies et al [82]. The fraction (fe) of the test compound excreted in urine was calculated as the cumulative amount of dose excreted unchanged in urine divided by the dose of the test compound administered. Renal clearance $\left(\mathrm{CL}_{\mathrm{r}}\right)$ values were determined from the total plasma $\mathrm{CL}$ and the fraction excreted in urine using fe*CL $\mathrm{L}_{\text {total. }}$ The net processes such as 
filtration, reabsorption and secretion a drug undergoes in the kidney can be evaluated using excretion ratio (Eratio). This was calculated using CLr/(fup*GFR).

\section{Macrophage uptake assay}

Uptake of spectinamide compounds (Lee 1329, 1443, 1445, 1544, 1599), SP and ST into murine macrophages was studied in the J774A.1 cell line (ATCC, Manassas, VA). J774A.1 cells were cultured in T25 flasks in Dulbecco's Modified Eagle's Medium (DMEM; Gibco, USA) with 10\% Fetal bovine serum (Sigma-Aldrich, USA) and maintained at $37^{\circ} \mathrm{C}, 5 \% \mathrm{CO}_{2}$. Cells were scraped using teflon cell scraper from the T25 flasks and the final cell density of 2 to $4 \times 10^{5}$ cells $/ \mathrm{mL}$ was adjusted using fresh DMEM. The cells were allowed to grow for $48 \mathrm{~h}$ at $37^{\circ} \mathrm{C}$ until $60-80 \%$ confluent in a 6 -well plate (each plate representing individual time point and concentration). The media was aspirated from the wells and fresh DMEM containing a final test compound concentration of $25 \mu \mathrm{g} / \mathrm{mL}$ or $100 \mu \mathrm{g} / \mathrm{mL}$ was added. The plates were incubated at $37^{\circ} \mathrm{C}, 5 \% \mathrm{CO}_{2}$ for $0.5,1,4,8$ and $24 \mathrm{~h}$. Additional plates were also incubated for 48, 72 and $96 \mathrm{~h}$. The media containing test compound was aspirated at every time point and the cells were washed with ice-cold Dulbecco's Phosphate-Buffered Saline (DPBS) for three times. The cells were suspended in $1 \mathrm{~mL}$ of water and sonicated for $2 \mathrm{~min}$. The cell suspension was centrifuged for $5 \mathrm{~min}$ at 10,000 rpm and the supernatant collected was used to determine the drug uptake using LC-MS/MS assay. The drug uptake was expressed in terms of $\mu \mathrm{L} / \mathrm{mg}$ of protein. The protein content in cells was determined using the Pierce BCA assay kit (Thermo Scientific, Pierce Biotechnology, IL, USA).

\section{Sample preparation and LC-MS/MS analysis}

The plasma and urine samples were prepared by the protein precipitation method by adding $50 \mu \mathrm{L}$ aliquots to $200 \mu \mathrm{L}$ methanol (spiked with the internal standard 3'dihydro-3'-deoxy-3'(R)-isopropylacetylamino spectinomycin) followed by vortexing for $1 \mathrm{~min}$, centrifugation at $10,000 \mathrm{~g}$ for $10 \mathrm{~min}$ at $4^{\circ} \mathrm{C}$. The supernatant was separated via chromatography on a Luna $3 \mu \mathrm{M}$ hydrophobic interaction liquid chromatography (HILIC) $100 \times 4.6 \mathrm{~mm}$ column (Phenomenex, Torrance, CA) using a gradient mobile phase of methanol and $10 \mathrm{mM}$ ammonium formate, $\mathrm{pH} 2.75$, at a flow rate of $0.4 \mathrm{~mL} / \mathrm{min}$.

Detection was performed with an API 3000 triple-quadruple mass spectrometer (ABISciex, Foster City, CA) with electrospray ionization in multiple reaction monitoring mode using the compound-specific mass transfers of $\mathrm{m} / \mathrm{z} 453.3 / 247.3$ for Lee $1329, \mathrm{~m} / \mathrm{z}$ 459.2/207.2 for Lee 1443, $\mathrm{m} / \mathrm{z}$ 471.3/207.1 for Lee 1445, $\mathrm{m} / \mathrm{z}$ 487.2/128.3 for Lee 1544, $\mathrm{m} / \mathrm{z}$ 487.2/207.1 for Lee 1599 and m/z 418.3/207.1 for Lee 1369 .

A calibration curve (range: 1.95 to $5,000 \mu \mathrm{g} / \mathrm{L}$ ) was constructed for each test compound and validated with spiked samples of rat plasma or urine. The peak area ratios of analyte to internal standard were linear over the concentration range tested for all compounds, with all correlation coefficients (weighted least-square linear regression analyses) $>0.997$. Accuracy (deviation of the analyzed quality-control samples from 
nominal values) was within $\pm 3 \%$ over the entire range of the calibration curve, and the precision (coefficient of variation of repeated measurements of the quality-control samples) was $<2 \%$ for all compounds.

\section{Biodistribution}

Radiolabeling of Lee 1329 (3'-Dihydro-3'-deoxy-3'(R)-(pyridin-2yl) acetylamino spectinomycin Trihydrobromide) compound was performed by Dr.Richard E. Lee's group at St. Jude Children's Research Hospital. The biodistribution study was conducted in Sprague-Dawley rats ( $\mathrm{N}=7$, one control and 6 in the treatment group). The rats were administered ${ }^{3} \mathrm{H}-1329$ intravenously (IV) via a femoral vein catheter at a dose of $0.9 \mathrm{mg} / \mathrm{kg}$ body weight $(0.87 \mathrm{mCi} / \mathrm{kg})$ every $12 \mathrm{~h}$ for 4.5 days. The control rat received normal saline only. Serial blood samples were collected at 0 (pre-dose), 0.25, 2, 8 and $12 \mathrm{~h}$ after the $1 \mathrm{st}$ dose and at 0 (before 8 th dose), $0.25,0.5,1,2,4,6$, and $12 \mathrm{~h}$ after the 8 th dose to evaluate the pharmacokinetics after single and multiple dosing. Plasma was separated immediately after sample collection by centrifugation $(10,000 \mathrm{~g}$ for $10 \mathrm{~min}$ at $4^{\circ} \mathrm{C}$ ) and stored at $-80^{\circ} \mathrm{C}$ until analysis of radioactivity by scintillation counting. Urine and feces specimens were collected at $0 \mathrm{~h}$ (pre-dose) and every $12 \mathrm{~h}$ after dosing up to the end of the study and stored at $-80^{\circ} \mathrm{C}$ until analysis. The volume of urine and weight of feces were noted at every sampling point for the calculation of mass balance. One hour after the administration of the 9th dose, the animals were euthanized and all major organs such as liver, kidneys, spleen, lung, heart, brain, thigh muscle and blood were collected to determine tissue distribution and accumulation. Total blood was collected by cardiac puncture. Major organs and tissues were collected and stored at $-80^{\circ} \mathrm{C}$ until analysis. Total volume of blood, urine, total weight of the organs, muscle and feces was noted for the calculation of mass balance.

\section{Sample preparation of biological samples for ${ }^{3} \mathrm{H}-1329$}

\section{Blood}

$0.2 \mathrm{~mL}$ of blood was added to $1 \mathrm{~mL}$ of Solvable ${ }^{\mathrm{TM}}$ (aqueous based solubilizer, PerkinElmer, Waltham, MA) in a glass scintillation vial and incubated at $60^{\circ} \mathrm{C}$ for $1 \mathrm{~h}$. $0.1 \mathrm{~mL}$ of $0.1 \mathrm{M}$ EDTA-di-sodium solution was added to reduce foaming due to $\mathrm{H}_{2} \mathrm{O}_{2}$. $0.5 \mathrm{~mL}$ of $30 \% \mathrm{H}_{2} \mathrm{O}_{2}$ was added in $0.1 \mathrm{~mL}$ increments and gently agitated after each addition to allow reaction and foaming to subside. $\mathrm{H}_{2} \mathrm{O}_{2}$ treatment helps to reduce the amount of color present, and thus reduces color quench in the final mixture. The mixture was allowed to stand for $30 \mathrm{~min}$ at room temperature to complete the reaction and was incubated in a water bath at $60^{\circ} \mathrm{C}$ for $1 \mathrm{~h}$, venting any slight pressure occasionally. The sample was then cooled to room temperature and $15 \mathrm{~mL}$ of liquid scintillation cocktail Ultima Gold ${ }^{\mathrm{TM}}$ (Perkin Elmer, Waltham, MA) was added. The samples were light adapted for one hour before counting the radioactivity using a scintillation counter. 


\section{Serum and urine}

The direct addition method was acquired to determine the amount of radioactivity in serum and urine. $1.5 \mathrm{~mL}$ of ethanol and $15 \mathrm{~mL}$ of liquid scintillation cocktail Ultima Gold $^{\mathrm{TM}}$ was added in a glass scintillation vial to $0.1 \mathrm{~mL}$ of serum or $0.5 \mathrm{~mL}$ of urine and shake well. The samples were light adapted for at least one hour before scintillation counting.

\section{Organs and muscle tissue}

Organs (liver, kidney, spleen, lung, heart and brain) and muscle samples were prepared by the solubilization method for the determination of accumulated radioactivity. $50 \mathrm{mg}$ of organs or muscle tissue was weighed into a scintillation vial and $2 \mathrm{~mL}$ of Solvable ${ }^{\mathrm{TM}}$ was added and heated on a water bath at $60^{\circ} \mathrm{C}$ for 1 to $3.5 \mathrm{~h}$ with occasional swirling. After cooling to room temperature, $0.2 \mathrm{~mL}$ of $30 \% \mathrm{H}_{2} \mathrm{O}_{2}$ was added slowly with swirling between additions, and the mixture was allowed to subside any reaction between additions of the $\mathrm{H}_{2} \mathrm{O}_{2}$. The mixture was heated again at $60^{\circ} \mathrm{C}$ for $30 \mathrm{~min}$ for complete decolorization. $10 \mathrm{~mL}$ of liquid scintillation cocktail Ultima Gold ${ }^{\mathrm{TM}}$ was added, and the samples were light adapted for at least one hour before scintillation counting.

\section{Feces}

The amount of radioactivity excreted in feces was determined by sample combustion with a sample oxidizer (PerkinElmer Model 307 Sample Oxidizer, Waltham, MA) and the recovered ${ }^{3} \mathrm{H}$ was analyzed by scintillation counting. Briefly, feces specimens of each animal collected at different time intervals were combined together and homogenized with 4 volumes of water. Triplicate samples from each animal of approximately $300 \mathrm{mg}$ of homogenate were placed in the sample oxidizer and combusted in an oxygen rich atmosphere to oxidize the tritium present in the samples to water $\left({ }^{3} \mathrm{H}_{2} \mathrm{O}\right)$. The water was separated into a scintillation vial and mixed with $10 \mathrm{~mL}$ of scintillation cocktail Monophase-S (PerkinElmer, Waltham, MA). The samples were light adapted for at least one hour before scintillation counting.

\section{Sample analysis of biological samples for ${ }^{3} \mathrm{H}-1329$}

The blood, serum, urine, organs, muscle and feces samples mixed with liquid scintillation cocktail as described above were placed in a Tri-carb 2800 TR liquid scintillation analyzer (PerkinElmer, Waltham, MA) to determine the tritium activity $\left({ }^{3} \mathrm{H}\right)$. The radioactivity was measured in terms of disintegrations per minute (DPM) setting the energy window from channel 0 to channel 20. The luminescence from the sample was reduced by setting a 10min pre-count delay. Samples were counted in the luminescence correction mode. The average counting efficiency for ${ }^{3} \mathrm{H}$ is $65.45 \%$. The counting time for each sample was $1 \mathrm{~min}$ and each sample was analyzed three times. The quench indicator tSIE (transformed spectral index of the external standard) was used as an indicator of a good spectrum. 


\section{Results and Discussion}

\section{Biopharmaceutical properties of spectinamides}

As shown in Table 3-1, the molecular weight of spectinamides ranged from between 450 to $600 \mathrm{Da}$ and is larger as compared to the spectinomycin with weighs around 332.3Da. All of the spectinamides are highly hydrophilic in nature with clogP between -3 and 0 .

Plasma protein binding is an essential parameter in determining the drug distribution, metabolism and elimination. A drug molecule that is circulating in the system exists in two variants, protein bound and unbound (free), assuming that the protein binding is reversible. The unbound and the bound form exist in equilibrium. The unbound (free) drug is the only pharmacologically active drug as it can permeate the cell membranes and exert the pharmacological effect on binding to target structure. Thus, it is important to estimate the extent of plasma protein binding [43, 83, 84].

In general, spectinamides showed low to intermediate plasma protein binding in rats. The only exception was Lee 1601 with $75 \%$ protein binding which can be attributed to its increased molecular weight (563Da) as compared to the other lead compounds in this series. The low plasma protein binding suggests that a large fraction of molecules is freely available to enter the intracellular space for eliciting their therapeutic effect.

Lee 1544, Lee 1599, Lee 1601, Lee 1603, Lee 1661 and Lee 1666 are 2heteroaryl acetic acid amide analogs of spectinomycin that showed potent in vitro activity against $M . t b$. The pharmacokinetic parameters for all these compounds are shown in Table 3-1. Following intravenous administration of $10 \mathrm{mg} / \mathrm{kg}$ in rats, all molecules exhibited bi-exponential concentration time profiles with distinct distribution and elimination phase (Figures 3-2 to 3-8) except Lee 1601.

All the lead candidate compounds in the spectinamide series showed comparable alpha half-life of 0.58 to $1.06 \mathrm{~h}$, except for Lee 1601 with a very low alpha half-life of $0.28 \mathrm{~h}$. The compounds showed prolonged beta half-life, except Lee 1601. This prolonged beta phase did not significantly contribute to the overall systemic exposure (AUC) because of 100 to 1000 fold lower plasma concentrations than Cmax. This trend is commonly seen in aminoglycosides and other amines and is associated with slow release of the trapped molecules from deep tissue compartments. This phenomenon may be attributed to lysosomal trapping and/or complexation with membrane phospholipids [8589].

The compounds showed a steady state volume of distribution in the range of 0.8 to $1.48 \mathrm{~L} / \mathrm{kg}$ except for Lee 1601 and Lee 1661 with $\mathrm{Vd}$ of 0.17 and $0.4 \mathrm{~L} / \mathrm{kg}$, respectively. The AUC ranged from 8.3 to $19.3 \mathrm{~h} . \mathrm{mg} / \mathrm{L}$. The AUC for Lee 1599 was slightly lower than other spectinamide compounds. The MRT ranged from 0.2 to $1.84 \mathrm{~h}$ and the mean systemic clearance ranged from 0.5 to $1.22 \mathrm{~L} / \mathrm{h} / \mathrm{kg}$. The percent dose excreted unchanged 
Table 3-1. Physico-chemical properties and pharmacokinetic parameters for spectinamides after intravenous administration at $10 \mathrm{mg} / \mathrm{kg}$ dose.

\begin{tabular}{lllllllllllll}
\hline $\begin{array}{c}\text { Name of the } \\
\text { compound }\end{array}$ & $\begin{array}{c}\text { MW } \\
\text { (Da) }\end{array}$ & cLogP & $\begin{array}{c}\mathbf{P B} \\
\mathbf{( \% )}\end{array}$ & $\begin{array}{c}\mathbf{C m a x} \\
\mathbf{m g} / \mathbf{L}\end{array}$ & $\begin{array}{c}\mathbf{t} \text { / } / 2 \\
\mathbf{h}\end{array}$ & $\begin{array}{c}\mathbf{A U C} \\
\mathbf{h} * \mathbf{m g} / \mathbf{L}\end{array}$ & $\begin{array}{c}\mathbf{C L} \\
\mathbf{L} / \mathbf{h} / \mathbf{k g}\end{array}$ & $\begin{array}{c}\mathbf{V d} \\
\mathbf{L} / \mathbf{k g}\end{array}$ & $\begin{array}{c}\text { MRT } \\
\mathbf{h}\end{array}$ & Fe & Eratio & \% F \\
\hline Lee 1544 & 486.9 & -2.51 & 15.0 & 12.1 & 1.06 & 10.7 & 0.935 & 0.868 & 0.931 & 0.520 & 1.70 & 4.00 \\
Lee 1599 & 486.9 & -2.51 & 13.0 & 9.94 & 0.58 & 8.37 & 1.22 & 0.820 & 0.680 & 0.885 & 3.02 & 3.47 \\
Lee 1601 & 563.0 & -0.697 & 75.0 & 15.9 & 0.297 & 12.7 & 0.828 & 0.167 & 0.197 & 0.129 & 1.08 & 0.377 \\
Lee 1603 & 550.6 & -2.30 & 55.0 & 16.2 & 1.05 & 13.7 & 0.748 & 1.41 & 1.84 & 0.283 & 1.82 & 2.03 \\
Lee 1661 & 504.9 & -2.34 & 40.0 & 23.4 & 0.732 & 19.3 & 0.521 & 0.358 & 0.687 & 0.860 & 1.91 & 1.75 \\
Lee 1666 & 500.9 & -2.01 & 42.0 & 15.2 & 1.04 & 13.6 & 0.740 & 1.48 & 1.98 & 0.74 & 2.33 & - \\
Spectinomycin & 332.3 & -2.87 & 13.0 & 20.6 & 1.25 & 16.8 & 0.602 & 0.756 & 0.757 & 0.553 & 1.00 & - \\
\hline
\end{tabular}

Notes: MW: Molecular Weight

cLogP: Calculate logarithm of partition coefficient

$\mathrm{PB}(\%)$ : Percentage protein binding

Cmax: Peak concentration in plasma

$\mathrm{t}_{1 / 2}$ : Alpha half-life

Fe: Fraction excreted unchanged in the urine

Eratio: Excretion ratio

$\% \mathrm{~F}$ : Percent bioavailability is calculated using the AUC values obtained after oral administration at $100 \mathrm{mg} / \mathrm{kg}$ 


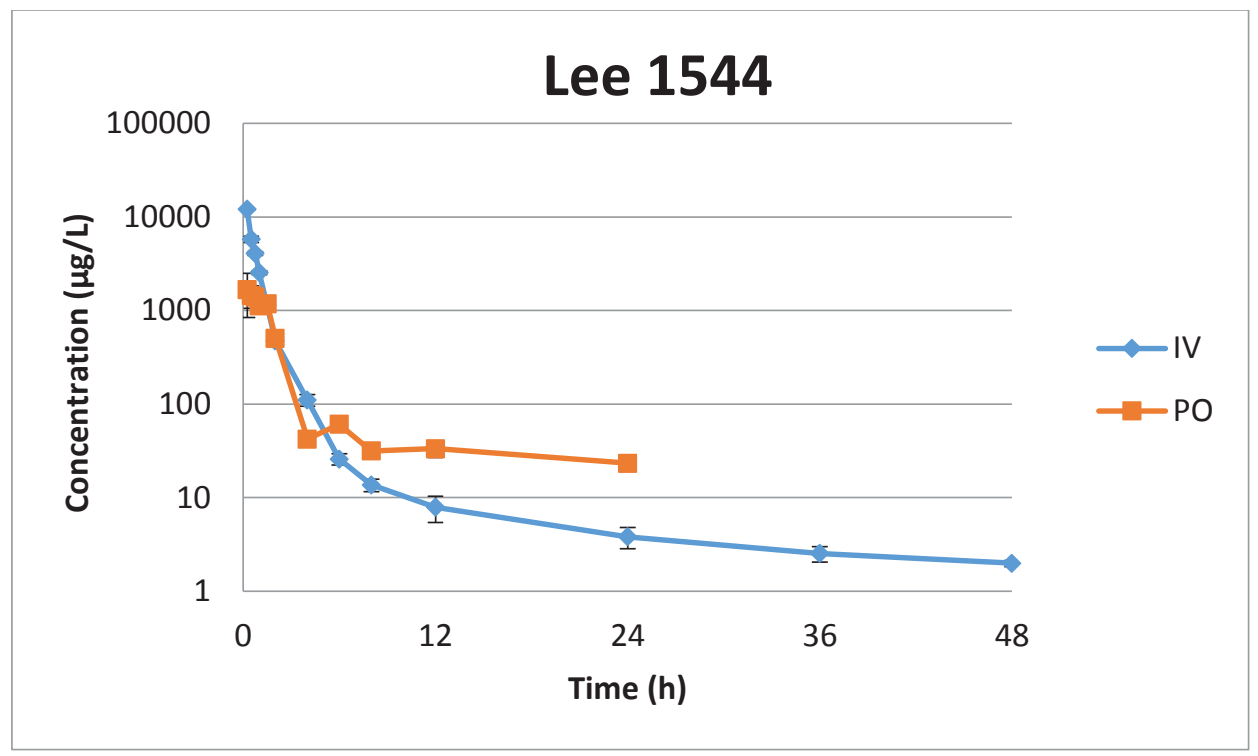

Figure 3-2. Measured plasma concentration-time profiles (mean $\pm \mathrm{SEM}$ ) after intravenous $(10 \mathrm{mg} / \mathrm{Kg})$ and oral $(100 \mathrm{mg} / \mathrm{Kg})$ administration of Lee 1544 in rats. 


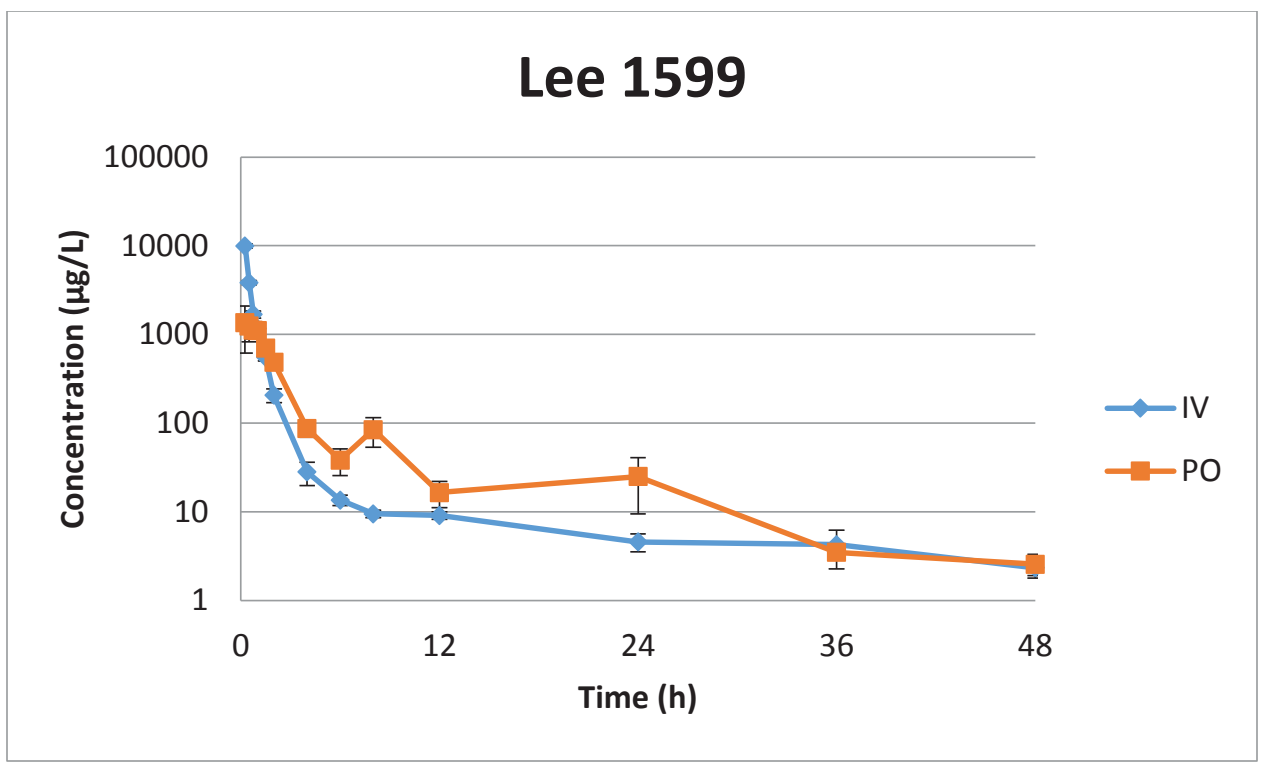

Figure 3-3. Measured plasma concentration-time profiles (mean $\pm \mathrm{SEM}$ ) after intravenous $(10 \mathrm{mg} / \mathrm{Kg})$ and oral $(100 \mathrm{mg} / \mathrm{Kg})$ administration of Lee 1599 in rats. 


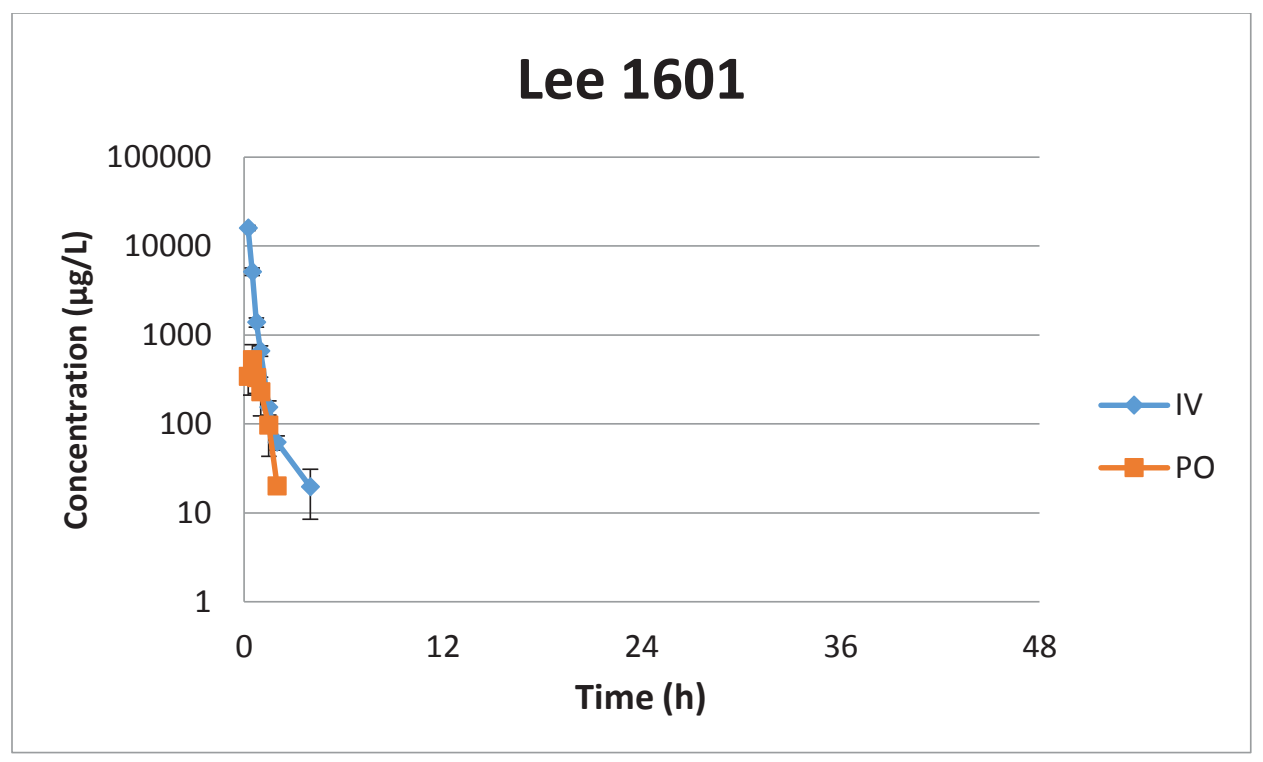

Figure 3-4. Measured plasma concentration-time profiles (mean \pm SEM) after intravenous $(10 \mathrm{mg} / \mathrm{Kg})$ and oral $(100 \mathrm{mg} / \mathrm{Kg})$ administration of Lee 1601 in rats. 


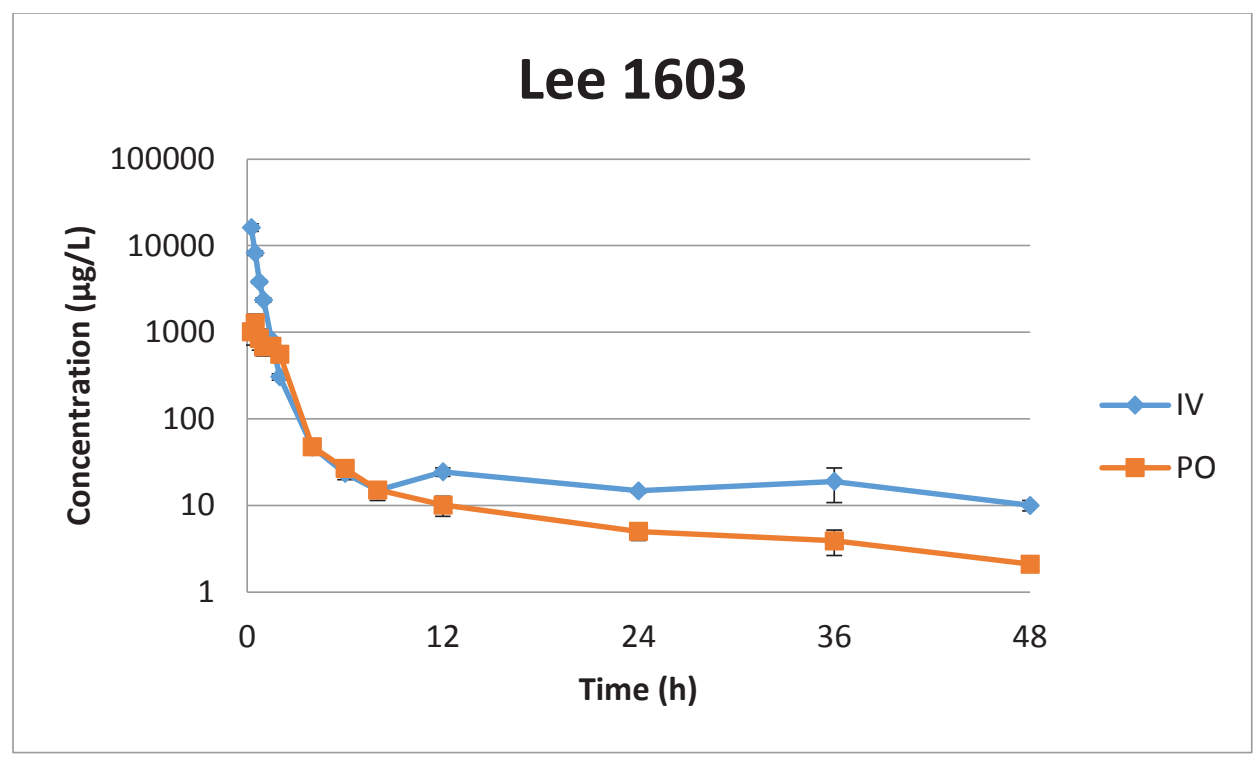

Figure 3-5. Measured plasma concentration-time profiles (mean \pm SEM) after intravenous $(10 \mathrm{mg} / \mathrm{Kg})$ and oral $(100 \mathrm{mg} / \mathrm{Kg})$ administration of Lee 1603 in rats. 


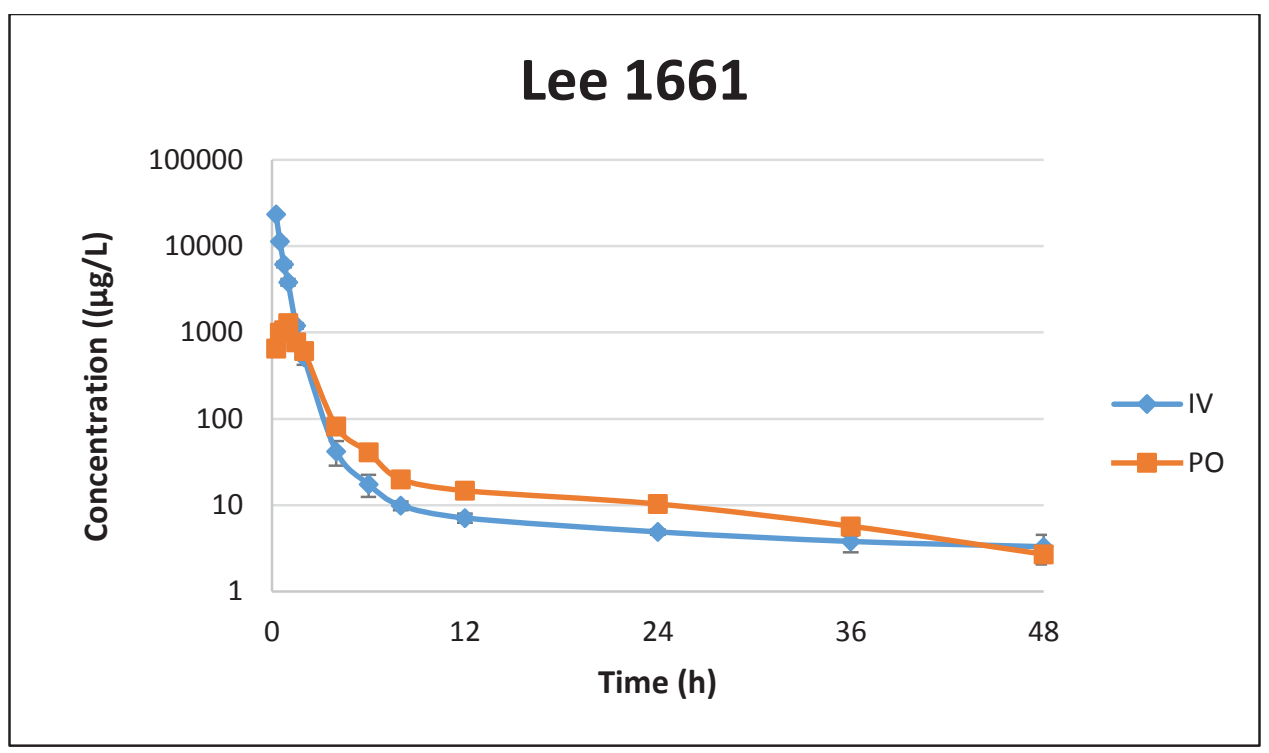

Figure 3-6. Measured plasma concentration-time profiles (mean $\pm \mathrm{SEM}$ ) after intravenous $(10 \mathrm{mg} / \mathrm{Kg})$ and oral $(100 \mathrm{mg} / \mathrm{Kg})$ administration of Lee 1661 in rats. 


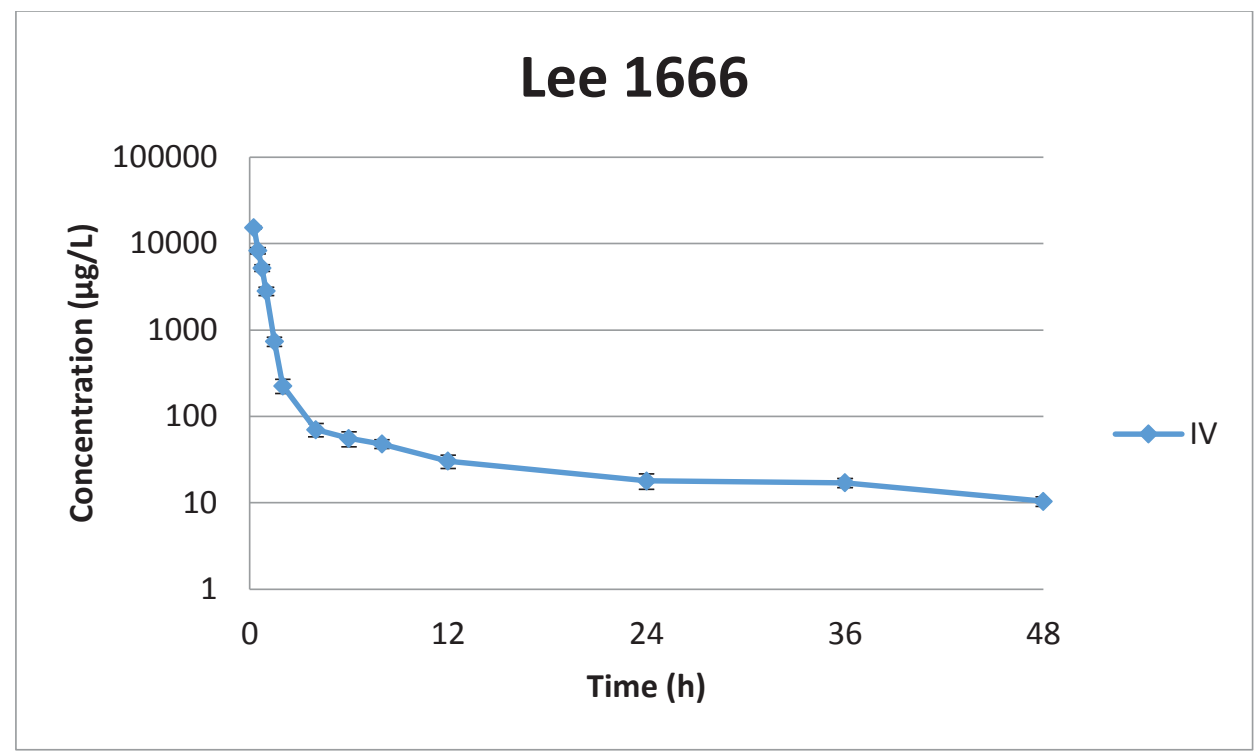

Figure 3-7. Measured plasma concentration-time profiles (mean $\pm \mathrm{SEM}$ ) after intravenous $(10 \mathrm{mg} / \mathrm{Kg})$ administration of Lee 1666 in rats. 


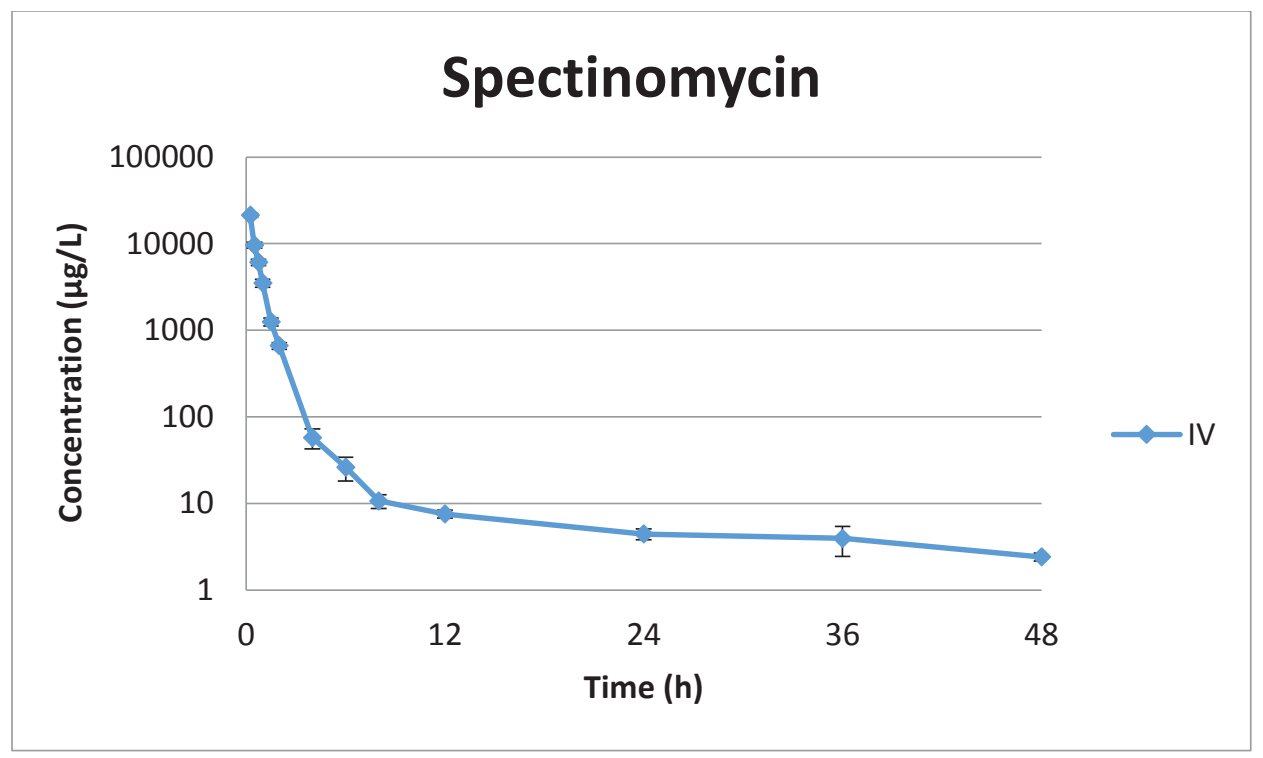

Figure 3-8. Measured plasma concentration-time profiles (mean $\pm \mathrm{SEM}$ ) after intravenous $(10 \mathrm{mg} / \mathrm{Kg})$ administration of spectinomycin in rats. 
in the urine (fe) ranged from 13\% to 89\%. Except for Lee 1601 and Lee 1603, all the compounds had a high fe value 0.5 , suggesting that the urinary excretion is the major route of elimination for these compounds. The Eratio $>1$ for all the compounds suggests active secretion as the net urinary elimination process.

Following $100 \mathrm{mg} / \mathrm{kg}$ oral administration in rats, all compounds showed similar bi-exponential concentration-time profiles (Figures 3-2 to 3-6) except for Lee 1601. However, all tested spectinamides had poor oral bioavailability (F) ranging from 0.4 to $4 \%$. Due to higher hydrophilicity, these molecules have limited membrane permeability that likely leads to the poor oral bioavailability. One of the strategies to improve oral bioavailability is by increasing the lipophilicity and reducing the polar surface area without compensating the solubility of these molecules. Alternative route of administration such as intrapulmonary route can also be assessed to determine an improvement in the bioavailability [90-93].

\section{Macrophage uptake assay}

It has been commonly observed that macrophage ingest the $M$. $t b$ as a defense mechanism. After being ingested, $M$. $t b$ continue to survive and multiply within macrophages. Hence, it is important that the antimycobacterial agents reach the intracellular region where bacteria thrive within macrophage [94-97]. The macrophage uptake of spectinamides was evaluated by incubating the spectinamide agents with macrophages and quantifying the intracellular uptake of the agents by macrophages. Spectinomycin and streptomycin were used as controls for macrophage uptake. Spectinamides are chemically derived from spectinomycin and streptomycin is an aminoglycoside and also a second line agent to treat tuberculosis. The concentration of drug uptake by macrophages after $24 \mathrm{~h}$ incubation are shown in Table 3-2 and Figure 3-9. Lee 1329 and Lee 1599 showed significant penetration into macrophages as compared to spectinomycin and streptomycin. As shown in Figure 3-10, Lee 1329 has a 6-fold and Lee 1599 has 5-fold higher uptake into macrophages as compared to streptomycin. 1329 also has 2.2 fold higher uptake than spectinomycin. The results indicate that spectinamides have substantial intracellular penetration into macrophages.

\section{Biodistribution}

Biodistribution studies with radiolabeled compounds provide a foundation in the assessment of drug disposition as they provide understandings into mass balance, tissue distribution, drug accumulation, circulatory and excretory metabolites, clearance mechanisms and pharmacokinetics. This information is crucial to identify potential toxicity and safety concerns of novel drug candidates, but also provides basic information on systemic exposure [6]. 
Table 3-2. Mean concentration of drug uptake into J774A.1 murine macrophage cell line at $24 \mathrm{~h}$ for two different doses.

\begin{tabular}{lccccc}
\hline & \multicolumn{2}{c}{$\mathbf{2 5} \boldsymbol{\mu g} / \mathbf{m L}$} & & \multicolumn{2}{c}{$\mathbf{1 0 0} \boldsymbol{\mu g} / \mathbf{m L}$} \\
\cline { 2 - 3 } \cline { 5 - 6 } \multicolumn{1}{c}{ Compounds } & $\mathbf{n g} / \boldsymbol{\mu g}$ protein & SEM & & $\mathbf{n g} / \boldsymbol{\mu g}$ protein & SEM \\
\hline Lee 1329 & 1.17 & 0.287 & & 4.04 & 0.753 \\
Lee 1443 & 0.44 & 0.205 & & 0.624 & 0.187 \\
Lee 1445 & 0.762 & 0.125 & & 2.71 & 0.411 \\
Lee 1544 & 0.413 & 0.026 & & 1.37 & 0.036 \\
Lee 1599 & 1.04 & 0.032 & & 3.31 & 0.055 \\
SP & 0.599 & 0.099 & & 1.86 & 0.503 \\
ST & 0.184 & 0.017 & & 0.68 & 0.052 \\
\hline
\end{tabular}




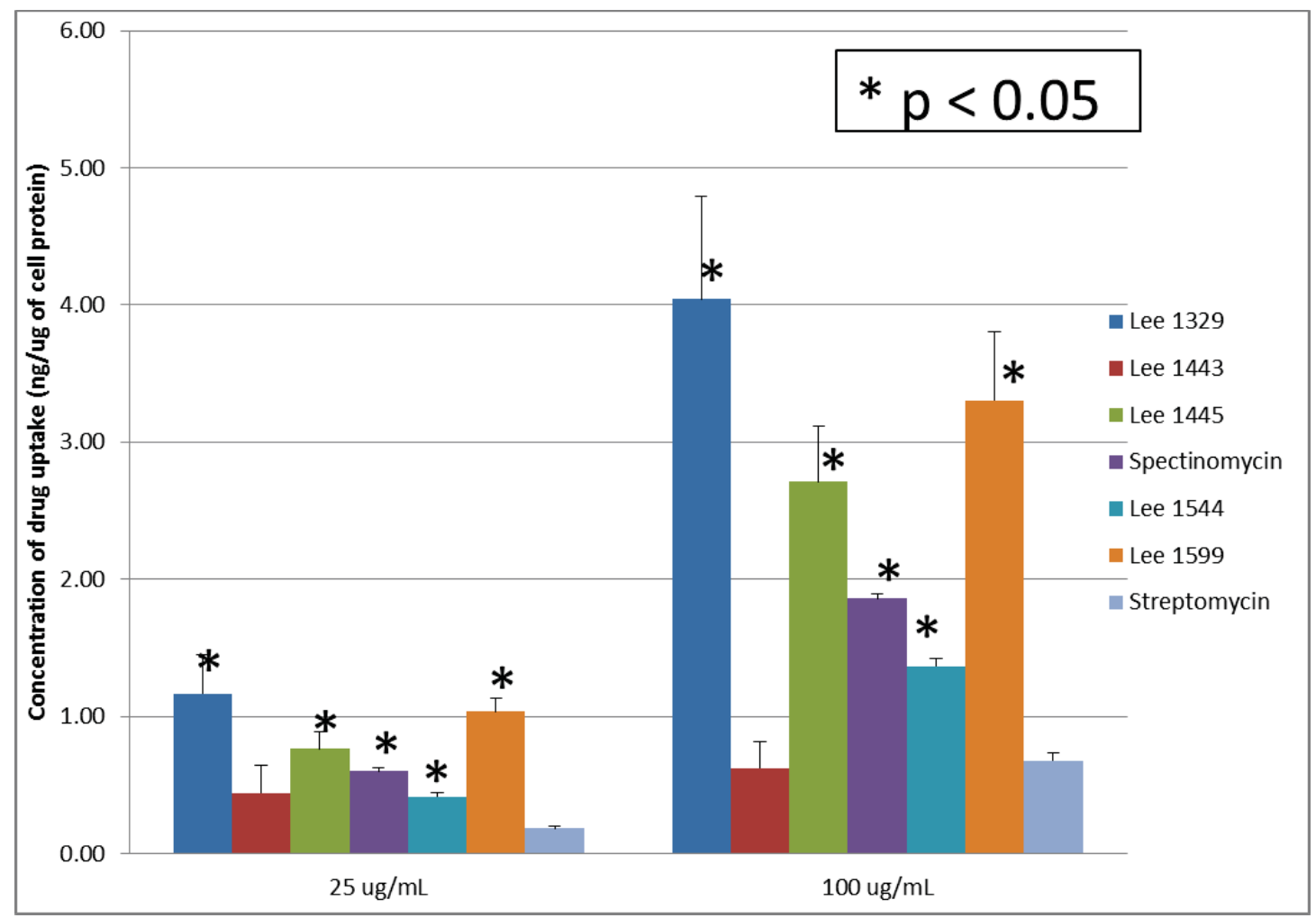

Figure 3-9. Mean average concentrations ( \pm SEM) of drug uptake into J774A.1 murine macrophage cell line at $24 \mathrm{~h}$. 


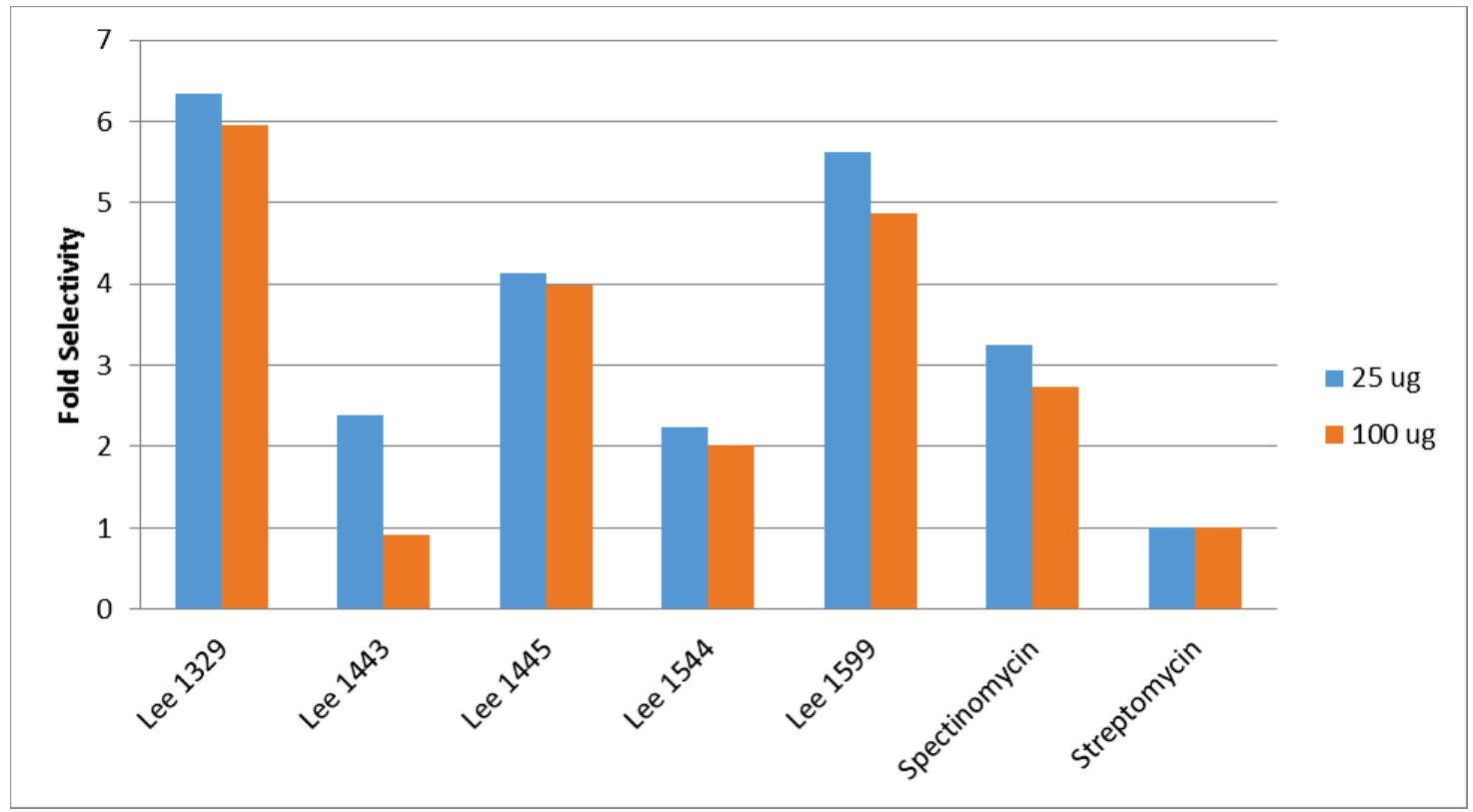

Figure 3-10. Fold differences in drug uptake in J774A.1 murine macrophage cell line. 


\section{Mass balance}

The scintillation assay results revealed that $86.6 \%$ of administered radioactivity was recovered in urine, feces, blood, muscle and organs throughout the length of the study that included 9 doses of $0.9 \mathrm{mg} / \mathrm{kg}{ }^{3} \mathrm{H}$-Lee 1329 administered intravenously every $12 \mathrm{~h}$. It is challenging to achieve $100 \%$ recovery in mass balance studies due to several practical limitations influenced by methodological, analytical or biological factors and the quantitative investigation were not performed on all organs and tissues at the termination of the study. These results, as shown in Figure 3-11, are in accordance with other mass balance studies [98-100]. The samples were collected post $1 \mathrm{~h}$ after the 9 th dose for mass balance determination. Approximately $70 \%$ of administered ${ }^{3} \mathrm{H}$-Lee 1329 was recovered in urine, $12.6 \%$ in feces and only $4 \%$ from all major organs, muscle tissue and whole blood. The residual amount of $13.4 \%$ can likely be found in the animal carcasses. Urine samples collected every $12 \mathrm{~h}$ showed similar amount of radioactivity in the range of 119.3 to $138.9 \mu \mathrm{Ci}$ as shown in Figure 3-12. These results indicate that there is no considerable accumulation of drug in the body during multiple dose administration.

\section{Tissue distribution}

The tissue distribution, penetration and accumulation of ${ }^{3} \mathrm{H}$-Lee 1329 and its labeled metabolite was determined by analyzing the distribution of radioactivity to major organs and muscles post $1 \mathrm{~h}$ after administering the 9 th dose. The observed data for relative and absolute radioactivity for each major organ and tissue are presented in Table 3-3. The degree of tissue penetration was identified by measuring the fold differences in amount of radioactivity per $\mathrm{mg}$ of tissue as compared to whole blood Figure 3-13. The amount of radioactivity in lungs and spleen was 2.79 and 3.06 fold higher as compared to whole blood. This infers that ${ }^{3} \mathrm{H}$-Lee 1329 possesses good tissue penetration into major organs which are the primary site of infections by $M$. $t b$. Moreover, the amount of radioactivity was less than one fold in other organs such as heart and brain.

\section{Pharmacokinetic profile of radioactivity in serum}

The concentration-time profiles for ${ }^{3} \mathrm{H}$-Lee 1329 after administration of 1 st dose and 8th dose are compared in Figure 3-14. The profiles are comparable for both the doses for the first two hours with identical Cmax values. However, the concentrations of radioactivity was $50 \%$ greater after the 8 th dose as compared to the 1 st dose. This

differences in concentrations at later time points indicates the possibility of metabolite formation circulating with longer half-life than the parent drug.

Conversely, the systemic exposure $\left(\mathrm{AUC}_{0-\tau}\right)$ of radioactivity after the 1 st dose and 8th dose were found to be very similar because of two reasons (i) The concentrations of ${ }^{3} \mathrm{H}$-Lee $13292 \mathrm{~h}$ post dose was very low compared to the Cmax and (ii) these concentrations added only $21 \%$ of the total exposure $\left(\mathrm{AUC}_{0-\tau}\right.$ ) (Table 3-4). A comparison of the systemic exposure characterized by $\mathrm{Cmax}$ and $\mathrm{AUC}_{0-\tau}$ following the 1 st dose and 8th dose indicated an accumulation ratio $\mathrm{R}$ of 1.1, providing further evidence for the absence of any substantial drug accumulation. $\mathrm{R}$ is a parameter used to quantify the 


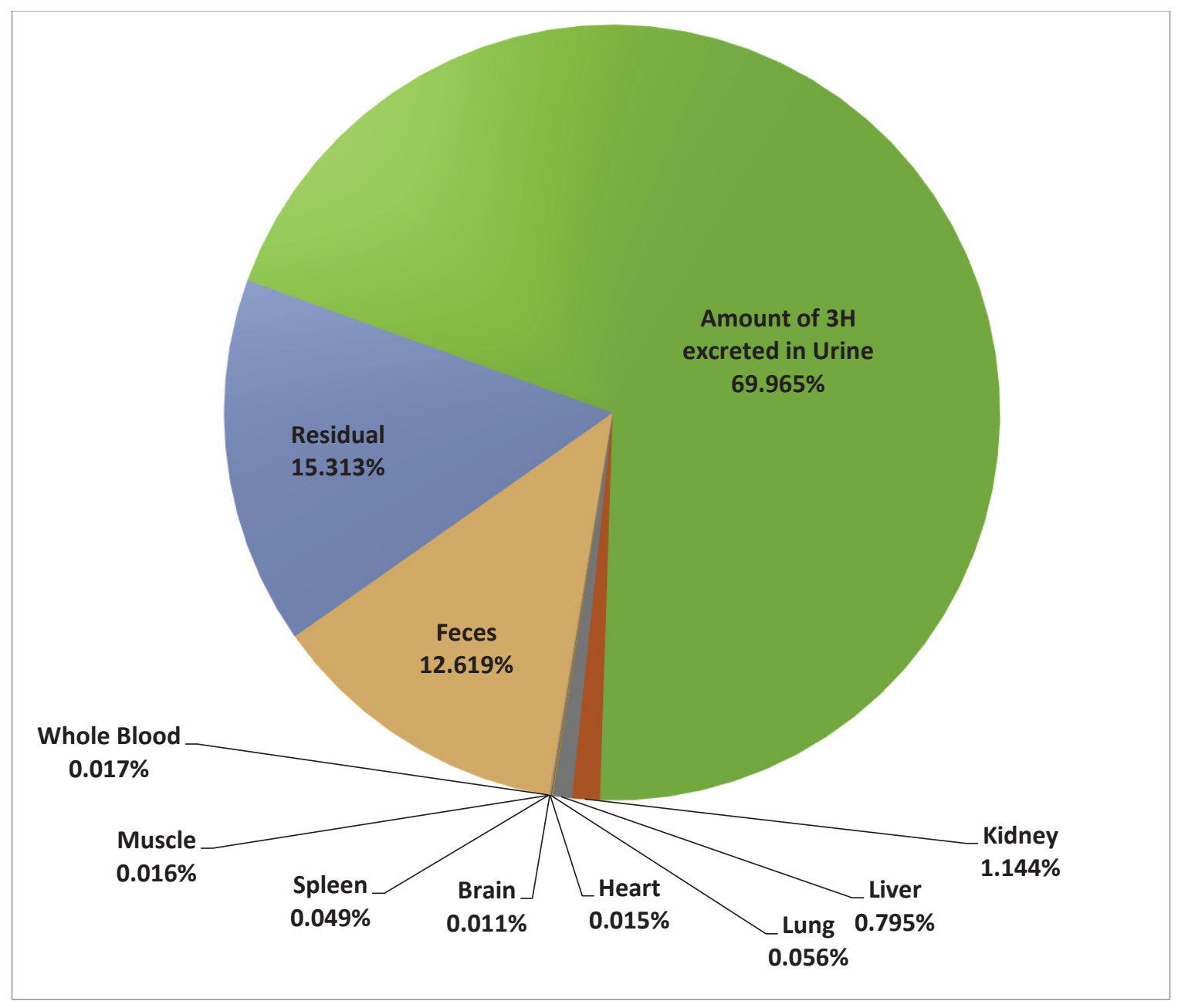

Figure 3-11. Mass balance and percentage distribution of Lee 1329-T at $1 \mathrm{~h}$ post $9^{\text {th }}$ dose of $0.9 \mathrm{mg} / \mathrm{kg}$. 


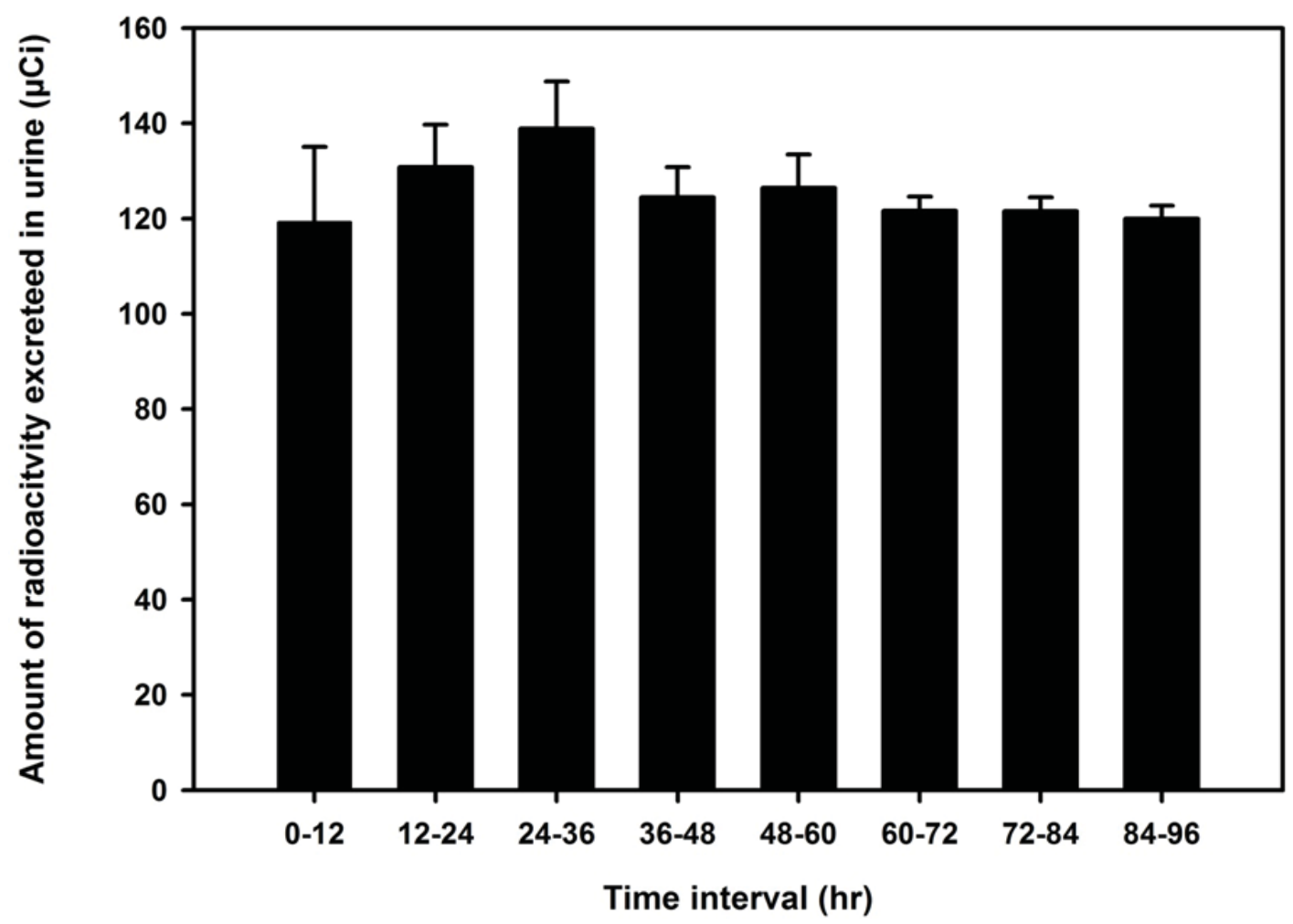

Figure 3-12. Amount of radioactivity (mean \pm SD) excreted in urine after each dosing interval $\left(0.9 \mathrm{mg} / \mathrm{kg}^{3} \mathrm{H}-1329\right.$, BID for 4.5 days). 
Table 3-3. Tissue distribution and recovery of radioactivity (mean(\%CV)) following IV administration of ${ }^{3} \mathrm{H}-1329$ at $0.9 \mathrm{mg} / \mathrm{kg}$ BID for 4.5 days in rats.

\begin{tabular}{|c|c|c|c|}
\hline Sample/Organ & $\begin{array}{c}\text { Relative amount } \\
\text { of radioactivity } \\
\text { [ } \mu \mathrm{Ci} / \mathrm{g} \text { tissue] }\end{array}$ & $\begin{array}{c}\text { Total amount } \\
\text { of radioactivity } \\
{[\mu \mathrm{Ci}]}\end{array}$ & $\begin{array}{c}\% \text { of } \\
\text { radioactivity } \\
\text { recovered }\end{array}$ \\
\hline \multicolumn{4}{|l|}{ ADMINISTRATION } \\
\hline $\begin{array}{l}\text { Total amount } \\
\text { administered }\end{array}$ & & $1432(3.44)$ & \\
\hline \multicolumn{4}{|l|}{ RECOVERY } \\
\hline Blood & $0.24(12.2)$ & 3.47 & $0.242(26.8)$ \\
\hline Liver & $1.19(13.7)$ & 11.4 & $0.796(5.99)$ \\
\hline Kidney & $7.92(8.98)$ & 16.4 & $1.15(10.9)$ \\
\hline Lung & $0.64(9.35)$ & 0.805 & $0.056(12.1)$ \\
\hline Spleen & $0.69(11.5)$ & 0.658 & $0.046(13.8)$ \\
\hline Heart & $0.22(9.32)$ & 0.219 & $0.015(24.9)$ \\
\hline Brain & $0.10(18.1)$ & 0.160 & $0.011(39.6)$ \\
\hline Muscle & $0.23(21.8)$ & 24.7 & $1.72(34.9)$ \\
\hline Urine & $17.90(21.2)$ & 1003 & $70.0(2.99)$ \\
\hline Feces & $5.91(39.6)$ & 181 & $12.6(29.8)$ \\
\hline $\begin{array}{l}\text { Total amount } \\
\text { recovered }\end{array}$ & & 1242 & $86.6(5.09)$ \\
\hline
\end{tabular}




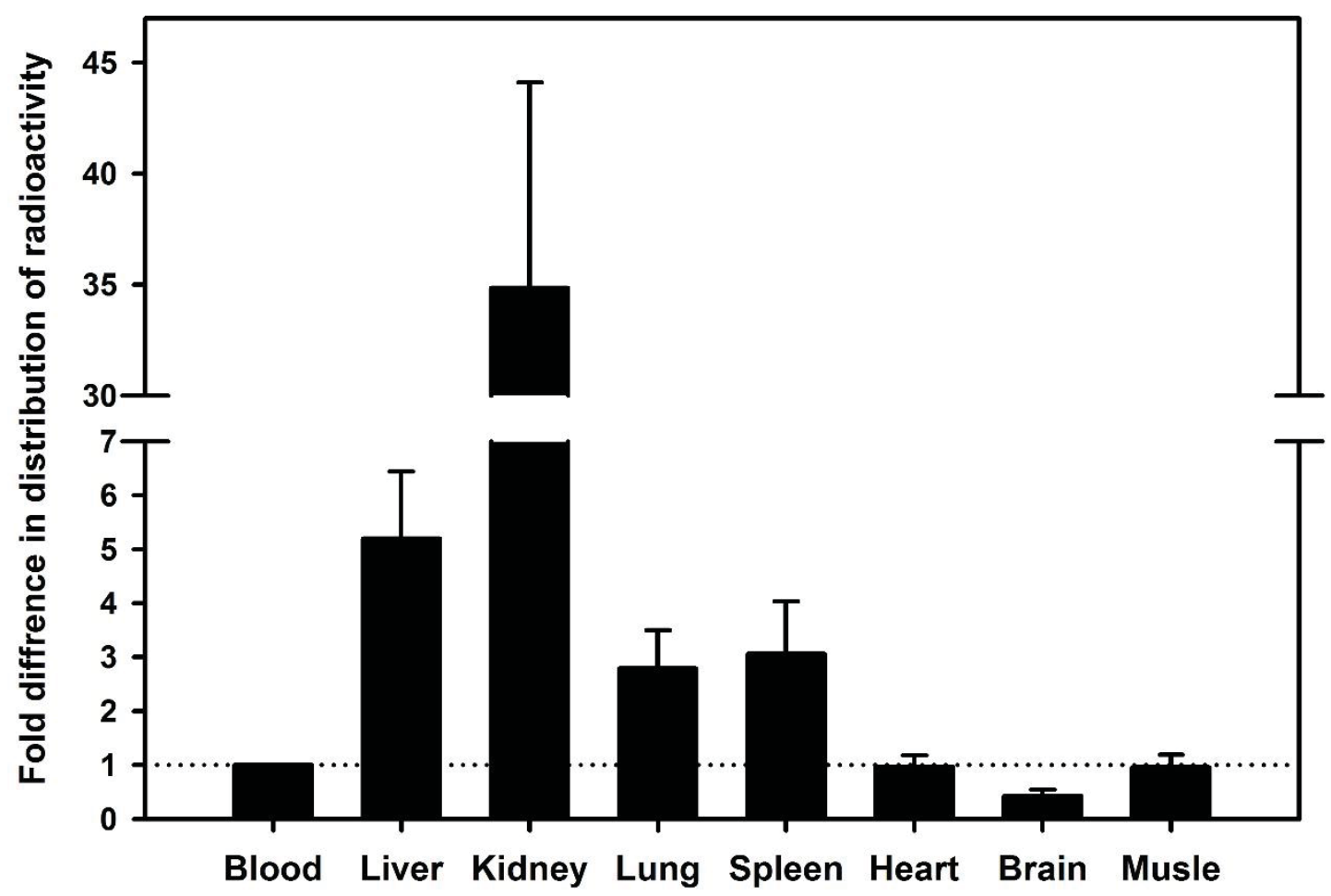

Figure 3-13. Fold difference (mean \pm SD) in tissue distribution of radioactivity compared to amount in whole blood (after normalizing the distributions to $\mu \mathrm{Ci} / \mathrm{mL}$ or $\mu \mathrm{Ci} / \mathrm{mg}$ of blood or tissue). 


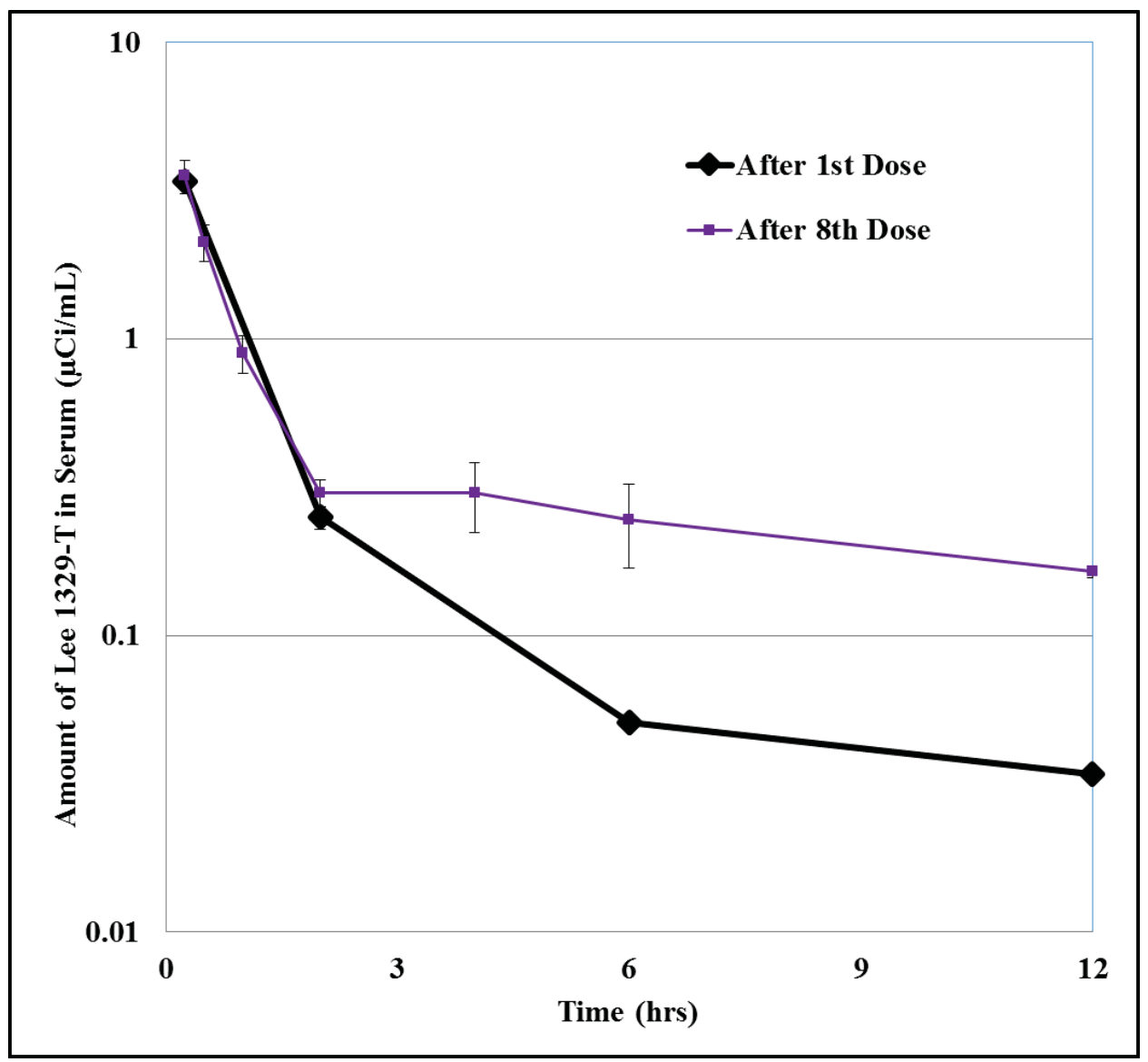

Figure 3-14. Comparison of single and multiple dose pharmacokinetics showing average $( \pm \mathrm{SD})$ serum concentration-time profiles of radioactivity after the 1 st dose and 8th dose during multiple dosing with $0.9 \mathrm{mg} / \mathrm{kg}{ }^{3} \mathrm{H}-1329$ given intravenously every $12 h$. 
Table 3-4. Serum pharmacokinetic parameters after the 1st and 8th intravenous dose of $0.9 \mathrm{mg} / \mathrm{kg}^{3} \mathrm{H}-1329$ (values are expressed as mean $(\% \mathrm{CV})$ ).

\begin{tabular}{llc}
\hline \multirow{2}{*}{ Parameter } & \multicolumn{2}{c}{ Dosing interval } \\
\cline { 2 - 3 } & \multicolumn{1}{c}{$\mathbf{1}^{\text {st }}$} & $\mathbf{8}^{\text {th }}$ \\
\hline $\mathrm{t}_{\max }(\mathrm{h})$ & 0.25 & 0.25 \\
$\mathrm{C}_{\max }[\mathrm{mCi} / \mathrm{L}]$ & $3.39(7.4)$ & $3.55(28.9)$ \\
$\mathrm{AUC}_{0-\tau}\left[\mathrm{mCi}^{*} \mathrm{~h} / \mathrm{L}\right]$ & $5.08(6.8)$ & $5.17(20.5)$ \\
\hline
\end{tabular}


extent to which a compound will accumulate during multiple dosing relative to the first dose and is calculated as ratio between AUC or Cmax during one dosing interval during multiple dosing compared to the first dosing interval. An $\mathrm{R}$ value of 1 indicates absence of any drug accumulation [101]

These results confirm that there is no substantial accumulation of ${ }^{3} \mathrm{H}$ - Lee 1329 or its metabolites. The recovery of $70 \%$ radioactivity in urine and 35 -fold higher concentration in kidneys compared to blood suggests that renal excretion is the major route of elimination (or kidney is the major eliminating organ) for Lee 1329 and its metabolites.

\section{Conclusion}

Select molecules from the spectinamide series were identified and characterized via screening prototype involving various in vitro and in vivo assays. Spectinamides demonstrated low to intermediate protein binding, shorter in vivo half-life at clinically relevant concentrations and very low oral bioavailability. The compounds in the series also expressed higher cellular uptake into macrophages as compared to streptomycin and spectinomycin.

The biodistribution and mass balance study emphasized the favorable pharmacokinetic properties of spectinamides as anti-TB agents; augmenting that spectinamide Lee 1329 has excellent penetration into target tissues, did not accumulate in tissue during multiple dosing, and forms low levels of circulating metabolites that are excreted into urine and feces.

The pharmacokinetic parameters and tissue distribution data obtained in this chapter provide the basis for the pharmacometrics-directed integrated PK/PD characterizations in Chapters 4 and 5. 


\section{CHAPTER 4. A PHARMACOMETRICS-BASED APPROACH USING IN VITRO PK/PD MODELING TO DEVELOP DOSING REGIMENS FOR IN VIVO STUDIES FOR A NOVEL SPECTINAMIDE ANTI-TUBERCULOSIS AGENT}

\section{Introduction}

The increasing emergence of resistant mycobacterial strains in recent years and the complications arising from treatment regimens are a strong reminder of the urgent need for the development of new and more effective treatment options for tuberculosis patients worldwide $[67,68,72,73]$. Spectinamides, a novel class of spectinomycin analogs, were designed to combate the increasing TB pandemic [81]. Spectinamides have shown potent activity against mycobacteria in vitro and in vivo. Based on in vitro screening assays and pharmacokinetic studies in rodents, Lee 1599 emerged as one of the lead candidate molecules from the class of synthesized compounds. Lee 1599 has a minimum inhibitory concentration (MIC) of $1.6 \mu \mathrm{g} / \mathrm{mL}$, and a favorable pharmacokinetic profile with low $(12.5 \%)$ protein binding, high microsomal metabolic stability, and renal excretion as the primary elimination pathway. Although the half-life at effective concentrations in rats was with $0.58 \mathrm{~h}$ is relatively low, this property is counterbalanced by a long post-antibiotic effect $[81,102,103]$ that last approximately $133 \mathrm{~h}$ when mycobacteria were exposed to Lee 1599 at 10X the MIC.

The preliminary screening assays for new anti-infectives routinely include MIC testing as one of the major pharmacodynamic measures of potency. Although the MIC parameter is very informative at the early discovery phase, the limitations of this testing method become evident as the in vitro knowledge about MIC can often not correlate very well with in vivo efficacy in clinical settings. MIC is just a point estimate of pharmacodynamic effect and does not describe the nature of bacterial killing over time $[39,104,105]$. Thus, it is essential to have a more dynamic approach that has the ability to translate the in vitro bacterial killing effect to in vivo conditions. Various in vitro $\mathrm{PK} / \mathrm{PD}$ modeling approaches have been utilized in recent years to capture the interaction of fluctuating drug concentrations with bacterial killing over time. The benefits and pitfalls of each method have been described elsewhere [10]. To obtain initial assessments on $\mathrm{PK} / \mathrm{PD}$ drivers of efficacy for new leads in drug discovery programs, a spinner-flask based in vitro $\mathrm{PK} / \mathrm{PD}$ model is a simple tool to generate time-kill curves for mycobacteria under exposure to antibiotics. The fluctuating concentration-time profiles of the free, pharmacologically active antibiotic as experienced during multiple dosing in vivo are simulated in this approach using previously determined in vivo pharmacokinetic parameters of the compound

In this article, we describe the dynamics of bacterial killing by Lee 1599 using an in vitro $\mathrm{PK} / \mathrm{PD}$ model. The Lee 1599 facilitated bacterial killing was characterized at multiple dosing regimens by means of $M$. bovis BCG as model organism. An integrated PK/PD model was generated based on the generated bacterial time-kill curves and the simulated pharmacokinetic profiles of Lee 1599. Numerical simulations were subsequently performed to predict the anti-mycobacterial activity of Lee 1599 for 
untested dosing regimens. This methodology has potential to guide researchers for optimizing the dose selection process and study designs for further in vivo efficacy testing.

\section{Materials and Methods}

\section{Culture, media and antibiotics}

M. bovis BCG was grown in Middlebrook $7 \mathrm{H} 9$ broth (Becton Dickinson, Sparks, MD). The cultures were stored at $-80^{\circ} \mathrm{C}$ in Middlebrook $7 \mathrm{H} 9$ broth. For each experiment, cultures were thawed and incubated at $37^{\circ} \mathrm{C}$ in Middlebrook $7 \mathrm{H} 9$ broth until the bacteria reaches logarithmic phase (OD 600 0.4-0.7). Lee 1599 (3'-Dihydro3'-deoxy-3'(R)- (5-chloropyridin-2-yl)acetylamino spectinomycin Trihydrobromide) was synthesized and provided by our collaborators at St.Jude Children's Research Hospital. A solution of Lee 1599 was freshly prepared in sterile water before the start of each experiment.

\section{In vitro $\mathrm{PK} / \mathrm{PD}$ model}

As previously reported [39], the in vitro PK/PD model system consisted of a twoarmed, water jacketed flask (1965 series spinner flask, Bellco Glass, Vineland, NJ) as depicted in Figure 4-1 [71]. A filter unit attached to a hollow steel tube is introduced into the system. The filter unit contains a prefilter $(5 \mu \mathrm{m}$, Millipore, Billerica, MA) and filter membrane $(0.22 \mu \mathrm{m}$, Millipore, Billerica, MA) to prevent leakage of bacteria during the dilution process. The other end of the tube is connected to plastic tubing (PharMed tubing, Cole-Parmer, Vernon Hills, IL) from which the media is withdrawn continously at a defined flow rate using a peristaltic pump (Masterflex L/S, Cole-Parmer, Vernon Hills, IL). The flask is placed on a magnetic stirrer for homogeneity of the culture and preventing membrane blockage. The temperature of the system is maintained at $37^{\circ} \mathrm{C}$ with the help of thermostatic water bath attached to the water-jacketed flask. One arm of the flask in connected by plastic tubing to the fresh sterile media reservoir and the other arm is used for dosing and repeated sampling. The solution of Lee 1599 is added through the sidearm. The concentration of Lee 1599 in flask decreases exponentially as per the equation:

$$
C=C_{0} * \mathrm{e}^{-\mathrm{k} * \mathrm{t}}
$$

$\mathrm{C}_{0}$ is the initial concentration of Lee 1599 in the flask following administration, $\mathrm{C}$ is the concentration of Lee 1599 at any given time $\mathrm{t}, \mathrm{k}$ is the elimination rate constant.

$$
k=\frac{C L}{V d}=\frac{F}{V m}=\frac{0.693}{t_{1 / 2}}
$$




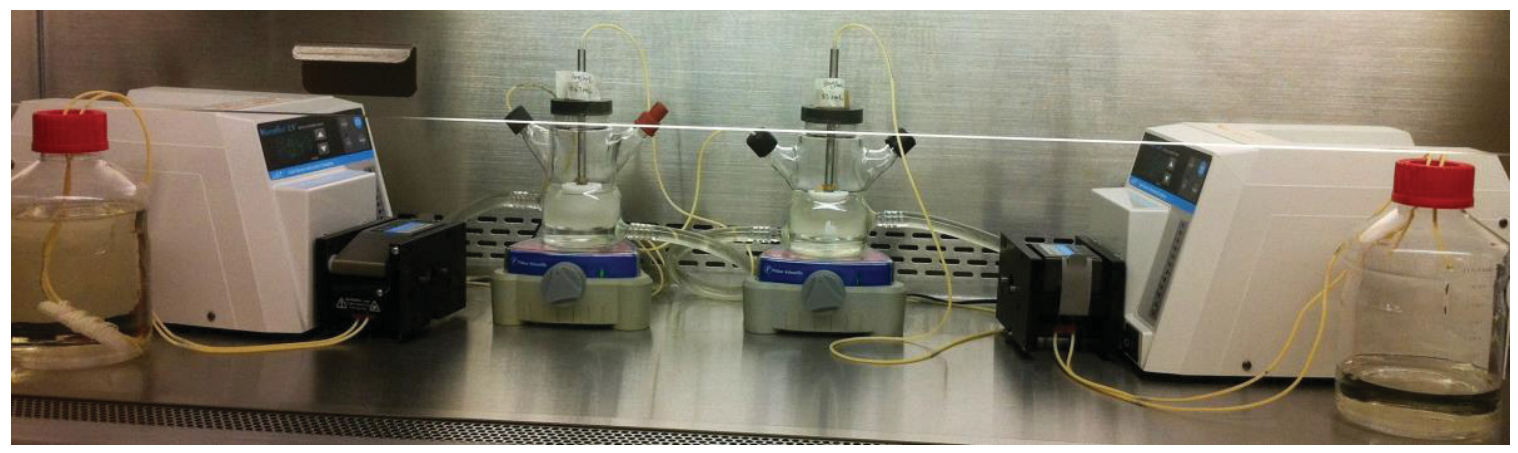

Figure 4-1. A representation of working unit of an in vitro PK/PD model. 
where CL is the clearance of $1599, \mathrm{Vd}$ is the Volume of distribution of $1599, \mathrm{~F}$ is the flow rate of the media depicting Clearance, $\mathrm{Vm}$ is the volume of media in the flask, and $\mathrm{t}_{1 / 2}$ is the half-life of 1599. All the above mentioned PK parameters were from obtained by performing PK study in rats. The in vitro set up is assembled in a biosafety cabinet in a sterile environment. The flask and the tubes are cleaned and sterilized by autoclaving before starting every experiment.

\section{Time kill curves for Lee 1599}

M. bovis BCG was used as a test organism for evaluating the effect of Lee 1599 in vitro model. The organism was grown to early logarithmic phase (O.D $600.0 .4-0.7)$ in Middlebrook $7 \mathrm{H} 9$ medium. This actively growing bacteria was used as an inoculum for the in vitro model making the final density in the culture as $10^{6} \mathrm{CFU} / \mathrm{mL}$.

In separate experiments, different dose levels and dosing intervals of Lee 1599 were tested. The dosing regimens tested were $1 \mathrm{mg}$ QD, 5mg QD and BID, 10mg QD and BID, 20mg QD, 25mg QD and BID, 50mg QD and BID and 100mg QD. Samples with an approximate volume of $200 \mu \mathrm{L}$ were collected from the flask every $12 \mathrm{~h}$. The samples were centrifuged at $10,000 \mathrm{rpm}$ for $10 \mathrm{~min}$ at $37^{\circ} \mathrm{C}$. The pellets were collected and resuspended in an antibiotic-free medium. This step ensured that there was no drug carry over effect. The samples were serially diluted and the dilutions were plated on 7H11 agar plates in duplicates. The agar plates were incubated for 21 days at $37^{\circ} \mathrm{C}$. The effect of Lee 1599 was characterized by measuring the reduction in the number of viable bacteria, in terms of CFU/mL. There was a control arm included in the study to determine the bacterial growth in absence of drug.

\section{PK/PD model building}

The chemostat flask in the in vitro system resembled the central compartment and total amount of drug administered in the central compartment. The concentration-time profiles of the drug in the in vitro $\mathrm{PK} / \mathrm{PD}$ model system were described with a simple one-compartment model with first-order elimination:

$$
C=C_{0} * \mathrm{e}^{-\mathrm{k} * \mathrm{t}}
$$

where $\mathrm{C}$ is the concentration of Lee 1599 at any given time $\mathrm{t}, \mathrm{C}_{0}$ is the concentration of Lee 1599 at time $0 \mathrm{~h}, \mathrm{k}$ is the elimination rate constant.

The rate of change in the number of bacteria in the presence of drug was modeled using the full PK/PD model as shown in Figure 4-2. The bacterial submodel and the PK model were combined and the parameters are combined to characterize the effect of antibiotic Lee 1599 on $M$. bovis $B C G[105,106]$ as shown in the equation below.

$$
\frac{d N}{d t}=\left[k_{0} *\left(1-\frac{N}{N_{\max }}\right)-\left(1-e^{-\alpha t}\right) *\left(\frac{\mathrm{I}_{\max } * \mathrm{C}}{\mathrm{IC}_{50}+\mathrm{C}}\right)\right] * \mathrm{~N}
$$




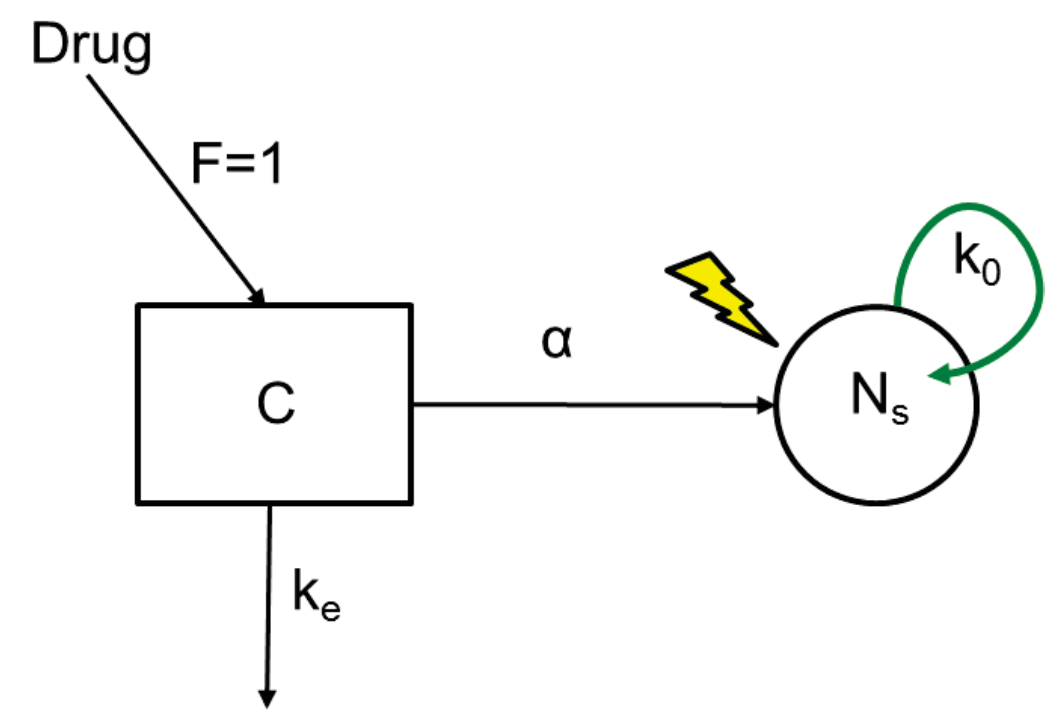

Figure 4-2. Schematic representation of PK/PD model to describe the rate of change in the number of bacteria in the in vitro PK/PD model system.

Notes: C: Concentration of drug in central compartment

F: Bioavailability

$\mathrm{k}_{\mathrm{e}}$ : Elimination rate constant

$\mathrm{k}_{\mathrm{o}}$ : Growth rate constant

$\mathrm{N}_{\mathrm{s}}$ : Total number of susceptible bacteria in the system

$\alpha$ : Delay rate constant 
The parameters in the equation are as follows: $\mathrm{N}$ is the number of viable bacteria in the system, $\mathrm{k}_{0}$ is the bacterial growth rate constant, Nmax is the maximum number of bacteria grown in the system in the absence of antibiotic, $\alpha$ is the delay rate constant for growth, Imax is the maximum kill rate of the bacteria, $\mathrm{C}$ is the concentration of the drug in the system at a given time point, $\mathrm{IC}_{50}$ is the inhibitory concentration at half maximal kill rate. The logistic growth function added to the equation implies that the entry into the stationary phase is attributed to self-limiting growth of bacteria. The delay rate constant in incorporated to take into account the time taken by the drug to reach the site of action in bacteria.

The time kill curves were analyzed using non-linear mixed effects modeling (NONMEM v.7.2, ICON plc). The pharmacokinetic parameters were fixed in the described PK/PD model to the following values: $V=55 \mathrm{~mL}$, volume of media in the system; half-life $\mathrm{t}_{1 / 2}=0.58 \mathrm{~h}$. The first order conditional estimate method within NONMEM was used to analyze the experimental time-kill curves. The between experimental variability was modeled as proportional error. The model was evaluated using various goodness of fit plots.

The appropriate PK/PD index associated with the bacterial kill by Lee 1599 was determined by calculating the individual indices and subsequently fitting an inhibitory Emax model to the colony count at a specific time point versus PKPD index data using nonlinear regression:

$$
E=E_{0}-\left(\frac{E_{\text {max }} * P K P D_{\text {index }}}{E C_{50}+P K P D_{\text {index }}}\right)
$$

where, $\mathrm{E}$ is the observed M. bovis BCG counts in $\mathrm{Log} \mathrm{CFU} / \mathrm{mL}, \mathrm{E}_{0}$ is the bacterial count in the control experiment, $\mathrm{E}_{\max }$ is the maximum anti-bacterial effect in Log CFU/mL and $\mathrm{EC}_{50}$ is the value of $\mathrm{PK} / \mathrm{PD}$ index that produces half-maximal antibacterial effect. $\mathrm{PKPD}_{\text {index }}$ is one of three empirical $\mathrm{PK} / \mathrm{PD}$ indices frequently used for antibiotics pharmacotherapy such as $\mathrm{AUC}_{0-24} / \mathrm{MIC}, \mathrm{C}_{\max } / \mathrm{MIC}$ or $\mathrm{T}>\mathrm{MIC}$. The most appropriate $\mathrm{PK} / \mathrm{PD}$ index that best described the bacterial killing was selected based on visual inspection and goodness of fit criteria.

\section{Numerical simulations}

Numerical simulations were performed using the developed PK/PD model and the parameter estimates derived from the time kill experiments to predict the effect of different untested doses and dosing regimens in a murine in vivo infection model of mycobacteria. The PK parameters of Lee 1599 in mouse were obtained from a mouse bridging studies as published elsewhere[81]. Dosing regimens ranging from $1 \mathrm{mg} / \mathrm{kg}$ to $200 \mathrm{mg} / \mathrm{kg}$ with QD, BID and TID dosing were simulated using the in vivo PK parameters and $\mathrm{PK} / \mathrm{PD}$ estimates obtained from experimental time kill curves. 1000 datasets were simulated for each dose/dosing regimen using NONMEM 7.2 


\section{Results}

\section{Time kill curves for Lee 1599}

The bacillary load in tuberculosis patients varies from 6-9 $\log \mathrm{CFU} / \mathrm{mL}$ in cavity walls [107]. Thus, the experiment was initiated with a bacterial burden of approximately $6 \log \mathrm{CFU} / \mathrm{mL}$ and $7 \log \mathrm{CFU} / \mathrm{mL}$. The time kill experiments were carried out for Lee 1599 against $M$. bovis BCG with various dose and dosing regimens as shown in Figure 4-3 $\left(\mathrm{N}_{0}\right.$ : 6-7 $\left.\log \mathrm{CFU} / \mathrm{mL}\right)$ and Figure 4-4 $\left(\mathrm{N}_{0}\right.$ : 7-8 $\left.\log \mathrm{CFU} / \mathrm{mL}\right)$. The samples were collected every $12 \mathrm{~h}$ up to $96 \mathrm{~h}$ (Day 4 ) for all the studies. All the studies were performed in duplicate $(\mathrm{N}=2)$. LC-MS analysis has demonstrated that Lee 1599 is stable in $7 \mathrm{H} 9$ media for up to $144 \mathrm{~h}$. The untreated control group showed a 2-log increase in bacterial growth through the length of the study. The lowest treatment dose of $1 \mathrm{mg} / \mathrm{kg}$ QD dosing did not show any change in bacterial counts, indicating similar doubling time and death rate. At $5 \mathrm{mg} / \mathrm{kg}$ QD and $10 \mathrm{mg} / \mathrm{kg}$ QD, Lee 1599 showed a bactericidal effect and a decrease in bacterial count was observed. However, Lee 1599 did not show a significant difference $(\mathrm{p}>0.05)$ in bacterial counts at a very high dose of $100 \mathrm{mg} / \mathrm{kg}$ QD compared to $50 \mathrm{mg} / \mathrm{kg}$ QD ( $\mathrm{p}=0.0729$ at $48 \mathrm{~h}$ and $\mathrm{p}=0.278$ at $72 \mathrm{~h}$ ). The antibiotic effect improved substantially with BID and TID dosing as compared to QD dosing using the same daily dose. An increase in bacterial killing was observed with $5 \mathrm{mg} / \mathrm{kg}$ BID (10mg/ $\mathrm{kg} /$ day) and $3.33 \mathrm{mg} / \mathrm{kg}$ TID $(10 \mathrm{mg} / \mathrm{kg} /$ day) as compared to $10 \mathrm{mg} / \mathrm{kg}$ QD dosing. Similarly, $50 \mathrm{mg} / \mathrm{kg}$ BID (100mg/kg/day) dosing was more effective than $100 \mathrm{mg} / \mathrm{kg}$ QD.

The time kill curves for $M$. bovis BCG were described using a semi-mechanistic PK/PD model. The effect of Lee 1599 on bacteria was characterized by incorporating an inhibitory sigmoidal Emax model with delay rate constants that reduced the growth rate in a concentration-dependent fashion. The growth rate constant was estimated to be $0.0368 \mathrm{~h}^{-1}$ that equals to a doubling time of $18.83 \mathrm{~h}$. The doubling time is in accordance with the values reported in the literature $[108,109]$ indicating that the growth rate was not affected by the in vitro $\mathrm{PK} / \mathrm{PD}$ model system. A maximum bacterial kill rate ( $\left.\mathrm{I}_{\max }\right)$ was calculated as $0.0355 \mathrm{~h}^{-1}$, suggesting that it takes nearly $19.5 \mathrm{~h}$ for the bacterial counts to be halved. The concentration of the drug required to produce half-maximum inhibition $\left(\mathrm{IC}_{50}\right)$ was calculated as $0.0437 \mathrm{mg} / \mathrm{mL}$. A delay rate constant was introduced in the equation to explain the delay in the initiation of the actual killing effect. The delay rate constant was estimated to be around $0.0209 \mathrm{~h}^{-1}$. The results of this analysis are shown in Table 4-1 and the model diagnostics and predictions for various dosage regimens are shown in Figures 4-5 and 4-6.

The PK/PD index for Lee 1599 was determined using a sigmoidal inhibitory Emax model. The bacterial kill on Day 2, 3 and 4 (only Day 4 data shown) suggested that Lee 1599 follows both AUC/MIC and Cmax/MIC as PK/PD index (Figure 4-7). Besides visual inspections, various model diagnostics such as AIC, BIC and -2LL are used to estimate the relative quality of statistical models and as a means of model selection. These goodness-of-criteria also demonstrated that AUC/MIC and Cmax/MIC are appropriate $\mathrm{PK} / \mathrm{PD}$ indices as compared to $\mathrm{T}>\mathrm{MIC}$ (Table 4-2). AUC/MIC index 


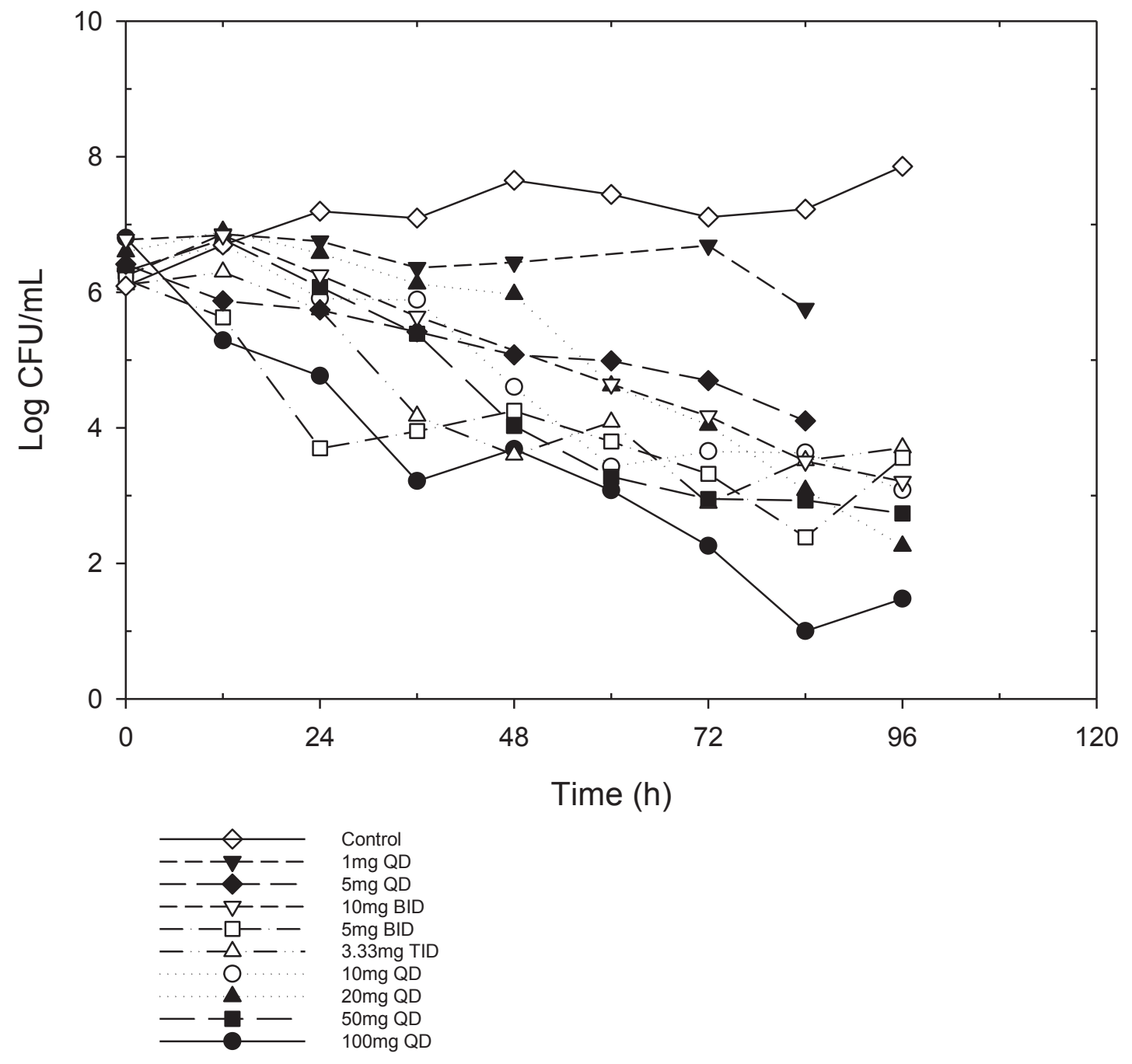

Figure 4-3. Timekill effect of Lee 1599 against $M$. bovis BCG (No: 6-7 log $\mathrm{CFU} / \mathrm{mL}$ ) with observed $\log \mathrm{CFU} / \mathrm{mL}$ plotted against time for different dosing regimens. 


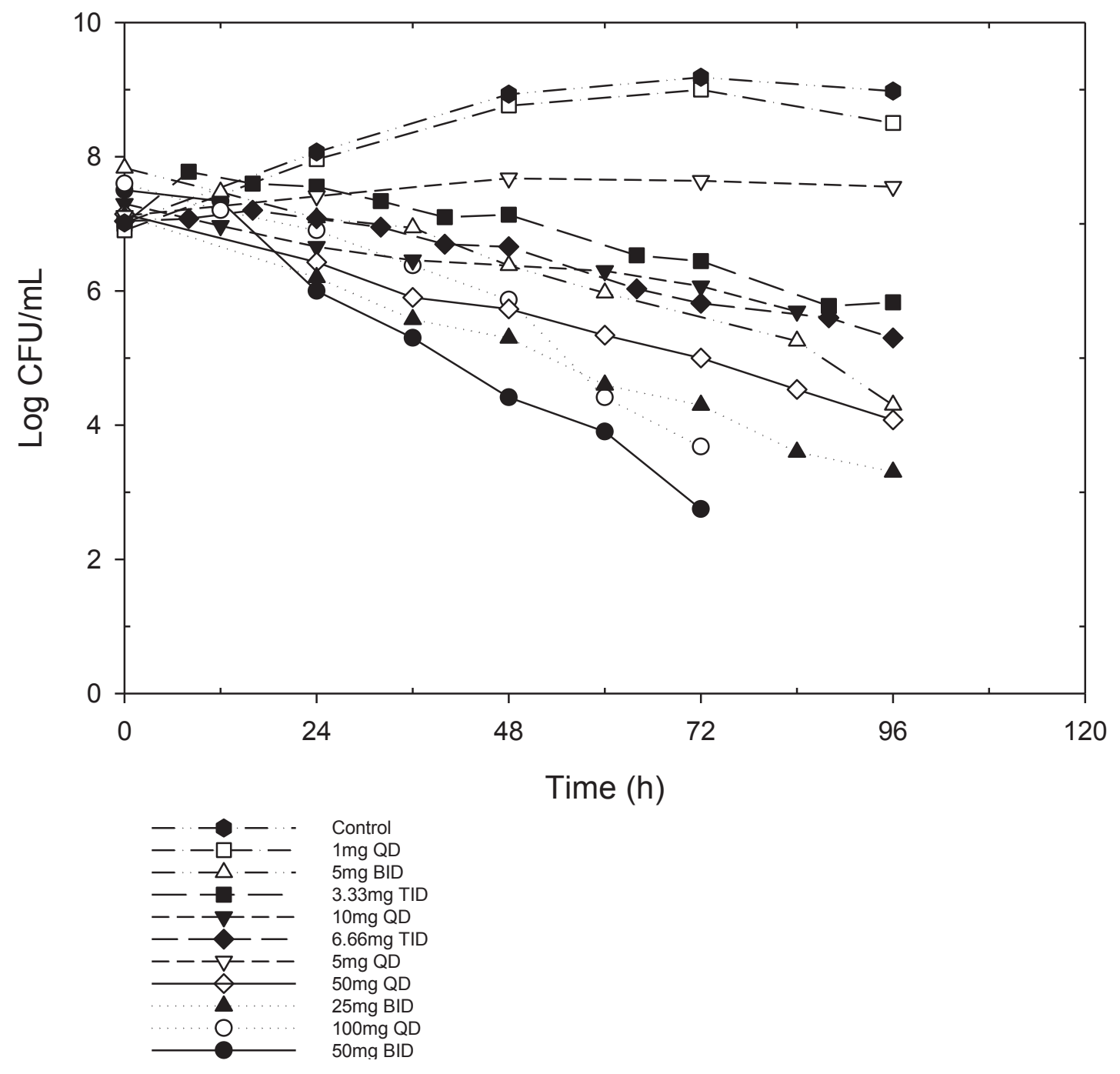

Figure 4-4. Timekill effect of Lee 1599 against $M$. bovis BCG (No: 7-8 log $\mathrm{CFU} / \mathrm{mL}$ ) with observed $\log \mathrm{CFU} / \mathrm{mL}$ plotted against time for different dosing regimens. 
Table 4-1. In vitro PK/PD parameter estimates for Lee 1599.

\begin{tabular}{llll}
\hline \multicolumn{1}{c}{ Parameter } & $\begin{array}{c}\text { Estimate } \\
(\% \text { RSE) }\end{array}$ & $\begin{array}{c}\text { Between } \\
\text { experimental } \\
\text { variability } \\
\text { (\%RSE) }\end{array}$ & $\begin{array}{c}\text { Residual error } \\
\text { (\%RSE) }\end{array}$ \\
\hline$\alpha\left(\mathrm{h}^{-1}\right)$ & $0.0209(49 \%)$ & $0.754(38 \%)$ & $0.00591(32 \%)$ \\
$\mathrm{K}_{0}\left(\mathrm{~h}^{-1}\right)$ & $0.0368(40 \%)$ & $0.124(106 \%)$ & \\
$\mathrm{N}(\mathrm{CFU} / \mathrm{mL})$ & $6.82(2 \%)$ & $0.00304(85 \%)$ & \\
$\mathrm{N}_{\max }(\mathrm{CFU} / \mathrm{mL})$ & $8.27(4 \%)$ & $0.00483(57 \%)$ & \\
$\mathrm{I}_{\max }\left(\mathrm{h}^{-1}\right)$ & $0.0355(27 \%)$ & & \\
$\mathrm{IC}_{50}(\mathrm{mg} / \mathrm{mL})$ & $0.0437(61 \%)$ & & \\
\hline
\end{tabular}

Notes: RSE: Residual Standard Error

$\alpha$ : Delay rate constant

$\mathrm{K}_{\mathrm{o}}$ : Growth rate constant

$\mathrm{N}$ : Initial number of bacteria

$\mathrm{N}_{\max }$ : Maximum number of bacteria

$I_{\max }$ : Maximum bacterial kill rate

$\mathrm{IC}_{50}$ : Concentration required to produce half-maximal effect 

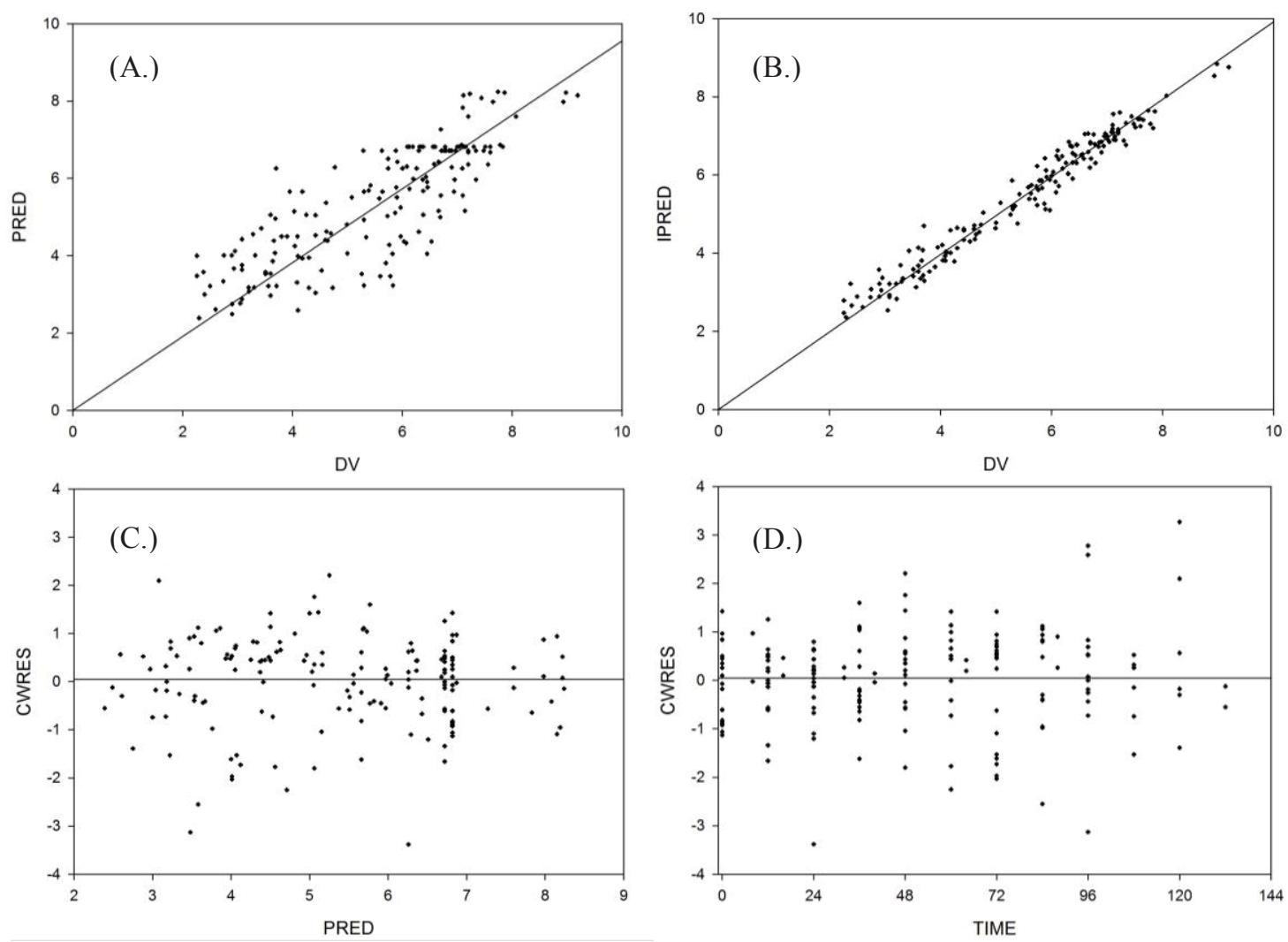

Figure 4-5. Panels showing goodness of fit plots for the Lee 1599 PK/PD model fit (A.) DV vs PRED (B.) DV vs IPRED (C.) PRED vs CWRES (D.) TIME vs CWRES.

Notes: (A.) Observed effect (DV) vs population prediction (PRED)

(B.) Observed effect (DV) vs individual prediction (IPRED)

(C.) Population prediction (PRED) vs conditional weighted residuals (CWRES)

(D.) Time vs conditional weighted residuals (CWRES)

CWRES is a model diagnostic for evaluating model misspecification. It is calculated based on first order conditional estimate (FOCE). 


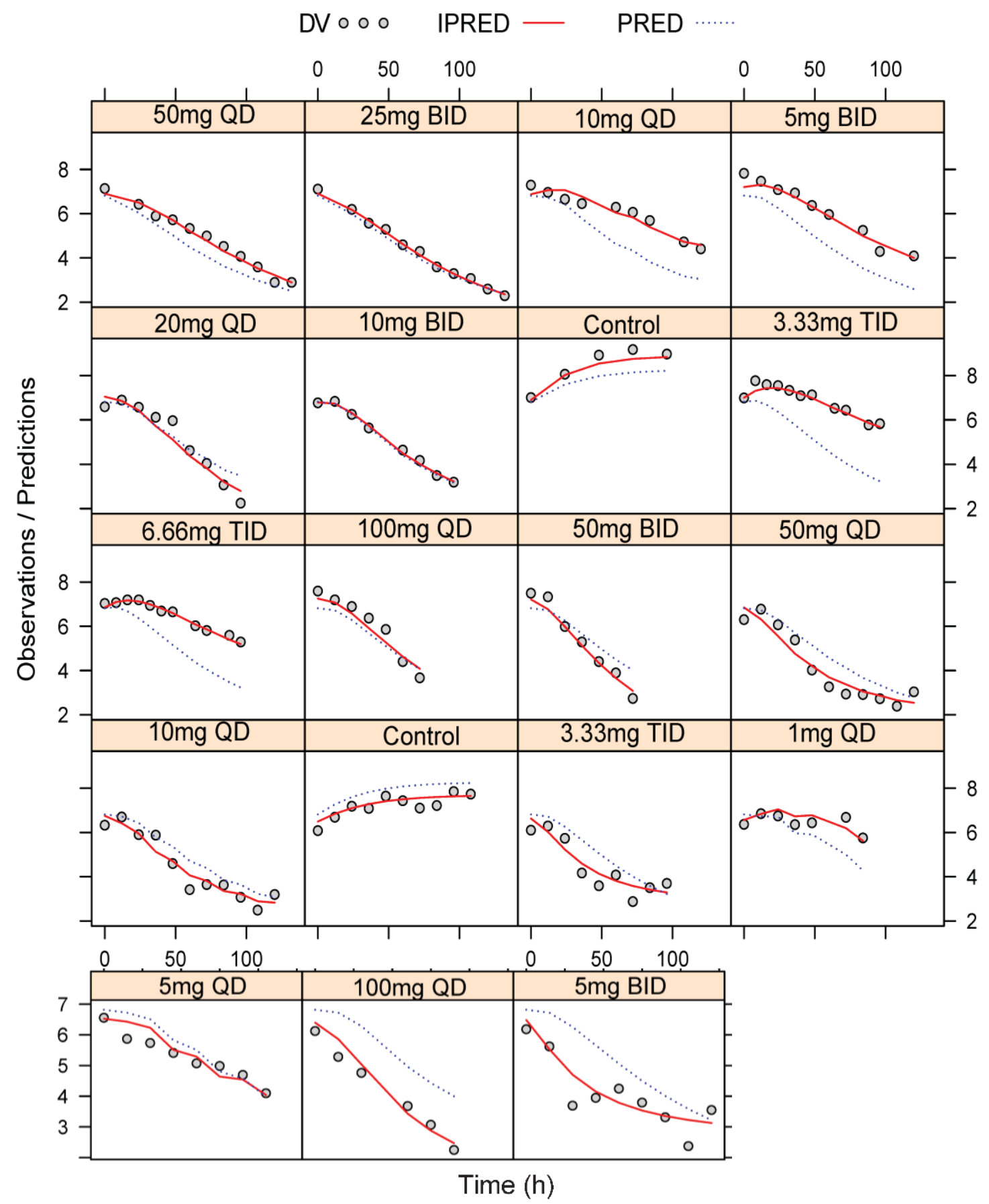

Figure 4-6. $\quad$ Plots showing measured (DV is observed data), individual predictions IPRED (black lines) and population predictions (red lines) for $M$. bovis BCG CFU/mL over time for the Lee $1599 \mathrm{PK} / \mathrm{PD}$ model. 

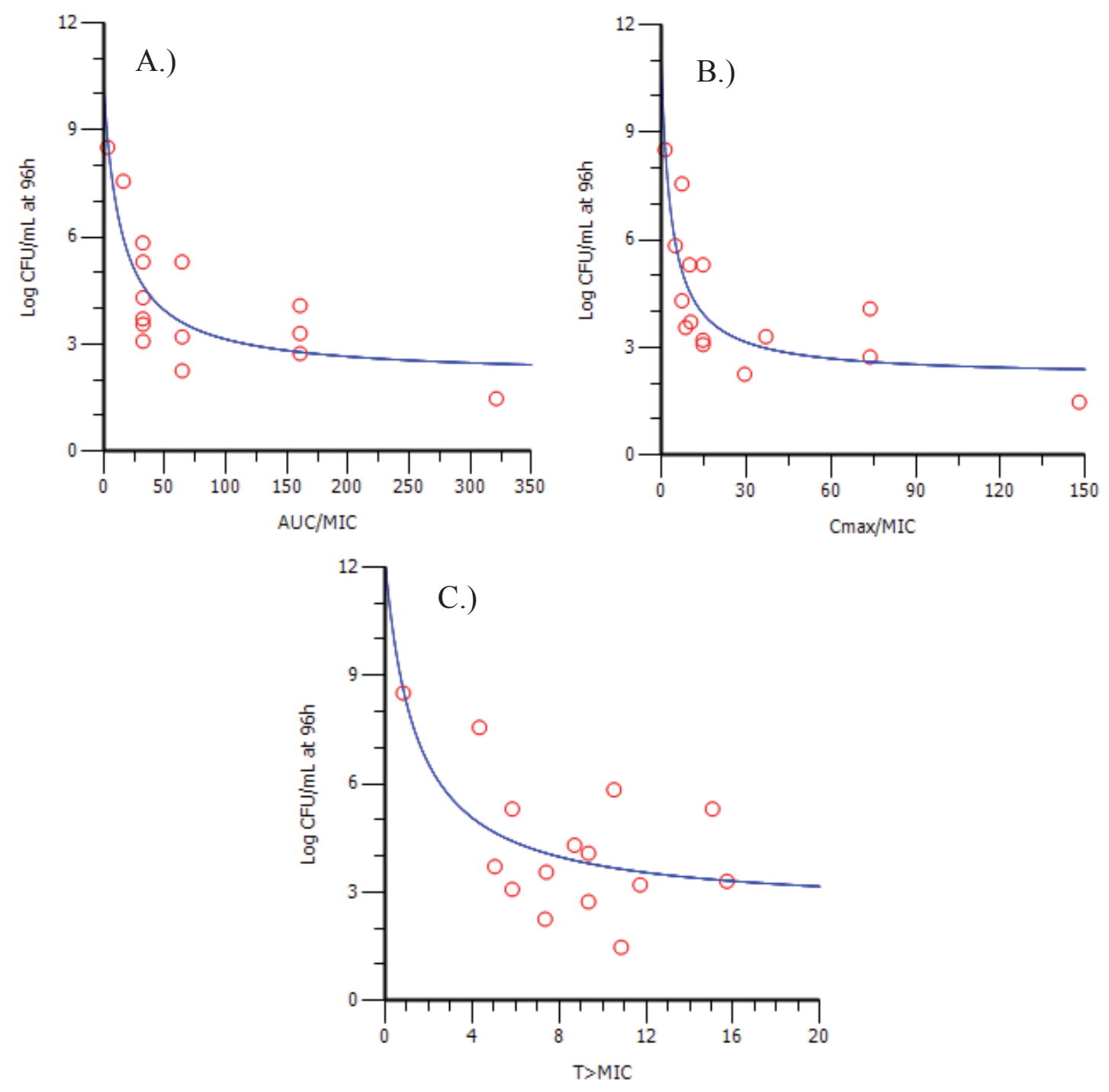

Figure 4-7. Relationship between PK/PD indices and microbial kill on Day 4 after treatment.

Notes: Panels A, B and C shows AUC/MIC, Cmax/MIC and T>MIC, respectively. The red dots are observed data points and blue lines are model predicted lines. 
Table 4-2. Empirical PK/PD indices based on day 4 data.

\begin{tabular}{lccc}
\hline \multicolumn{1}{c}{ Parameter } & AUC/MIC (\%CV) & Cmax/MIC (\%CV) & T>MIC (\%CV) \\
\hline $\mathrm{EC}_{50}$ & $14.7(71.03 \%)$ & $3.63(79.06 \%)$ & $1.42(211.8 \%)$ \\
$\mathrm{E}_{\text {control }}$ & $10.2(20.7 \%)$ & $11.2(28.4 \%)$ & $12.2(65.2 \%)$ \\
Emax & $8.09(24.09 \%)$ & $8.97(32.5 \%)$ & $9.70(68.6 \%)$ \\
AIC & 48.3 & 47.9 & 56.4 \\
$\mathrm{BIC}$ & 50.4 & 50.09 & 58.5 \\
\hline
\end{tabular}

Notes: $\mathrm{EC}_{50}$ : Effective concentration to achieve $50 \%$ of maximal effect

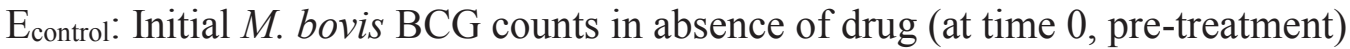

$E_{\max }$ : Maximum effect achieved on Day 3

AIC: Akaike information criterion

BIC: Bayesian information criterion

$\% \mathrm{CV}: \%$ Coefficient of Variation 
suggests that Lee 1599 follow both concentration and time dependent killing as opposed to time dependent killing pattern observed commonly with aminoglycosides. The potential explanation for the difference in PK/PD index of Lee 1599 and other aminoglycosides can be related to the lengthy post-antibiotic effect (PAE) of $133 \mathrm{~h}$ for Lee 1599 at 10X MIC. This can be achieved clinically by administering higher doses more frequently so that higher concentration of drug stays above MIC for longer periods in spite of clinically relevant shorter half-life for Lee 1599.

\section{Numerical simulations}

The pharmacokinetic parameters from a mice bridging study and pharmacodynamic parameters from the in vitro time kill experiments were combined in a PK/PD model as shown in Figure 4-8. Numerical simulations for time-kill curves were performed utilizing parameters from this PK/PD model to predict the effect ascertained by Lee 1599 at various untested dosing regimens in mice. The simulated profiles for QD, BID and TID dosing regimens are shown in Figure 4-9, 4-10 and 4-11 respectively. The simulations also suggest that there is a dose dependent killing indicating an evident dose response relationship. The efficacy was higher with increasing doses for all the three regimes, however, for TID dosing regimen, there was a ceiling effect observed at very high doses of $50 \mathrm{mg}, 100 \mathrm{mg}$ and $200 \mathrm{mg}$ TID. Although the total daily doses were the same, BID and TID dosing showed better efficacy as compared to QD dosing regimens.

\section{Discussion}

The urge to combat tuberculosis is constantly on the rise and numerous research groups have discovered new drugs and tested globally. The preliminary screening of these drugs during the early discovery program are often based on target inhibition studies and MIC testing. The monitoring of the dynamic interplay between the drug and bacteria becomes more relevant as the concentration of drug changes over time in vivo as opposed to the static time kill studies of MIC testing where the concentration of drug remains constant throughout the course of the study. Several research groups have performed static time kill studies using bacteria that have very fast doubling time [110]. Since, $M$. $t b$ have a lengthy doubling time, it might be even more misleading to perform a time kill study under static conditions. Hence, the need for dynamic in vitro PK/PD models are evident. The utility of dynamic models such as the applied in vitro $\mathrm{PK} / \mathrm{PD}$ model is primarily to identify the nature and time course of the anti-bacterial effect obtained from the antibiotic in question and to apply these findings to extrapolate the PD effect to the in vivo situation.

The time kill curves for Lee 1599 showed dose-dependent killing with the tested dosing regimens. The estimates obtained from semi-mechanistic PK/PD model were used for numerical simulations of the kill dynamics of varying dosing regimen in a mouse model of tuberculosis infection under the assumption of an absence of the animal's immune response. For this purpose, PK parameter estimates were used from a mouse 


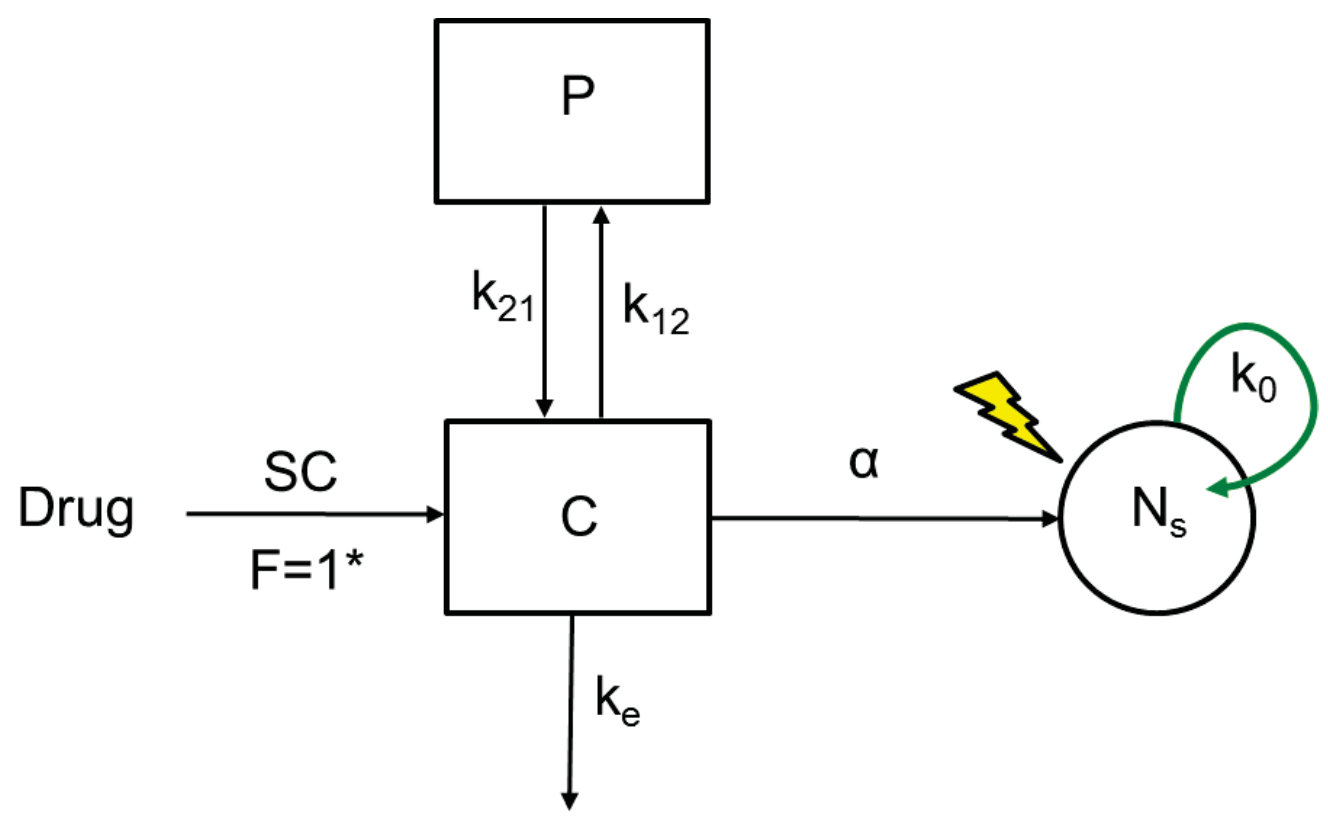

Figure 4-8. Schematic representation of PK/PD model used for simulations.

Notes: * indicates that the bioavailability of 1 was assumed for modeling and simulation purposes. SC is subcutaneous route of administration, $\mathrm{C}$ is the central compartment and $\mathrm{P}$ is the peripheral compartment. The pharmacokinetic parameter estimates were obtained from PK studies performed in mice. 

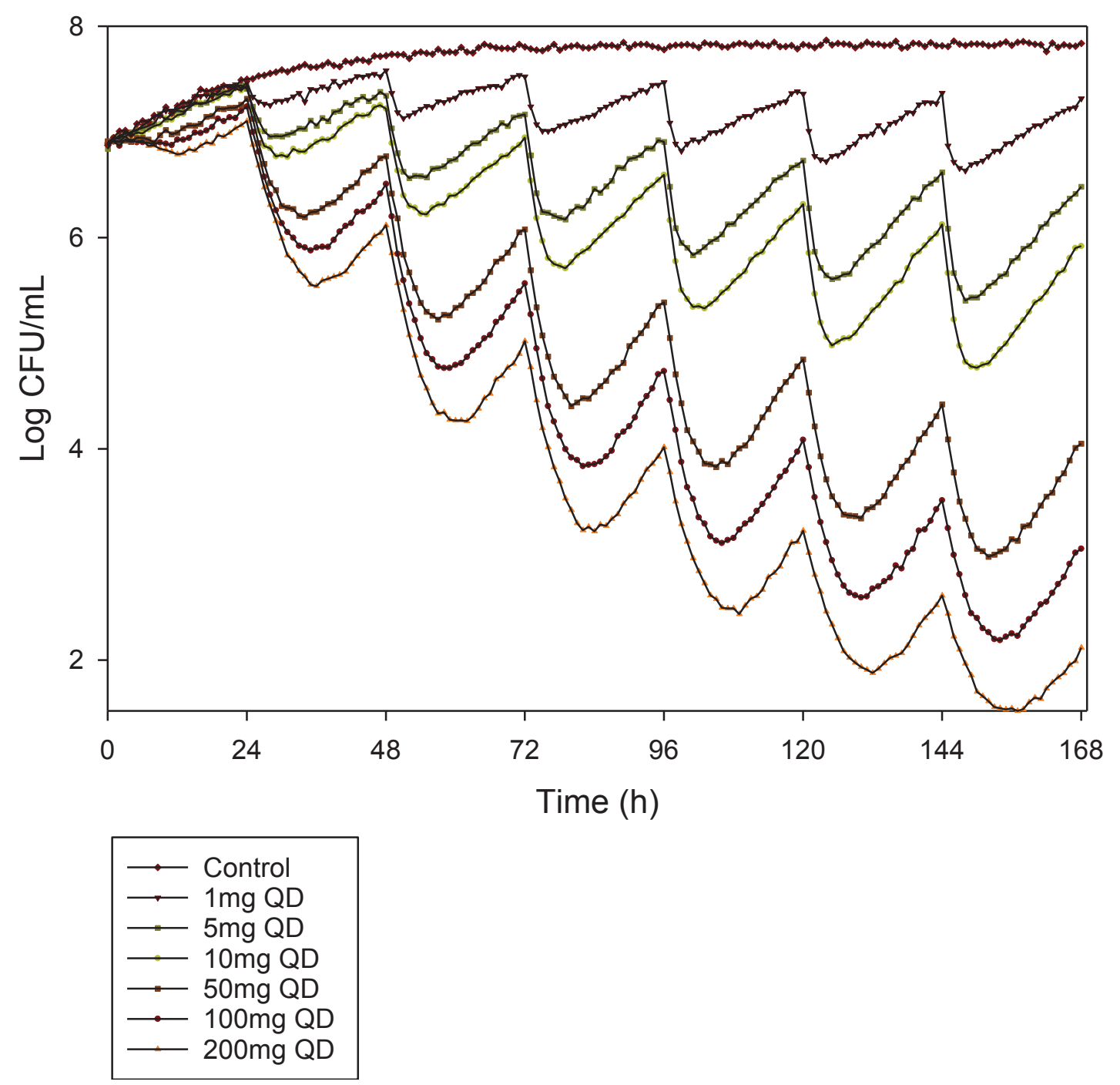

Figure 4-9. Time kill curves calculated from 1000 numerical simulations for once daily dosing regimen of Lee 1599 in mice. 


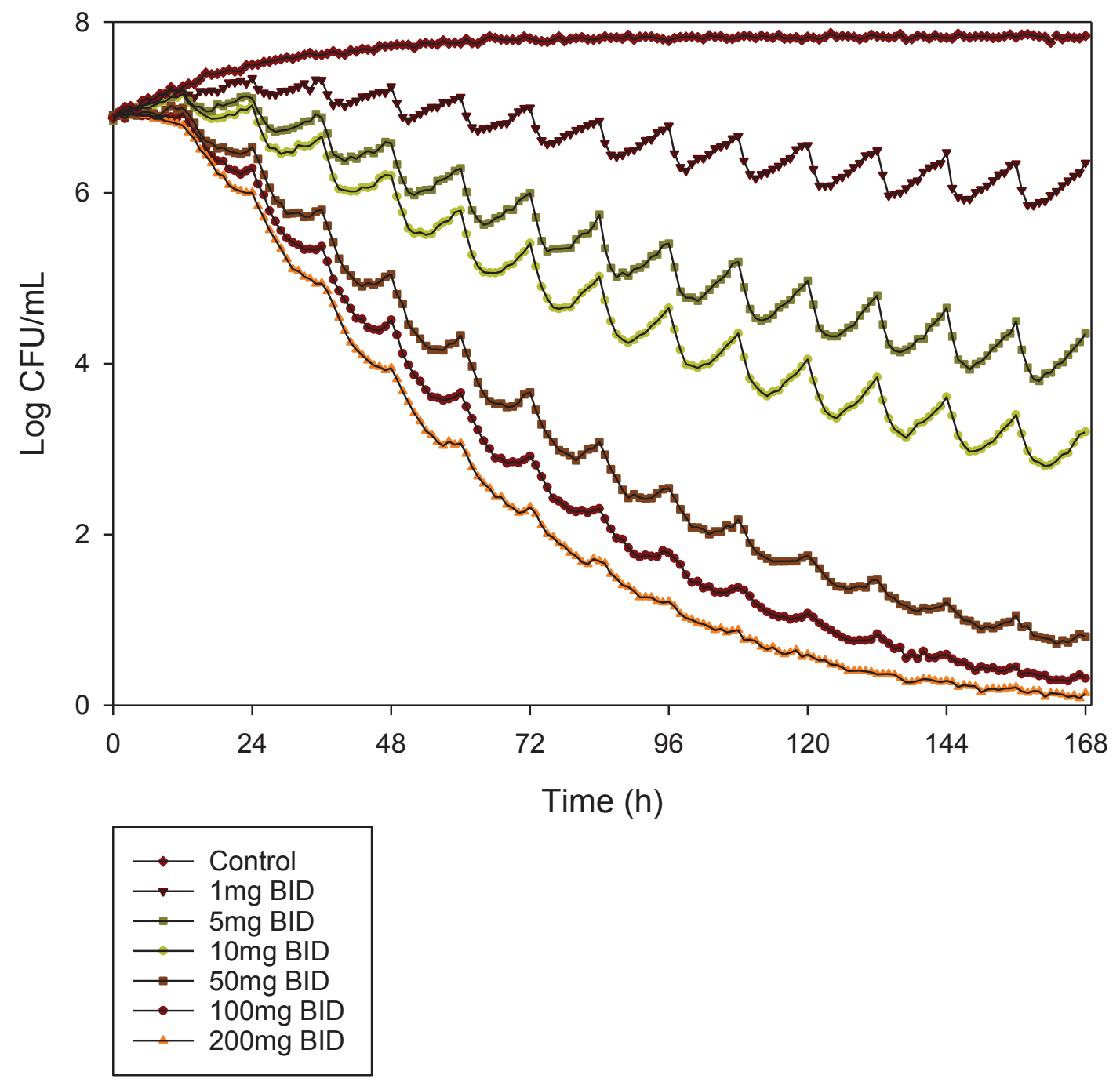

Figure 4-10. Time kill curves calculated from 1000 numerical simulations for twice daily dosing regimen of Lee 1599 in mice. 


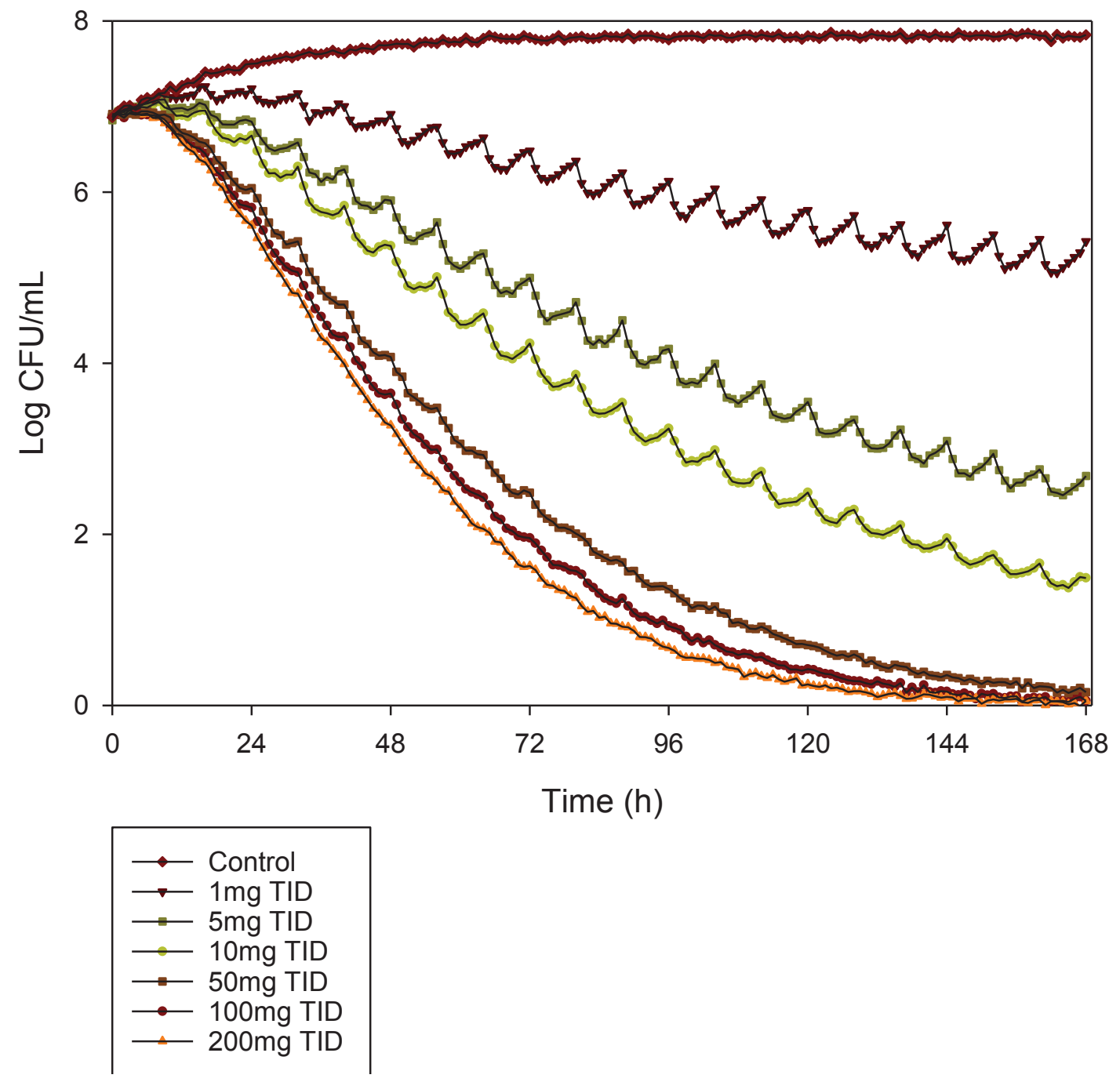

Figure 4-11. Time kill curves calculated from 1000 numerical simulations for thrice daily dosing regimen of Lee 1599 in mice. 
bridging studies previously performed by our group. The simulations using mouse PK parameters suggested that Lee 1599 elicits exposure (concentration and time) dependent killing as opposed to only dose dependent killing. For QD dosing regimens, the simulations indicate regrowth in the bacterial counts once the drug is cleared from the system. This can be possible due to short half-life of the Lee 1599 at clinically relevant concentrations. The regrowth could not be captured in vitro model system because of the limited number of sampling time points. The compound still causes a significant bacterial reduction with QD regimen at higher doses. With BID and TID regimen, a similar effect in efficacy is observed for higher doses 50mg, 100mg and 200mg. At such high doses, there is a dramatic reduction in bacterial counts reaching sterilization. However, prolonged administration at such high doses is not necessary as similar efficacy can be achieved at a dose lower than 50mg BID.

We also performed simulation exercises with the dosing regimens used for the in vivo efficacy trials by our collaborator Dr.Lenaert's and her group at Colorado (5 days a week with 2 consecutive drug holidays) in order to visualize the effect of dosing holidays with regards to efficacy of Lee 1599 in mice. The simulations are shown for QD and BID dosing in Figure 4-12 and 4-13. These simulations are stochastic simulations taking into account the drug holidays and prediction intervals. The simulated effect was the bacterial $\log$ reduction in the central compartment. There is a regrowth of bacteria observed during the holiday period. With QD dosing, only $200 \mathrm{mg} / \mathrm{kg}$ showed a significant effect as compared to other dose groups. There was no efficacy observed at doses up to $40 \mathrm{mg} / \mathrm{kg}$. In BID dose groups, there was a substantial decrease in bacterial counts at doses above $20 \mathrm{mg} / \mathrm{kg}$ BID (i.e. $40 \mathrm{mg} / \mathrm{kg} /$ day). This suggests that higher doses with shorter dosing intervals are desirable for accomplishing an optimal antibacterial effect for Lee 1599. The simulations of the in vivo efficacy trials also helped us in understanding the relevant PK/PD index. It clearly suggests that, both, higher exposure of drug and shorter dosing intervals are required to achieve optimal effect. This finding correlates well with the identified relevant PK/PD index of AUC/MIC.

However, the simulations based on the in vitro PK/PD model may not be extrapolated precisely and quantitatively to predict the in vivo conditions due to several factors. The PK/PD model established from the in vitro $\mathrm{PK} / \mathrm{PD}$ model provides information about direct interaction of drug with bacteria in the absence of the immune system. Also, $100 \%$ of drug is available at the site of action i.e. the bacteria in the central compartment of the in vitro PK/PD model without any barrier for drug distribution such as biomembranes. In contrast, in the in vivo situation, the bacteria reside in the lungs and localized within the alveolar cellular compartment (and spleen) as well as within macrophages and the drug has to permeate into the lung tissues to cause the desired effect. The results might be more accurate if we obtain further information such as biodistribution in lung tissues and subcellular compartment with respect to plasma.

In addition, the drug is administered subcutaneously in the in vivo efficacy trials in mice and the bioavailability of Lee 1599 is unknown for this route of administration in mouse. The model prediction assumes bioavailability of $100 \%$ reaching the lung tissues for numerical simulations, which may not be the case. Also, different bacterial strains 


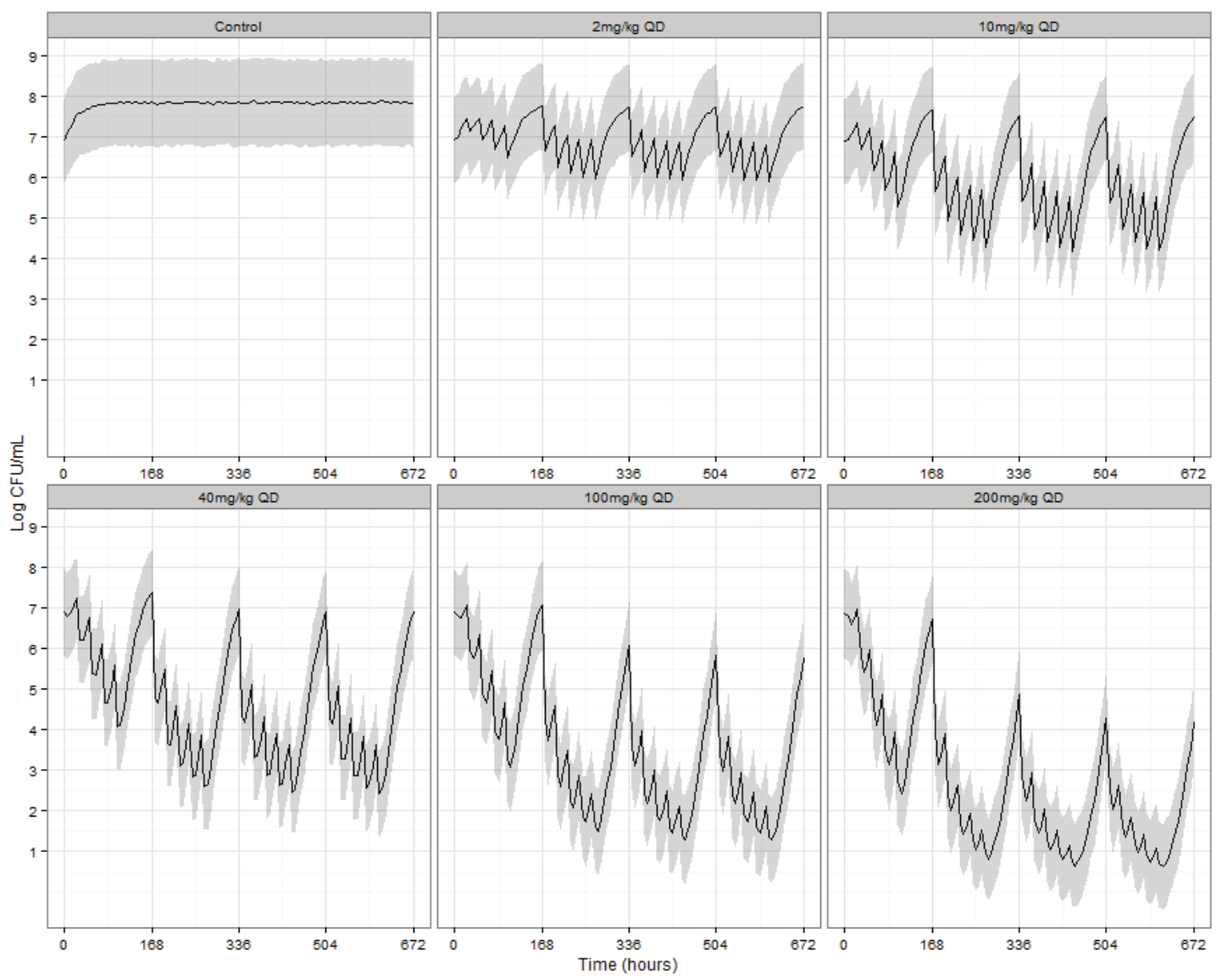

Figure 4-12. Time kill curves calculated from 1000 numerical simulations for once daily (5 days a week) dosing regimen of Lee 1599 in mice.

Notes: The shaded region (grey zone) is the $90 \%$ confidence interval and the dark lines are the mean bacterial counts in $\log \mathrm{CFU} / \mathrm{mL}$. 


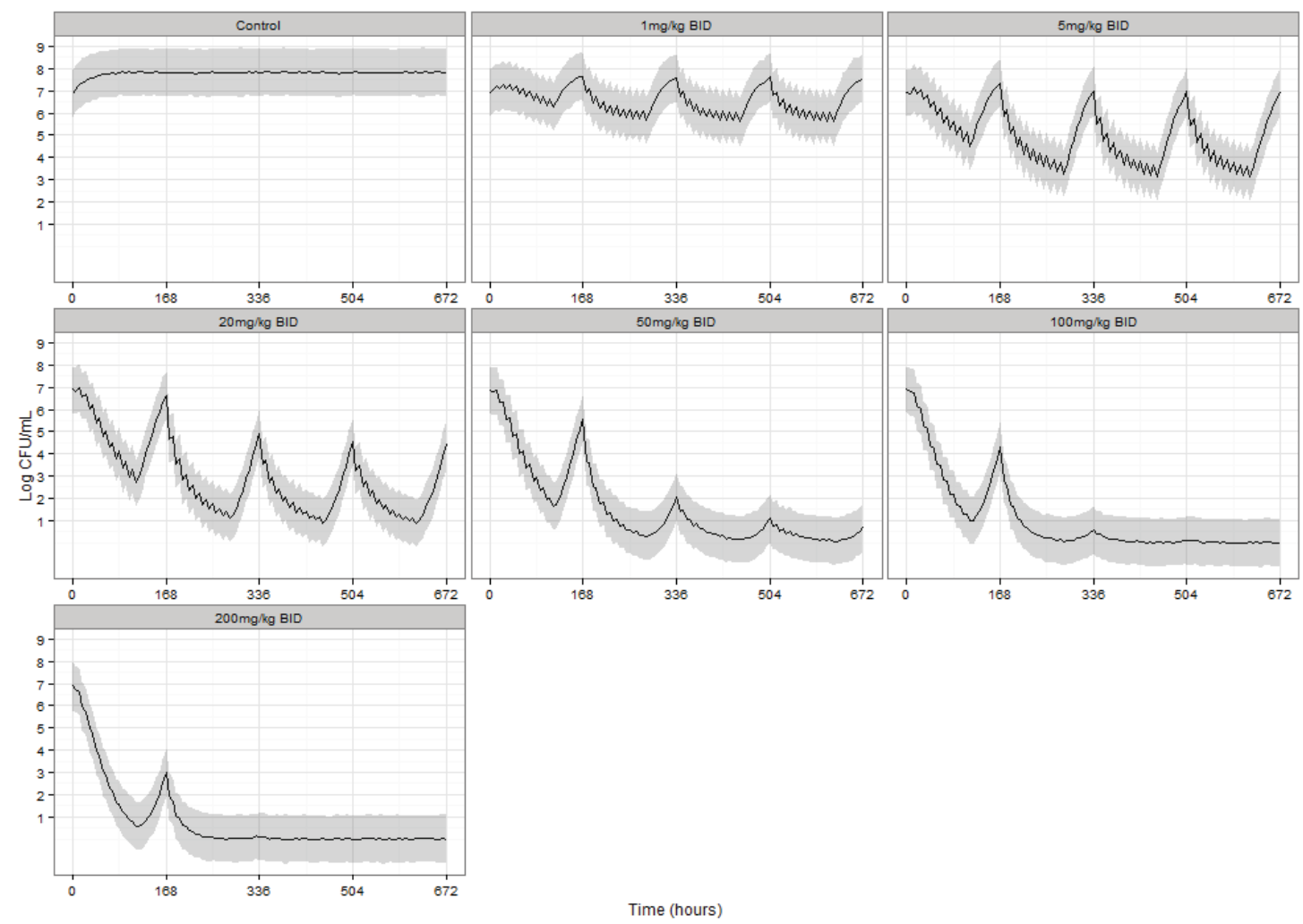

Figure 4-13. Time kill curves calculated from 1000 numerical simulations for twice daily (5 days a week) dosing regimen of Lee 1599 in mice.

Notes: The shaded region (grey zone) is the $90 \%$ confidence interval and the dark lines are the mean bacterial counts in $\log \mathrm{CFU} / \mathrm{mL}$. 
were used for the in vivo studies (M. tb. Erdman) and the in vitro PK/PD model (M. bovis BCG) which may affect the model based predictions of in vivo efficacy trials. The doubling times and the logarithmic growth phase of bacteria can be effected under in vitro and in vivo conditions. Despite these shortcomings, it is beneficial to perform studies using an in vitro PK/PD model and execute pharmacometric analyses to gain knowledge about the dose fractionation studies and identifying PK/PD indices. These in vitro studies helped us in facilitating the decision making process during the transition to in vivo studies. It aided us in selecting an appropriate dosing regimen for in vivo trials in order to characterize an exposure-response relationship.

\section{Conclusions}

We successfully determined the time kill profiles for dosing regimens of Lee 1599 against $M$. bovis BCG. The semi-mechanistic PK/PD model was competent to describe the effect of Lee 1599 on the growth and survival of bacteria. The simulations suggested that higher doses are more effective than very low doses irrespective of the frequency of dosing. The optimal effect in in vivo mouse models can likely be achieved with twicedaily dosing regimens. These findings support the rational of utilizing a PK/PD based in vitro model system to characterize the dose response relationship of spectinamides and obtain an understanding of the best PK/PD index as driver of efficacy and the effect of dose fractionation studies to maximize efficacy for in vivo trials. 


\section{CHAPTER 5. APPLICATION OF PHARMACOMETRIC TOOLS FOR IDENTIFYING PHARMACODYNAMIC INTERACTIONS IN ANTIBIOTIC COMBINATIONS}

\section{Introduction}

The mechanism of action for spectinamides is similar to that of spectinomycininhibiting protein synthesis by selectively binding to the head domain of the $30 \mathrm{~S}$ ribosomal subunit and blocking its translocation [77]. Although there can be multiple redundancies or alternate pathways in response to such inhibition by a single antibiotic, most often this results in drug resistance or clinical relapse. For these reasons, combination therapies are needed for more durable and effective treatment [111] Combination therapy of new and existing anti-TB agents are constantly being evaluated to determine the pharmacodynamic interaction between two agents. The selection of combination compounds will aid in treating patients with MDR-TB and also shorten the duration of treatment [112].

The primary objective of this research study was to find a combination partner agent for lead spectinamide molecule Lee 1599. We selected rifampicin (RIF) as a model compound for combination agent as rifampicin has been in use for TB therapy for several decades. The elementary justification for combination therapy is expecting an enhanced pharmacodynamic effect with two or more agents. The net effect of any pharmacodynamic interaction can be synergistic, antagonistic or additive. The screening for an efficacious partner agent for a new molecule is a critical step in the early discovery phase before performing any extensive in vivo trials.

To determine the interaction between the two agents, we applied the widely accepted checkerboard assay method as a primary screening tool. The checkerboard assay can be used for qualitative interpretation only as it does not provide any information on the degree of interaction between Lee 1599 and RIF. An alternative approach is to quantitatively assess the interaction by utilizing a parametric method known as three dimensional surface response assay. The basis for both these methodologies is set on different principles [113-115]. Thus, the expected outcome for an interaction between two drugs may or may not be similar from these methodologies. It is essential to identify an appropriate screening tool for selection of candidate compounds as it helps in accelerating the preclinical drug development process.

Herein, we illustrate the differences in outcomes of the checkerboard assay and the response surface assay, which is instrumental in screening the potential combination compounds that are urgently required to curb evolving resistant strains. The results of the surface response assay were validated using an in vitro PK/PD model for combination therapy by generating dynamic time kill curves at different dose levels and dosing regimens. Further, we compared these results of the pharmacodynamic interaction between Lee 1599 and RIF with in vivo studies in a mouse model of infection to further validate our outcomes. 


\section{Materials and Methods}

\section{Antimicrobial agents}

The spectinamide Lee 1599 (3'-Dihydro-3'-deoxy-3'(R)- (5-chloropyridin-2-yl) acetylamino spectinomycin Trihydrobromide) was synthesized in the laboratory of Dr. Richard.E. Lee at St.Jude Children's Research hospital. Rifampicin (RIF) was purchased from Sigma (St. Louis, MO). A stock solution of each agent was prepared and stored at $4^{\circ} \mathrm{C}$. Prior to each susceptibility testing, an aliquot of each agent was diluted to the desired concentration with $7 \mathrm{H} 9$ media.

\section{Microorganisms}

M. bovis BCG was grown in Middlebrook $7 \mathrm{H} 9$ broth (Becton Dickinson, Sparks, MD). The cultures were stored at $-80^{\circ} \mathrm{C}$ in Middlebrook $7 \mathrm{H} 9$ broth. For each experiment, cultures were thawed and incubated at $37^{\circ} \mathrm{C}$ in Middlebrook $7 \mathrm{H} 9$ broth until the bacteria reaches logarithmic phase $\left(\mathrm{OD}_{600}\right.$ 0.4-0.7). M. $t b$ Erdman (TMC 107, ATCC 35801) was used as testing organism for animal studies.

\section{Checkerboard assay}

The pharmacodynamic interaction between Lee 1599 and RIF against $M$. bovis BCG was evaluated using the checkerboard assay. The assay was carried out in 96-well plate format with varying concentrations of Lee 1599 and RIF serially diluted in 7H9 media across rows and columns, respectively. The concentrations for Lee 1599 and RIF ranged from 0.003 to $6.4 \mu \mathrm{g} / \mathrm{mL}$ and 0.00049 to $2 \mu \mathrm{g} / \mathrm{mL}$, respectively, with a final volume of $100 \mu \mathrm{L}$ in each well. Additionally, $100 \mu \mathrm{L}$ of $M$. bovis $\mathrm{BCG}$ culture with $\mathrm{OD}_{600}$ of 0.01 was also added to each well. The plate was incubated for 7 days at $37^{\circ} \mathrm{C}$ and the endpoint assessment was based on visual growth inspection. The fractional inhibitory concentration index (FICI) calculated for each concentration in each combination is represented by the following equations:

$$
\begin{gathered}
\mathrm{FICI}=\mathrm{FIC}_{\text {Lee } 1599}+\mathrm{FIC}_{\mathrm{Rif}} \\
F I C_{\text {Lee } 1599}=\frac{M I C_{\text {Lee } 1599} \text { in combination }}{M I C_{\text {Lee } 1599} \text { alone }} \\
F I C_{\text {Rif }}=\frac{M I C_{\text {Rif }} \text { in combination }}{M I C_{\text {Rif }} \text { alone }}
\end{gathered}
$$

FICI represents the extent of interaction between two drugs in question and the interaction can be defined as synergistic $(\mathrm{FICI}<0.5)$, antagonistic $(\mathrm{FICI}>4.0)$ or additive $(0.5<$ FICI $<4.0)$. 


\section{Response surface assay}

Static time-kill studies were performed in a $5 \times 5$ array with different concentration combinations for Lee 1599 and RIF. Five concentrations of each agent, 0 (Control), 0.05, $0.5,1$ and $2 \mathrm{X}$ MIC, were used. $M$. bovis $\mathrm{BCG}$ was grown to the logarithmic phase $\left(\mathrm{OD}_{600}\right.$ 0.4-0.7) in Middlebrook 7H9 medium. The logarithmically growing culture was then used to initiate the time kill studies (starting $\mathrm{OD}_{600} 0.15$ ). The final concentration of bacterial culture in each tube was approximately $10^{8} \mathrm{CFU} / \mathrm{mL}$. The culture was treated with different antibiotic concentrations for $24 \mathrm{~h}$ at $37^{\circ} \mathrm{C}$ on a shaker $(200 \mathrm{rpm})$. Bacterial samples were collected from each tube after $24 \mathrm{~h}$ for quantification. Prior to quantification, the samples were centrifuged at $37^{\circ} \mathrm{C}$ at $10,000 \mathrm{rpm}$ for $10 \mathrm{~min}$ and the supernatant was discarded. This step is required to ensure that there is no antibiotic carry over effect. The bacterial pellet was diluted with the same amount of fresh 7H9 media and serially diluted with 7H9 media. The dilutions were plated on 7H11 agar plates for 21 days at $37^{\circ} \mathrm{C}$ and the colonies were counted manually on each plate post-incubation. The anti-bacterial effect was determined as the decrease in number of viable bacteria in terms of $\mathrm{CFU} / \mathrm{mL}$.

The antibacterial effect after 24h of treatment with drugs was described using an inhibitory Emax model. The parameter estimates describing the killing effect were estimated by nonlinear regression analysis using Phoenix WinNonlin 6.3 (Certara, NJ). The total bacterial density for the treatment groups was then modeled with the obtained parameters using three dimensional surfaces. Null interaction (or additivity) was used to model the effect summation for combination treatment as follows:

$$
\begin{gathered}
\text { Effect }_{\text {total }}=\text { Effect }_{\text {Lee } 1599}+\text { Effect }_{\text {Rif }} \\
\text { Predicted } \log \mathrm{CFU} / \mathrm{mL}=E_{0}-\left(\frac{E_{\text {max,Lee } 1599} * C_{\text {Lee } 1599}}{E C_{50, \text { Lee } 1599}+C_{\text {Lee } 1599}}\right)-\left(\frac{E_{\text {max,Rif }} * C_{\text {Rif }}}{E C_{50, \text { Rif }}+C_{\text {Rif }}}\right)
\end{gathered}
$$

where $\mathrm{E}_{0}$ is the growth at $24 \mathrm{~h}$ in the absence of antibiotics, $\mathrm{E}_{\max , \text { Lee } 1599} / \mathrm{E}_{\max , \text { Rif }}$ is the

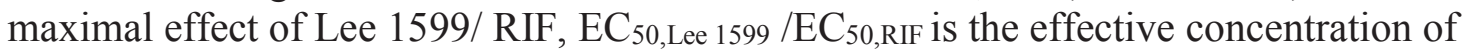

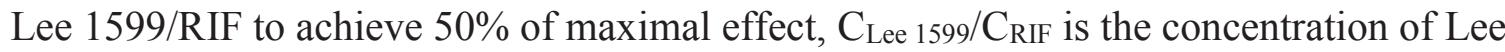
1599/RIF.

Volume under the plane (VUP) for both observed and predicted effect was calculated using MATLAB 8.2. The interaction index (II) is the ratio of VUPobserved/VUPpredicted and it defines the pharmacodynamic interaction between two agents as synergism $(\mathrm{II}<1)$ and antagonism (II $>1)$. An II around 1 suggests no interaction, i.e. an additive effect. 


\section{In vitro $\mathrm{PK} / \mathrm{PD}$ model}

The dynamic time kill curves for different doses of Lee 1599 and RIF were established using a modified version of our in vitro PK/PD model. As described previously, [39] the in vitro PK/PD model system consists of a two-armed, water jacketed flask (1965 series spinner flask, Bellco Glass, Vineland, NJ) as depicted in Figure 4-1. A filter unit attached to a hollow steel tube was introduced into the system. The filter unit contained a prefilter $(5 \mu \mathrm{m}$, Millipore, Billerica, MA) and filter membrane $(0.22 \mu \mathrm{m}$, Millipore, Billerica, MA) to prevent leakage of bacteria during the dilution process. The other end of the tube was connected to plastic tubing (PharMed tubing, Cole-Parmer, Vernon Hills, IL) from which the media was withdrawn continuously at a defined flow rate using a peristaltic pump (Masterflex L/S, Cole-Parmer, Vernon Hills, IL). The flask was placed on a magnetic stirrer for homogeneity of the culture and preventing membrane blockage. The temperature of the system was set at $37^{\circ} \mathrm{C}$ with the help of a thermostatic water bath attached to the water-jacketed flask. One arm of the flask was connected by plastic tubing to the fresh sterile media reservoir and the other arm was used for dosing and repeated sampling.

For simultaneously generating the concentration-time profiles for two antibiotics, additional components were added to the model utilized for a single drug treatment. The additional component is a supplementing compartment that contains the second administered drug. As shown in Figure 5-1, one of the sidearm of the flask is connected to the reservoir containing sterile medium and the supplementing compartment. The drug having the higher clearance was administered as bolus dose from the side arm. The flow rates $(\mathrm{F})$ of the inlet and outlet in the central compartment and supplementing compartment were computed based on equations described by Jürg Blaser [116]. The individual values of each flow rate in and out of supplementing and central compartment are shown in Figure 5-1. A supplementing reservoir contains media with the drug with the slower clearance. The change in concentration per unit time will be same in both the compartments. Thus, the volume of supplementing compartment and flow rate is calculated as:

$$
\begin{gathered}
V_{s}=\left(\frac{C L_{A}-C L_{B}}{C L_{B}}\right) * V_{C} \\
F=\frac{V * 0.693}{t_{1 / 2}}
\end{gathered}
$$

Where, Vs is volume of media in the supplementing compartment; $\mathrm{CL}_{\mathrm{A}}$ and $\mathrm{CL}_{\mathrm{B}}$ are the clearance of Drug A and B; Vc is volume of media in the supplementing compartment $(55 \mathrm{~mL}) ; \mathrm{F}$ is the flow rate of media and $\mathrm{t}_{1 / 2}$ of drug was obtained from in vivo studies in rats. The $\mathrm{t}_{1 / 2}$ of Lee 1599 was experimentally determined and RIF was obtained from literature [117].

The combination tested in this experiment was Lee 1599 and rifampicin. Lee 1599 (Drug A) has a higher clearance than rifampicin (Drug B). The in vitro set up is 

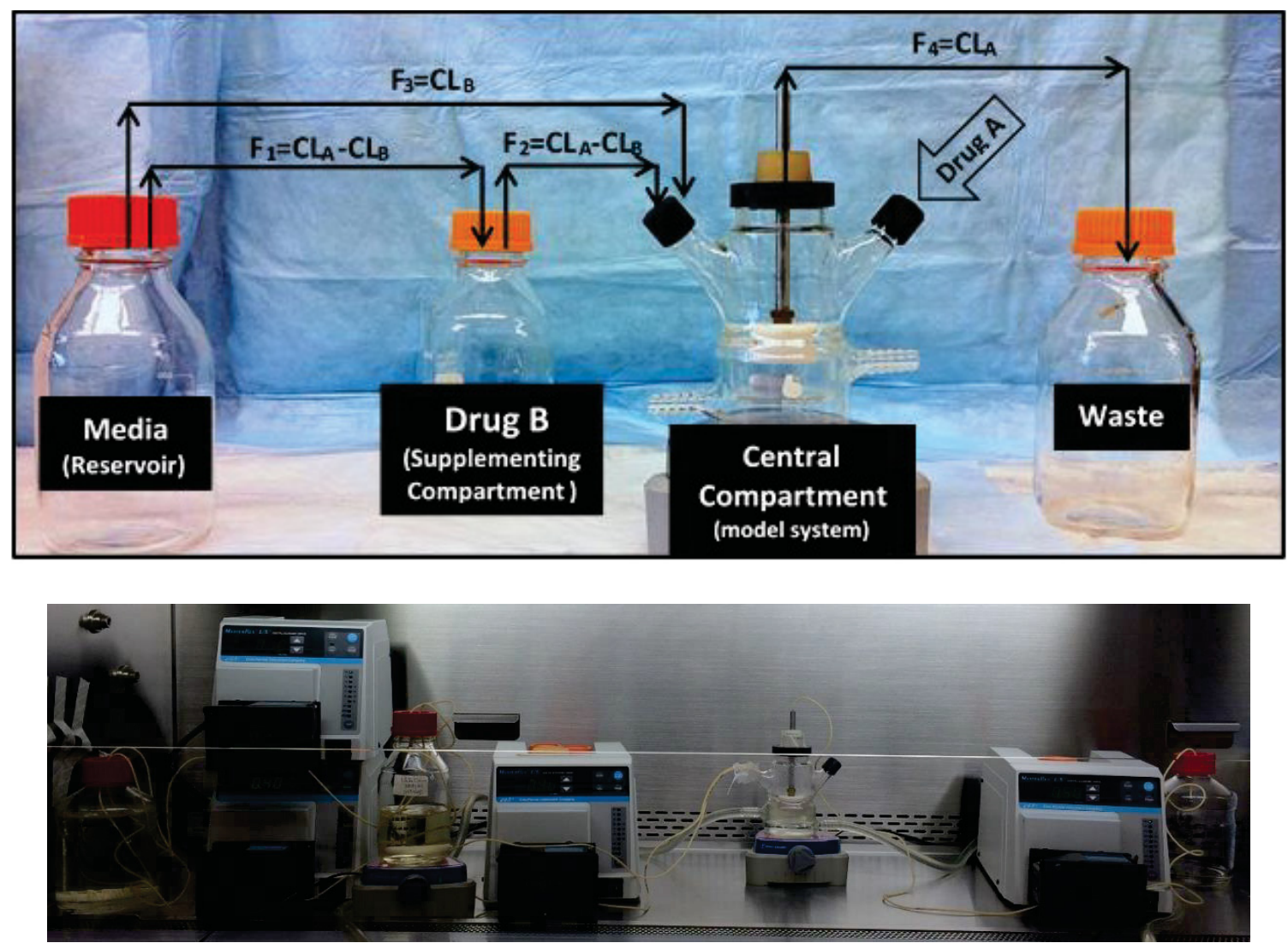

Figure 5-1. A representation of in vitro PK/PD model set up for dynamic time-kill studies.

Notes: Drug A is Lee 1599 and Drug B is RIF. 
assembled in a biosafety cabinet in a sterile environment. The flask and the tubes are cleaned and sterilized by autoclaving before starting every experiment.

\section{Time kill curves for Lee 1599}

M. bovis BCG was used as a test organism for evaluating the effect of drug in vitro model. The organism was grown to early logarithmic phase (O.D.600 0.4-0.7) in Middlebrook 7H9 medium. This actively growing bacteria was used as an inoculum for the in vitro model making the final density of the culture as $10^{6} \mathrm{CFU} / \mathrm{mL}$.

Samples of $200 \mu \mathrm{L}$ were collected every $12 \mathrm{~h}$ from the central compartment flask with volume replacement containing fresh media. The samples were centrifuged at $10,000 \mathrm{rpm}$ for $10 \mathrm{~min}$ at $37^{\circ} \mathrm{C}$. The formed pellets were collected and re-suspended in antibiotic-free media. This step was to ensure that there is no drug carry-over effect. The samples were serially diluted and the dilutions were plated on 7H11 agar plates in duplicate. To check if there are any resistant colonies forming bacteria, the samples were also plated on agar plates with $1 \mathrm{X}, 2 \mathrm{X}$ and $4 \mathrm{X}$ MIC of each drug. The agar plates were incubated for 21 days at $37^{\circ} \mathrm{C}$. The efficacy of Lee 1599 was characterized by measuring the reduction in number of viable bacteria, in terms of CFU/mL. There was a control arm included in the study to determine the bacterial growth in absence of drug.

\section{In vivo efficacy studies}

The results of the checkerboard assay, the response surface assay and the in vitro PKPD model were compared to results of in vivo efficacy studies for Lee 1599 and RIF. The methodology for the animal studies and the endpoint analysis are described as Model 2 and 3 in a previous study [81]. The formulation for Lee 1599 was freshly prepared using 5 parts of USP Multiple Electrolytes Solution (PlasmaLyte, Baxter Healthcare Corp., Deefield, IL) and 1 part sterile deionized water. RIF was ground to a fine powder using mortar and pestle, and sterile deionized water was added incrementally to the total volume. The formulation was stored at $4^{\circ} \mathrm{C}$ until required. Lee 1599 was administered subcutaneously at $200 \mathrm{mg} / \mathrm{kg}$ QD and RIF was administered orally at $10 \mathrm{mg} / \mathrm{kg}$ QD. For the combination studies, both drugs were administered simultaneously at the same doses and route of administration as given in monotherapy.

\section{Results}

\section{Checkerboard assay}

The drug aliquots were stable at the beginning of experiments and this was confirmed using LC-MS analysis. In the checkerboard assay, the positive control wells that did not contain any drug showed bacterial growth at the end of the incubation period 
as expected. The MIC of Lee 1599 was found to be $0.8 \mu \mathrm{g} / \mathrm{mL}$, which is consistent with the MIC determination that had been performed during the initial screening of the spectinamide series. The MIC of Lee 1599 was found to be similar for M. bovis BCG and M. $t b$. The FICI score for Lee 1599 was 0.375 as shown in Table 5-1. The MIC of both, RIF and Lee 1599 was significantly reduced in the presence of each other. As the FICI score for this tested combinations is below 0.5 it suggests that RIF has a synergistic interaction with Lee 1599.

\section{Response surface assay}

Lee 1599 and RIF exhibited similar concentration-killing profiles in pilot studies as shown in Figure 5-2. The optimal concentration was found to be approximately $6.4 \mu \mathrm{g} / \mathrm{mL}$ for 1599 and $1.6 \mu \mathrm{g} / \mathrm{mL}$ for RIF. There was no ceiling effect observed for both of the drugs. A reasonable model fit was obtained for Lee $1599\left(\mathrm{r}^{2}=0.992\right)$ and RIF $\left(r^{2}=0.996\right)$ for the applied inhibitory sigmoid Emax-model based on model diagnostics. The concentrations for capturing the most precise parameter estimates describing the killing effect for Lee 1599 were found at $0.04,0.4,0.8,1.6,3.2$ and $6.4 \mu \mathrm{g} / \mathrm{mL}$, whereas the concentrations to obtain parameter estimates for RIF were $0.02,0.2,0.4,0.8$ and $1.6 \mu \mathrm{g} / \mathrm{mL}$.

To analyze the pharmacodynamics interaction between Lee 1599 and RIF, we plotted the combined effect of both the agents using a three-dimensional response surface approach (Figure 5-3). A three dimensional plot of bacterial count vs. concentration was plotted with Lee 1599 concentration on the x-axis, RIF concentration on the y-axis and bacterial count in Log CFU on the z-axis. The "null interaction" surface was constructed in a separate plot using a set of points representing model predicted additive effect of combinations of Lee 1599 and RIF and is shown in Figure 5-4. In all different sets of concentrations of the compounds in combination, an increased killing effect was seen as compared to either drug alone at the same concentration. The killing effect by one agent was supplemented by the presence of the other agent. The volumes under the plane (VUP) for the observed effect and model predicted effect as shown in Table 5-2 are 274.84 and $271.86 \log \mathrm{CFU} \mu \mathrm{g}^{2} / \mathrm{mL}^{3}$. The interaction index calculated based on the obtained VUPs was found to be 1.01 indicating an additive effect exerted by the combination of Lee 1599 and RIF.

\section{In vitro $\mathrm{PK} / \mathrm{PD}$ model for combination agents}

For the in vitro $\mathrm{PK} / \mathrm{PD}$ model, three different dosing regimens for Lee 1599 and two for RIF were selected to be investigated in combination experiments: $100 \mathrm{mg} / \mathrm{kg} \mathrm{QD}$, $10 \mathrm{mg} / \mathrm{kg}$ QD and $1 \mathrm{mg} / \mathrm{kg}$ QD for Lee 1599 and $10 \mathrm{mg} / \mathrm{kg}$ QD and $0.5 \mathrm{mg} / \mathrm{kg}$ QD for RIF. As shown in Figure 5-5, there was a marginal increase in the average bacterial killing when both the agents were used in combination as compared to when administered individually. The bacterial counts were below limit of quantification for the timepoints without any data points beyond $48 \mathrm{~h}$ or $72 \mathrm{~h}$ in the time-kill curves. The bacterial counts at 
Table 5-1. Checkerboard assay results to determine pharmacodynamic interaction between Lee 1599 and RIF.

\begin{tabular}{|c|c|c|c|c|c|}
\hline Agent & $\begin{array}{c}\text { MIC of } \\
\text { agent alone } \\
(\mu \mathrm{g} / \mathrm{mL})\end{array}$ & $\begin{array}{c}\text { MIC in } \\
\text { presence of } \\
\text { Lee } 1599 \\
(\mu \mathrm{g} / \mathrm{mL})\end{array}$ & $\begin{array}{c}\text { MIC of Lee } \\
1599 \text { in } \\
\text { presence of } \\
\text { agent }(\mu \mathrm{g} / \mathrm{mL})\end{array}$ & $\begin{array}{l}\text { FICI } \\
\text { score }\end{array}$ & Indication \\
\hline Rifampicin & 0.002 & 0.0005 & 0.1 & 0.375 & Synergy \\
\hline
\end{tabular}

Note: The MIC of Lee 1599 alone is $0.8 \mu \mathrm{g} / \mathrm{mL}$. 
(A)

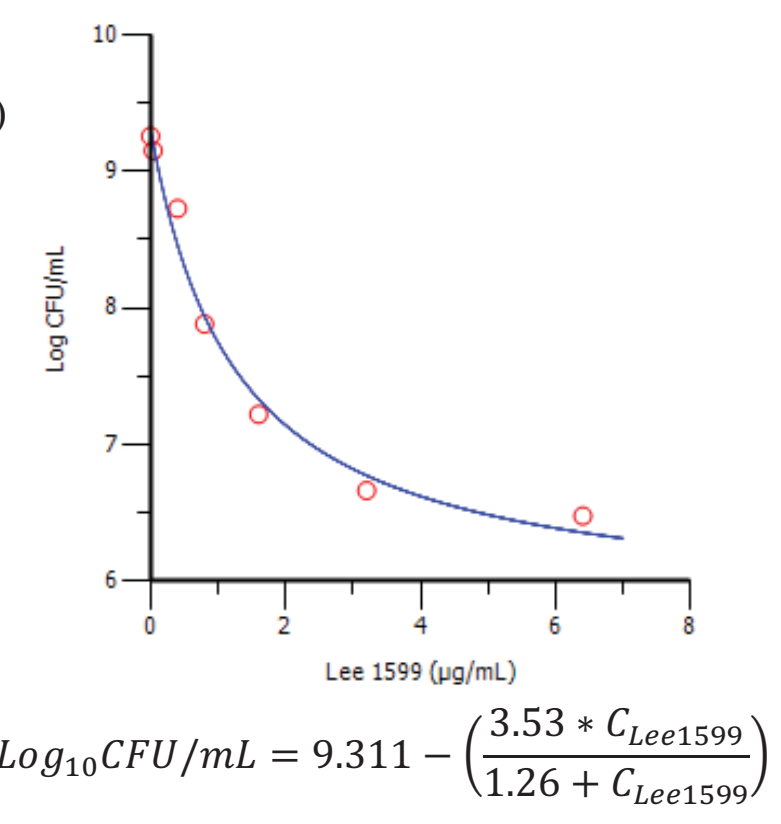

(B)

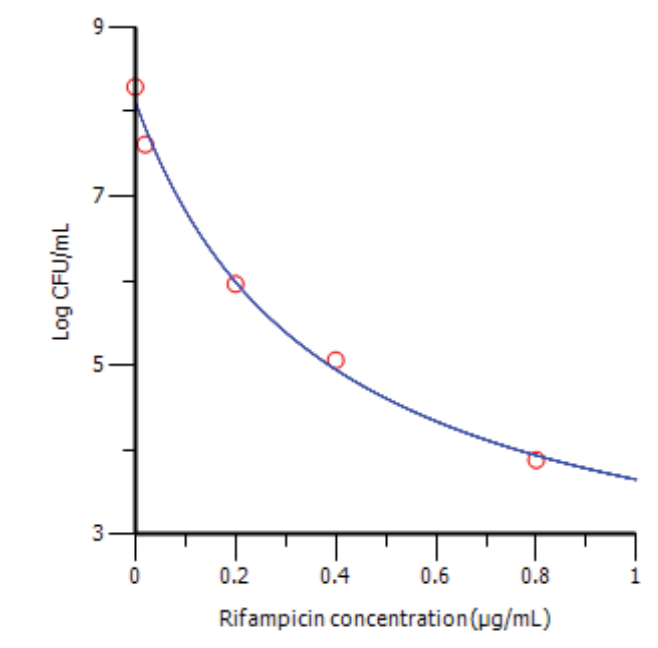

$$
\log _{10} C F U / m L=8.11-\left(\frac{6.15 * C_{R I F}}{0.377+C_{R I F}}\right)
$$

Figure 5-2. Model fits of bacterial burden at 24h in static time kill studies for Lee 1599 (A) and RIF (B) to obtain the parameter estimates such as E0, Emax and EC50. 


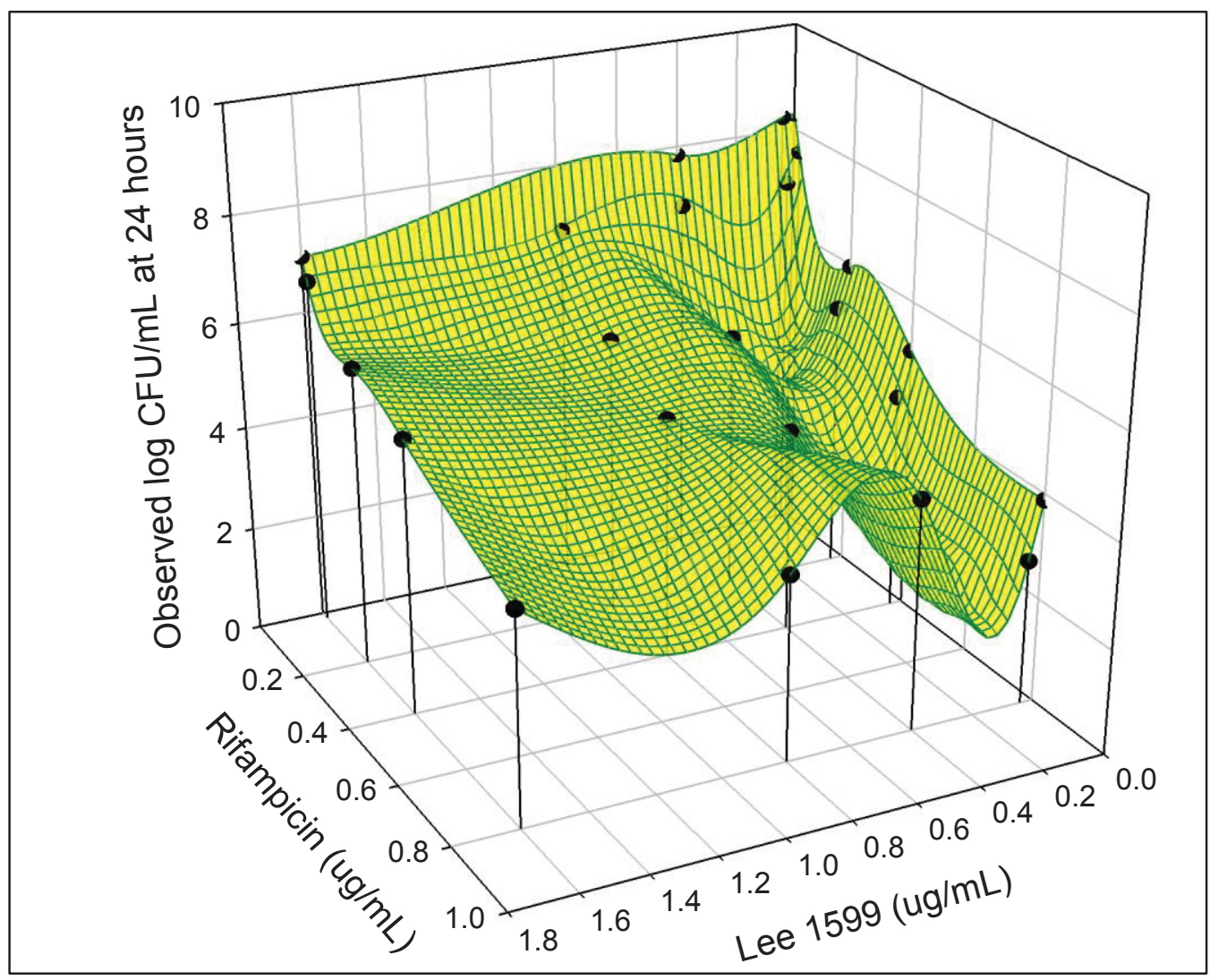

Figure 5-3. Observed effect of combination agent Lee 1599 and RIF. 


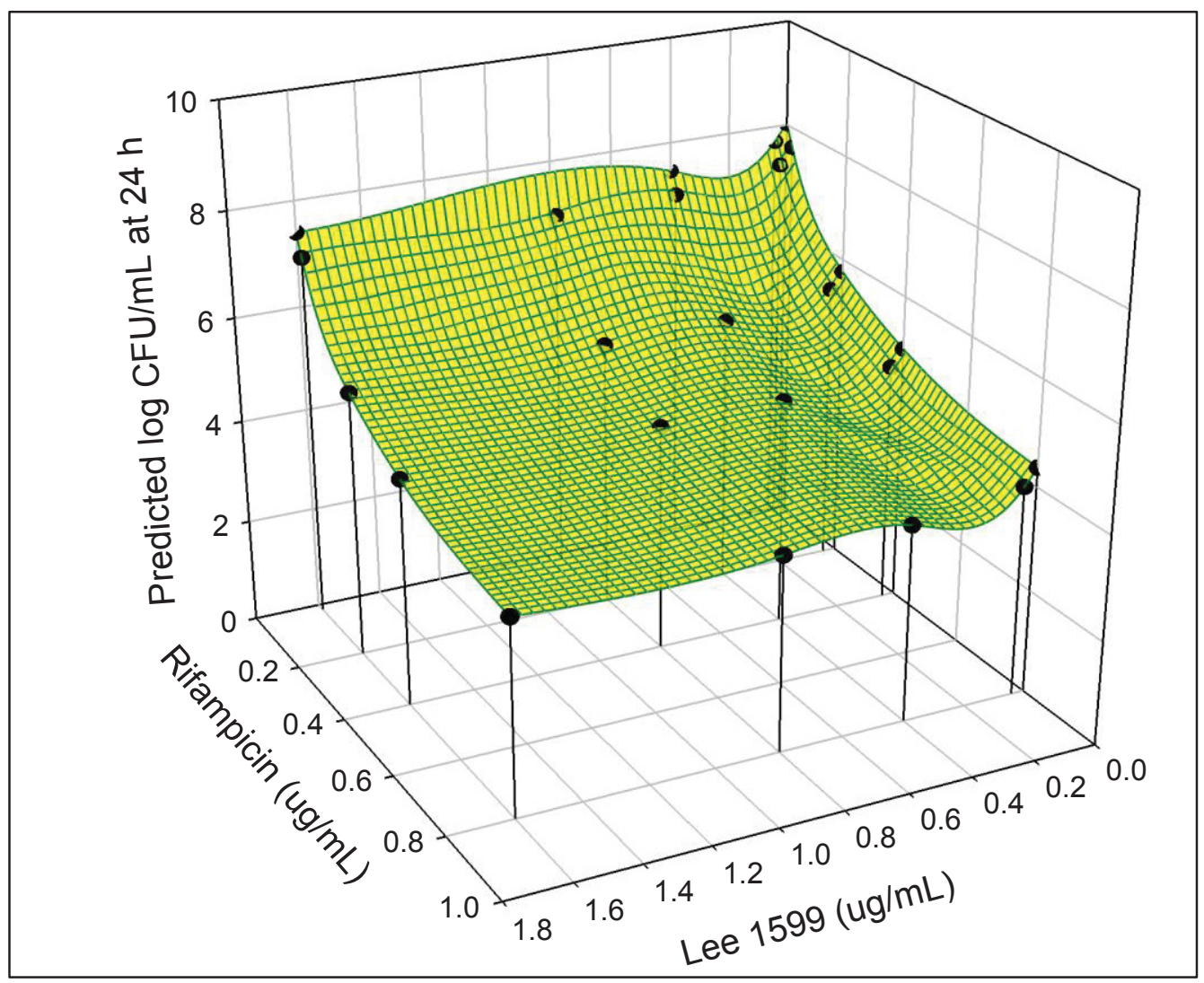

Figure 5-4. Model predicted effect of the combination compound Lee 1599 and RIF. 
Table 5-2. Results of three dimensional surface response assay.

\begin{tabular}{lccc}
\hline \multicolumn{1}{c}{ Model } & $\begin{array}{c}\text { VUP } \\
\text { value }\end{array}$ & $\begin{array}{c}\text { Ratio } \\
\text { (VUPobs/VUPpred) }\end{array}$ & Indication \\
\hline Observed effect & 274.84 & 1.01 & Additive effect \\
Model predicted effect & 271.86 & & \\
\hline
\end{tabular}




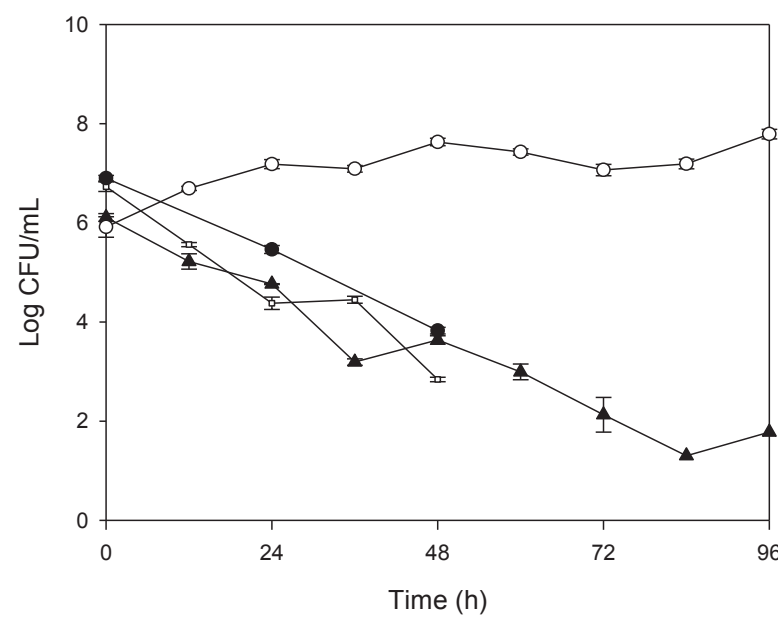

- Control

RIF $10 \mathrm{mg} / \mathrm{kg}$ QD

Lee1599 100mg/kg QD

? Lee 1599 100mg/kg QD; RIF 10mg/kg QD

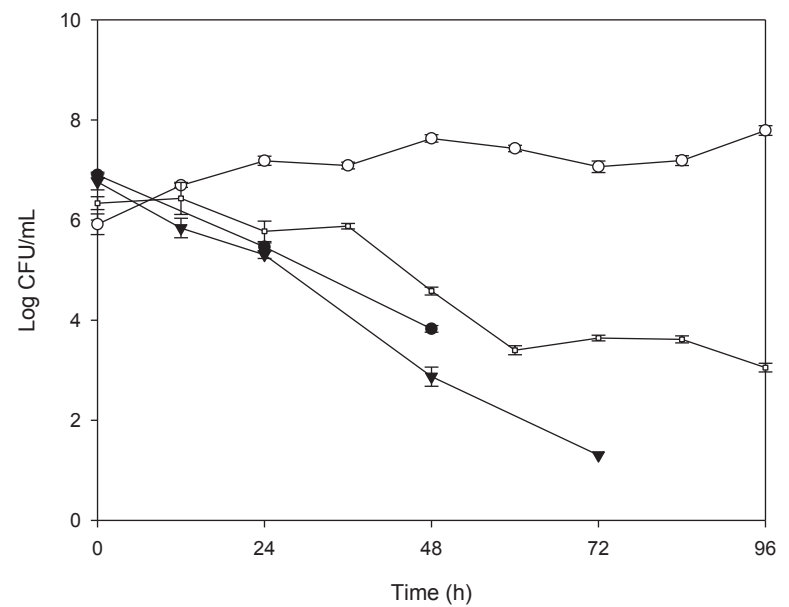

-0- Control
- Lee1599 10mg/kg QD

RIF $10 \mathrm{mg} / \mathrm{kg}$ QD

$\checkmark$ Lee $159910 \mathrm{mg} / \mathrm{kg}$ QD; RIF $10 \mathrm{mg} / \mathrm{kg}$ QD

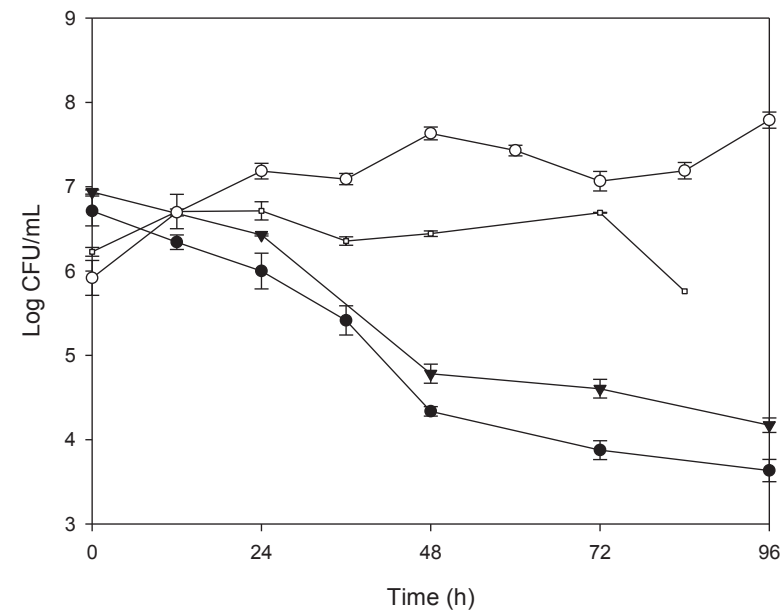

- - - Control

$\longrightarrow$ Lee 1599 1mg/kg QD

RIF $0.5 \mathrm{mg} / \mathrm{kg}$ QD

Lee $15991 \mathrm{mg} / \mathrm{kg}$ QD; RIF 0.5mg/kg QD

Figure 5-5. In vitro PK/PD dynamic time kill study for Lee 1599, RIF and its combination with different doses. 
$48 \mathrm{~h}$ for all the treatment groups were arbitrarily selected for quantitative comparison as shown in Figure 5-6. At higher doses of 100mg/kg Lee 1599 and $10 \mathrm{mg} / \mathrm{kg}$ RIF, there is an average of $4 \log \mathrm{CFU} / \mathrm{mL}$ reduction in bacterial counts when the agents are administered in combination as compared to $2.44 \log \mathrm{CFU} / \mathrm{mL}$ by Lee 1599 alone or 3 $\log \mathrm{CFU} / \mathrm{mL}$ by RIF alone. Similarly, an approximate $4 \log \mathrm{CFU} / \mathrm{mL}$ bacterial killing was observed when $10 \mathrm{mg} / \mathrm{kg}$ Lee 1599 was co-administered with $10 \mathrm{mg} / \mathrm{kg}$ RIF as compared to $1.73 \log \mathrm{CFU} / \mathrm{mL}$ killing with $10 \mathrm{mg} / \mathrm{kg}$ Lee 1599 alone. The efficacy observed with both dose group including the higher RIF dose $(100 \mathrm{mg} / \mathrm{kg}$ Lee $1599+$ $10 \mathrm{mg} / \mathrm{kg}$ RIF and $10 \mathrm{mg} / \mathrm{kg}$ Lee $1599+10 \mathrm{mg} / \mathrm{kg}$ RIF) were almost identical. This can be possibly due to a ceiling effect in the killing pattern by Lee 1599 when given with high doses of RIF.

At much lower doses, an average of $2.5 \log \mathrm{CFU} / \mathrm{mL}$ bacterial reduction was observed with $1 \mathrm{mg} / \mathrm{kg} 1599+0.5 \mathrm{mg} / \mathrm{kg}$ RIF. A dose of $1 \mathrm{mg} / \mathrm{kg}$ Lee 1599 did not show any evidence for sterilizing activity. However, the same dose when co-administered with $0.5 \mathrm{mg} / \mathrm{kg}$ RIF could improve bacterial killing in contrast to individual Lee 1599 dose at $48 \mathrm{~h}$ and $72 \mathrm{~h}(\mathrm{p}<0.05)$. All three sets of combination doses showed an increased bacterial killing when both the agents were administered in combination. This is an indication of an additive effect of both the anti-bacterial agents in combination.

\section{In vivo studies}

The results of our pharmacodynamic interaction assays of the Lee 1599-RIF combination were subsequently compared to in vivo efficacy results after 4 weeks of treatment in an acute $M$. $t b$ infection model in mice performed by our collaborators, Dr. Anne Lenaerts and her group at Colorado State University. The studies were carried out in two different groups: A high dose aerosol (HDA) and low dose aerosol (LDA) infection with 200mg/kg QD Lee 1599 (subcutaneously) and 10mg/kg QD RIF (oral) administered as shown in Figure 5-7. The HDA group was inoculated with $3.5 \log$ CFU per mouse and LDA group was inoculated with $2 \log$ CFU per mouse. For the HDA group, the observed bacterial reduction was 2.14, 1.08 and $2.97 \log$ CFU with Lee 1599, RIF and combination of both drugs, respectively. The expected combined effect of Lee 1599 and RIF assuming there is no interaction between the two drugs can be calculated as $3.22 \log$ CFU. Similarly, for the LDA group, the observed effect with combination was $2.79 \log \mathrm{CFU}$ and theoretical summation was $2.84 \log \mathrm{CFU}$. The close proximity of the observed and the expected value for efficacy of the combination regimens suggests that Lee 1599 and RIF have an additive effect when given in combination.

\section{Discussion}

Spectinamide Lee 1599 has excellent anti-TB activity both in vitro and in vivo and has demonstrated potency against MDR- and XDR-TB strains obtained from several clinical isolates. It is a well-known fact that $\mathrm{TB}$ therapeutic regimen require a combination of multiple anti-TB drugs. It is evident that eventually every drug against 


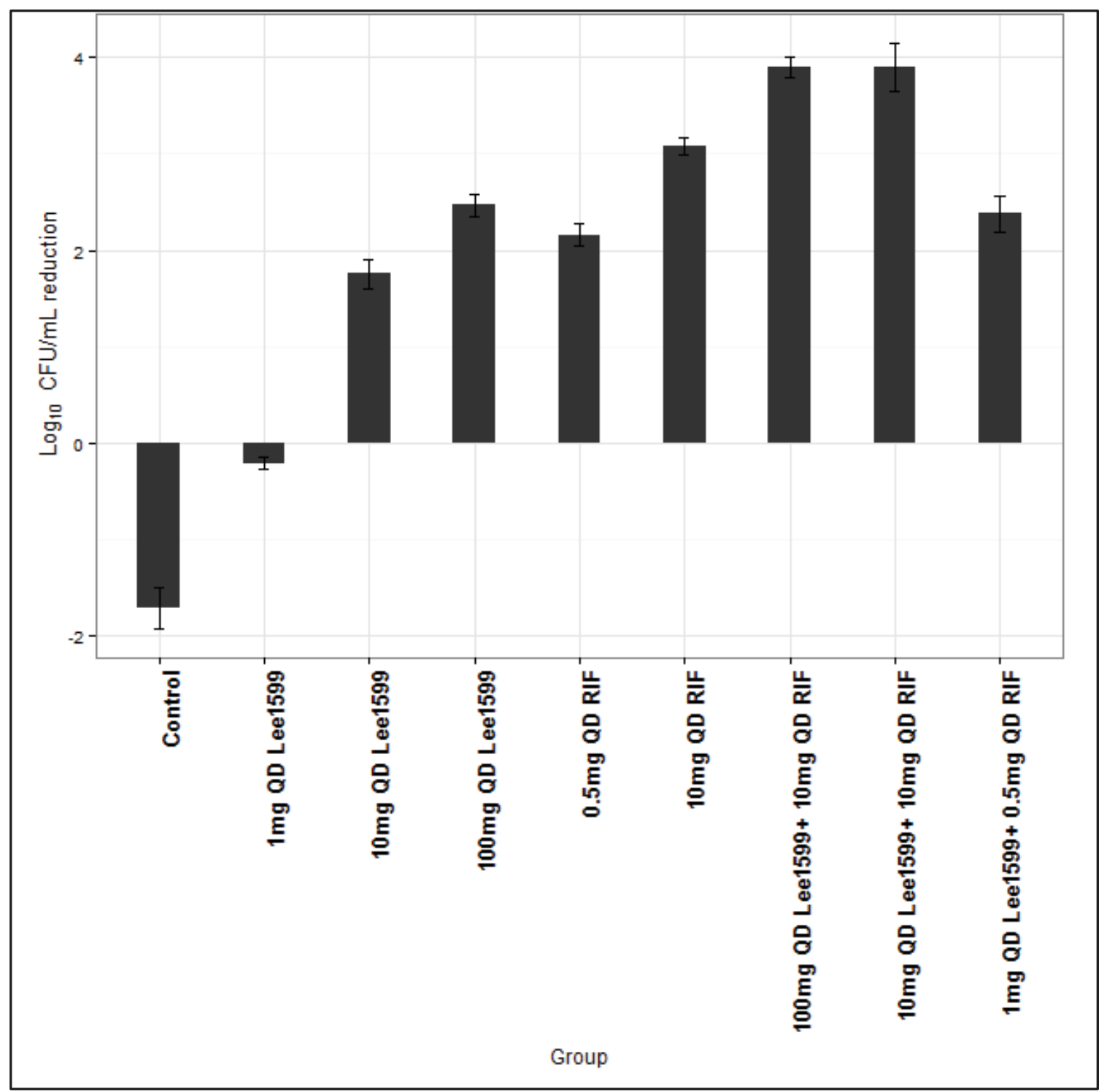

Figure 5-6. The bacterial log reduction with different doses using an in vitro PK/PD dynamic time kill experiment. 


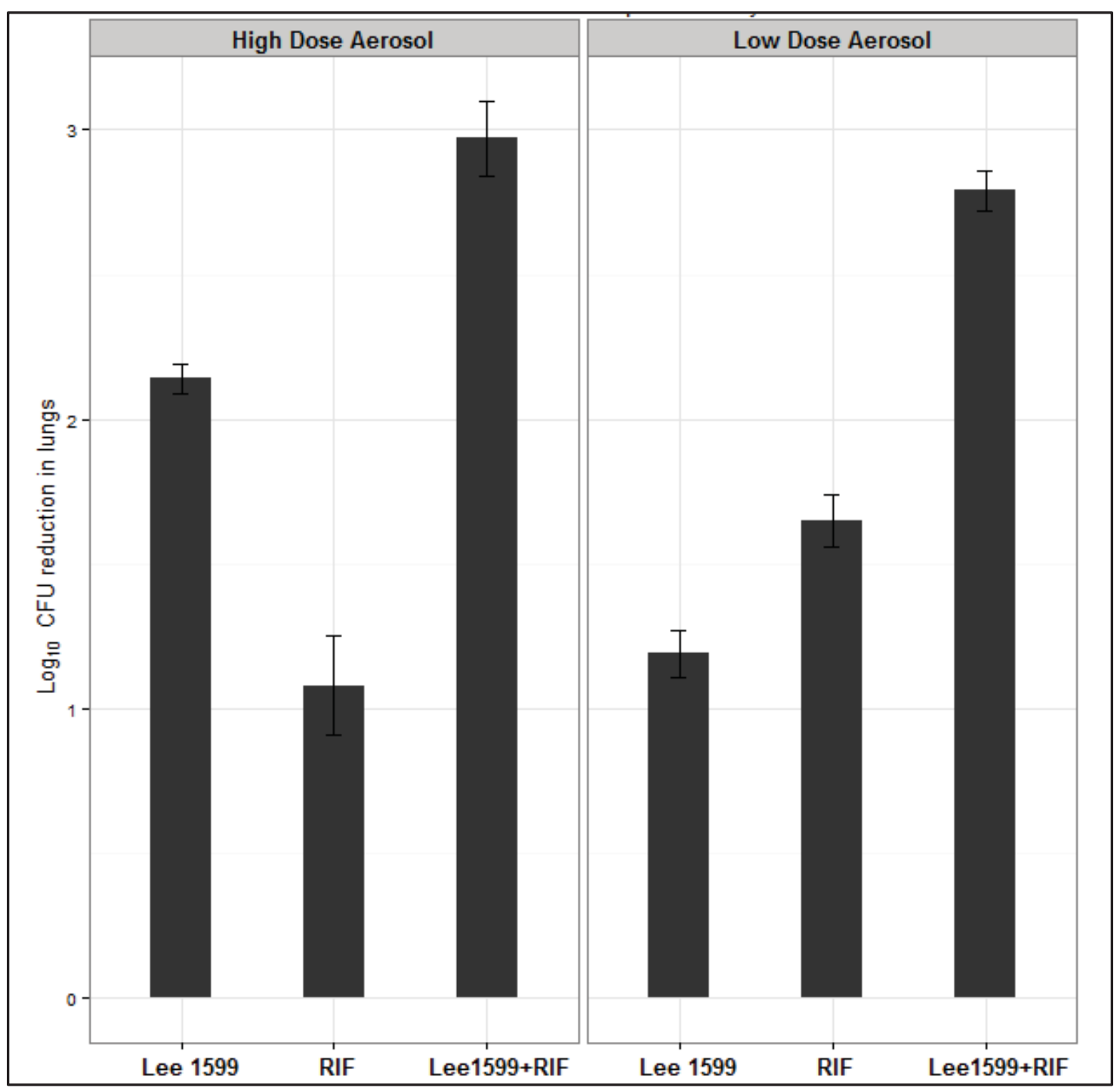

Figure 5-7. In vivo efficacy trial data showing bacterial burden reduction (log $\mathrm{CFU} / \mathrm{mL}$ ) in the lungs of $M$. $t b$ infected mice, $N=6$ for Lee 1599 and Lee 1599+RIF, $\mathbf{N}=\mathbf{5}$ for RIF.

Notes: Lee 1599 was administered subcutaneously at $200 \mathrm{mg} / \mathrm{kg}$ and RIF was dosed orally at $10 \mathrm{mg} / \mathrm{kg}$. The results are significant for all dose groups at $\mathrm{p}<0.05$ by pairwise multiple comparison procedures (Tukey test). 
TB will be co-administered with other anti-TB drugs [21]. In our ongoing research studies, we hypothesized an increase in pharmacodynamic effect when spectinamide Lee 1599 is co-administered with another established anti-TB drug and that this increase in in vivo effect can be predicted by adequate in vitro assays. The model drug selected for the purpose of our study was RIF, a first-line antibiotic used for TB therapy. The change in pharmacodynamic effect upon co-administration of two drugs is frequently determined using techniques such as the checkerboard assay, the E-test and time-kill curves both in vitro and in vivo $[118,119]$. We applied two of these methods for primary screening: the checkerboard assay and the three dimensional surface response assay. As shown by our results, there is a clear disconnect between the outcomes of these two methods as shown in Table 5-3. The checkerboard assay suggested a synergistic interaction between Lee 1599 and RIF. However, the three dimensional surface response assays indicated an additive effect between the two compounds.

The primary reason for the difference between these two methods is likely rooted in the underlying principles of both methods. The basis of null interaction for the FICI score derived from the checkerboard assay is the Loewe additivity method. However, there are several pitfalls associated with the checkerboard assay: (1) The initial bacterial load for testing interactions is much lower $\left(\mathrm{OD}_{600} 0.01\right.$ or $\left.10^{5} \mathrm{CFU} / \mathrm{mL}\right)$ than what is observed in in vivo studies or in patients $[120,121]$. (2) The endpoint is often based on visual inspection and very subjective, increasing the possibility of erroneous results. Since, it follows a 2-fold dilution technique; there is a high possibility of one-well errors. Though this error may be undervalued assuming a miniscule marginal error, the error is magnified and the extent of allowance increases at higher dilutions [122]. (3) Moreover, there are various methods to calculate the FICI index using the checkerboard assay and there has been variability reported with different methods of interpretation of checkerboard synergy testing [123].

To overcome these limitations, we advanced with a quantitative, parametric three dimensional surface response approach proposed by Tam et al. The surface response approach has several advantages over the checkerboard assay: (1) The endpoint is the quantification of bacterial counts on agar plates as opposed to visual inspection. (2) The initial number of bacteria pre-dose, approximately $10^{7}-10^{8} \mathrm{CFU} / \mathrm{mL}$, is much higher relative to the checkerboard assay and comparable to in vivo mouse infection models. (3) The bacterial inoculum is in higher volumes of media providing a more conducive environment with fresh nutrients for bacterial growth. (4) The difference in bacterial counts in dosing and control groups after $24 \mathrm{~h}$ of incubation normalizes the bacterial reduction thus providing us with a measure for extent of bacterial killing. Based on these facts, the indication of combination effects from the response surface assay seems to be more reliable compared to the checkerboard assay based on the above mentioned rationales.

It is obligatory to validate the results obtained from two different screening assays, particularly if the two applied methodologies provide discordant results as in our study. We therefore performed an in vitro PK/PD model based dynamic time-kill study as opposed to static time kill studies to validate the preliminary findings and confirm the 
Table 5-3. Summary of results of pharmacodynamics interactions from different methods.

\begin{tabular}{ll}
\hline \multicolumn{1}{c}{ Method } & \multicolumn{1}{c}{ Indication } \\
\hline Checkerboard assay & Synergy \\
3D surface response assay & Additive effect \\
Dynamic time kill curves & Additive effect \\
In vivo mouse studies & Additive effect \\
\hline
\end{tabular}


authenticity of the above mentioned assays. The in vitro PK/PD model based time-kill curves were performed under dynamic conditions and take into account the fluctuating concentration of drug over time mimicking the pharmacokinetic conditions observed in vivo. Although the hollow fiber infection model (HFIM) is now used by an increasing number of research groups for this purpose, our previously used in vitro PK/PD model has several advantages over the use of HFIM if used for the compound screening. Some of the major limitations of the HFIM is non-specific drug binding (especially highly lipophilic compounds) to the hollow fiber capillaries producing misleading results, relatively high cost and complex operation. Our in vitro model uses a substantially easier setup, and can be sterilized and reused between two cycles of different studies. This makes the in vitro model very cost-effective and ideal for use in exploratory trials to test multiple dose and dosing regimens [39].

The results from the time-kill curves experiments indicate a moderate increase in bacterial reduction with combination treatment as compared to monotherapy. The net bacterial reduction with combination is approximately the algebraic sum of bacterial reduction caused by the two agents during monotherapy. Thus, the time-kill results indicated an additive effect between Lee 1599 and RIF. To compare the efficacy among the treatment regimens, we selected the $48 \mathrm{~h}$ timepoint as the bacterial counts were below the quantification limit at later timepoints in the Lee $1599100 \mathrm{mg} / \mathrm{kg}$ QD and RIF $10 \mathrm{mg} / \mathrm{kg}$ QD dose groups. The bacterial killing increases with increasing doses of Lee 1599 or RIF alone, which is expected based on their previously observed non-linear dose response relationships. The combined effect at low doses of Lee $15991 \mathrm{mg} / \mathrm{kg}$ and RIF $0.5 \mathrm{mg} / \mathrm{kg}$ was marginally higher than RIF $0.5 \mathrm{mg} / \mathrm{kg}$. However, when higher doses for both Lee 1599 and RIF are co-administered there is a substantial increase in the reduction of bacterial counts. Theoretically, the bacterial reduction for the Lee $1599100 \mathrm{mg} / \mathrm{kg}+$ RIF $10 \mathrm{mg} / \mathrm{kg}$ group should be higher than Lee $159910 \mathrm{mg} / \mathrm{kg}+\mathrm{RIF} 10 \mathrm{mg} / \mathrm{kg}$ group. The observed effect for both groups, Lee 1599 100mg/kg+RIF 10mg/kg and Lee 1599 $10 \mathrm{mg} / \mathrm{kg}+$ RIF $10 \mathrm{mg} / \mathrm{kg}$ group, however, showed similar efficacy, that was significantly higher than for the groups treated with Lee 1599 alone $(p<0.05)$. This clearly suggests that doses of $10 \mathrm{mg} / \mathrm{kg}$ and $100 \mathrm{mg} / \mathrm{kg}$ of Lee 1599 when given in combination with $10 \mathrm{mg} / \mathrm{kg}$ RIF have the same efficacy possibly due to a ceiling effect.

There is always experimental variability associated with individual data points. The method of using a specific time point to compare the efficacy of different dose group as we applied can be erroneous, as it does not capture the cumulative effect of the treatment. To overcome this limitation, we calculated the area-under the curve $\left(\mathrm{AUC}_{0-\mathrm{t}}\right)$ for the individual time-kill curves to establish a cumulative measure of the overall effect. As the time-kill experiments were terminated at different time points, we determined $\mathrm{AUC}_{0-48}$ for all time-kill curves and normalized them with the control group. The percentages of $\mathrm{AUC}_{0-48}$ ratios were calculated to compare different groups as shown in Table 5-4. The higher the percentages, the higher the killing. The \%ratios were larger for combination therapy as compared to monotherapy. The \%ratios for Lee $1599100 \mathrm{mg} / \mathrm{kg}+$ RIF 10mg/kg was larger than Lee $159910 \mathrm{mg} / \mathrm{kg}+$ RIF 10mg/kg indicating more bacterial kill for the former group. Also, at lower doses (Figure 5-8), the \%ratio for Lee $15991 \mathrm{mg} / \mathrm{kg}+$ RIF $0.5 \mathrm{mg} / \mathrm{kg}$ group was larger than the individual Lee 1599 and RIF 
Table 5-4. Comparison of \%AUC ratios (the \%AUC were normalized with AUC of control group).

\begin{tabular}{lc}
\hline \multicolumn{1}{c}{ Group } & \%AUC ratio \\
\hline Lee $1599100 \mathrm{mg} / \mathrm{kg}+$ RIF $10 \mathrm{mg} / \mathrm{kg}$ & 94.1 \\
Lee $159910 \mathrm{mg} / \mathrm{kg}+$ RIF $10 \mathrm{mg} / \mathrm{kg}$ & 91.7 \\
Lee $1599100 \mathrm{mg} / \mathrm{kg}$ & 93.9 \\
Lee $159910 \mathrm{mg} / \mathrm{kg}$ & 86.1 \\
RIF $10 \mathrm{mg} / \mathrm{kg}$ & 84.5 \\
Lee $15991 \mathrm{mg} / \mathrm{kg}+$ RIF $0.5 \mathrm{mg} / \mathrm{kg}$ & 85.9 \\
RIF 0.5mg/kg & 74.9 \\
Lee $15991 \mathrm{mg} / \mathrm{kg}$ & 68.8 \\
Control & 0.0 \\
\hline
\end{tabular}




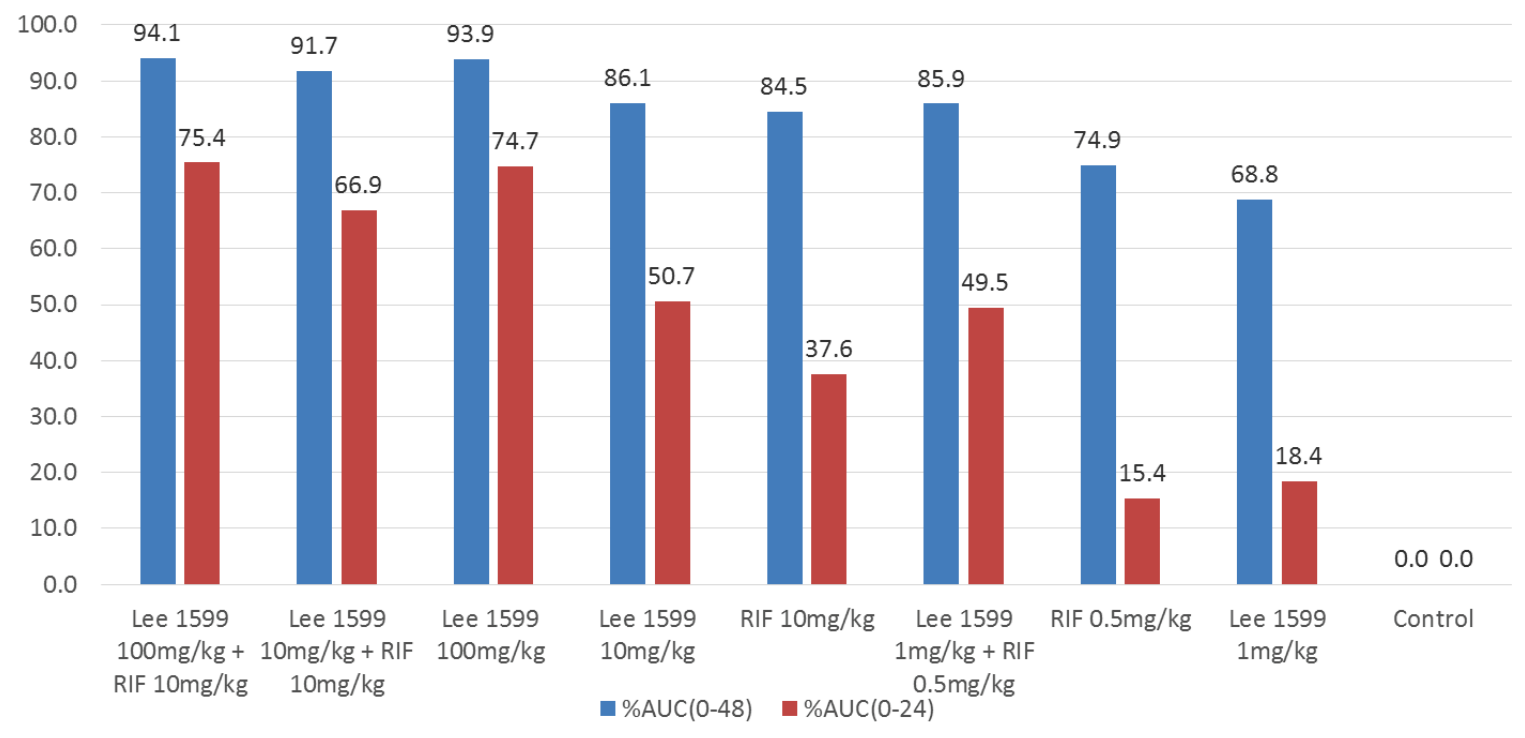

Figure 5-8. Comparison of \%AUC ratios after the \%AUC were normalized with AUC of control group indicating higher the \%AUC ratio, greater the bacterial killing. 
treatment arms. The enhanced killing in the combination group suggests an additive effect of both the agents. Thus, the $\mathrm{AUC}_{0-\mathrm{t}}$ ratios may be a better estimate for comparison of kill curves than a point estimate as it captures the dynamic range of the bacterial timekill effect.

The above in vitro results are corroborated by in vivo findings suggesting a additive effect between Lee 1599 and RIF. The in vivo studies were performed using different bacterial loads (HDA and LDA bacterial burden) for treatment. There is no "gold standard" definition of synergy observed under in vitro or in vivo conditions. Of the many definitions reported in the literature, synergy is commonly defined as $\geq 2 \log$ $\mathrm{CFU} / \mathrm{mL}$ reduction by combination as compared to single therapy $[124,125]$. Based on this assessment, we interpreted the in vivo results to be an additive effect. However, these definitions of synergy are not necessarily translatable to clinical scenarios where the endpoint of treatment is an improvement in the patient's condition. It is challenging to identify an additive effect or synergistic effect under clinical conditions as one can usually not quantify bacterial counts in patients. The primary application of these drug interaction characteristics determined under preclinical conditions is to adjust the dose and dosing regimen for the combination therapy and balancing the efficacy profile of the drugs without imparting any toxicity to the patient. In view of these considerations, drawing a line between additive effect and synergy at the preclinical stage may not give any edge for dose optimization in the clinic. Hence, the purpose of the drug interaction assays should focus on whether the combination is more efficacious or less toxic as compared to single dose treatment.

\section{Conclusions}

In summary, it is crucial to carry out in vitro experiments on pharmacodynamic interactions for antibiotics early during the preclinical drug development phase to test potential interactions between two or more molecules. The results from the checkerboard assay or any other qualitative analysis assay should be used with caution. It is advised to confirm the results with quantitative methods such as three dimensional surface response assay, dynamic time kill curve experiments or in vivo studies to get precise information about the drug interaction in question. Our studies show that the preclinical drug development process can be hindered or misguided if decisions are based on only one qualitative assay. In addition, the purpose of the drug interaction assays should focus on whether the combination is more efficacious or less toxic as compared to single dose treatment rather than trying to decipher between additivity and synergism. 


\section{CHAPTER 6. SUMMARY}

The number of resistant strains of $M . t b$ that have increased at an alarming rate has convinced researchers to focus on the discovery of new anti-tuberculosis drugs to combat this pandemic. To contribute to solutions for this problem, our research group discovered a novel series of anti-tuberculosis agents called spectinamides, semi-synthetic analogs of spectinomycin. Spectinamides are potent inhibitors of mycobacterial ribosomes and overcomes efflux mediated drug resistance in $M$. $t b$. Multiple of the compounds in the spectinamide series have shown an excellent in vitro activity and acceptable drug-like properties, thus making them excellent preclinical drug candidates. We hypothesized that a pharmacometrics-directed quantitative approach for integrated $\mathrm{PK} / \mathrm{PD}$ characterization can guide the selection of lead candidate compounds and is more predictive of in vivo efficacy than some qualitative of semi-quantitative standard approaches.

The screening for potential lead drug candidates included multiple experiments to determine the pharmacokinetic parameters. In vitro screening demonstrated that spectinamides have low plasma protein binding and are stable against hepatic microsomal activity. The pharmacokinetics studies in rats revealed that renal excretion is the major route of elimination for most spectinamides. This route of elimination suggests that there is a low potential for drug-drug interactions during combination pharmacotherapy as seen with agents that undergo extensive hepatic metabolism. Because spectinamides are highly hydrophilic, distribute well in aqueous distribution spaces, and show low plasma protein binding, they are advantageous as therapeutic candidates over other new anti-TB agents where most tend to be lipophilic and have high plasma protein binding. This results in spectinamides being able to target bacterial subpopulations that are unreachable by more lipophilic compounds.

An important aspect in the safety of novel drug candidates is their biodistribution and potential accumulation in tissues. On the other hand, intracellular uptake into macrophages is a prerequisite for antibiotic activity against $M$. tb residing inside infected macrophages. Our quantitative macrophage uptake studies showed that Lee 1329, Lee1445 and Lee 1599 had significantly higher macrophage uptake than spectinomycin and streptomycin.

The biodistribution of spectinamides was determined using a tritium labelled Lee 1329. About $70 \%$ of administered radioactivity was recovered in urine and $12.6 \%$ in feces, with a total mass balance of $84.7 \%$. Total radioactivity showed similar activitytime profiles for the first $2 \mathrm{~h}$ after I.V. administration. Deviation at later time points suggests formation of circulating metabolites with longer half-life than the parent drug. $\mathrm{C}_{\max }$ after the 1 st dose and the 8 th dose is similar: $3.39 \mu \mathrm{Ci} / \mathrm{mL}$ and $3.55 \mu \mathrm{Ci} / \mathrm{mL}$, suggesting no relevant accumulation of parent drug and metabolites. The activity of radiolabel was 3 times higher in lungs and spleen as compared to whole blood, suggesting good tissue penetration of Lee 1329. The results support the earlier findings that the major elimination pathway for Lee 1329 is renal excretion and that the compound 
accumulates neither in blood nor in tissues during multiple dosing with a BID regimen in rats, which is an important aspect in the safety profile of spectinamides.

The minimum inhibitory concentration (MIC) is one of the key pharmacodynamic parameters used to compare and differentiate drug candidates. However, point estimates of pharmacodynamic activity such as MIC do not take into account the dynamic interaction between bacteria and fluctuating exposure to unbound drug during dosing in vivo. We thus applied an in vitro $\mathrm{PK} / \mathrm{PD}$ model system to establish the quantitative interaction between bacterial growth and time-varying drug concentration for the emerging lead Lee 1599. The obtained results were used to identify the optimal PK/PD index driving Lee 1599's efficacy, and to perform model-based numerical simulations to determine appropriate dosing regimens for further in vivo efficacy trials. The results indicate that Lee 1599 exhibits a dose-dependent bactericidal effect. Lee 1599 showed up to 4-log reductions in bacterial counts at 100mg QD dosing. The PK/PD indices demonstrate that Lee 1599 elicits a concentration- and time-dependent killing with AUC/MIC as the optimal index. The in vitro PK/PD simulated profile suggests that higher doses with shorter dosing intervals may demonstrate optimal efficacy in vivo.

With an increasing frequency of mycobacterial resistant strains, there is an emerging need for robust and effective combination therapy. The conventional screening method for determining pharmacodynamic drug interactions using the Checkerboard assay depends on a subjective endpoint of growth inhibition and fails to provide any information on extent of bacterial growth or kill over time. We applied parametric approach to quantitatively assess the pharmacodynamics drug interaction between the lead candidate compound Lee 1599 and rifampicin. The three dimensional surface response assay demonstrated that there is an additive effect between both agents as opposed to the checkerboard assay, which showed synergism between these agents. The results of the surface response assay were validated using an in vitro PK/PD model for combination agents and in vivo efficacy trials. These results suggest that the quantitative response surface assay may be a screening tool for drug interactions that is more predictable of in vivo interactions than the traditional checkerboard assay. In addition, the additive effect between Lee 1599 and rifampicin suggest that a combination therapy may warrant optimal efficacy results at lower doses than single drug therapy of either drug.

In conclusion, we have successfully supported the further development of spectinamides using a pharmacometric approach. We have contributed to the selection of lead candidate compounds such as Lee 1599 using quantitative PK/PD approaches in its pre-clinical development. The application of PK/PD knowledge is essential for translating the in vitro screening assay findings to the in vivo stage. The results of the above studies may serve to illustrate the optimization of anti-infective agents in the early drug discovery and development. 


\section{LIST OF REFERENCES}

1. Zhang, L., M. Pfister, and B. Meibohm, Concepts and challenges in quantitative pharmacology and model-based drug development. AAPS J, 2008. 10(4): p. 5529.

2. $\quad$ Lalonde, R.L., et al., Model-based drug development. Clin Pharmacol Ther, 2007. 82(1): p. 21-32.

3. Sotto, A. and J.P. Lavigne, A mathematical model to guide antibiotic treatment strategies. BMC Med, 2012. 10: p. 90.

4. Joyner, M.L.P., C.C. Manning, and B.N. Canter, Modeling the effects of introducing a new antibiotic in a hospital setting: A case study. Math Biosci Eng, 2012. 9(3): p. 601-625.

5. Suryawanshi, S., et al., The current role of model-based drug development. Expert Opin Drug Discov, 2010. 5(4): p. 311-21.

6. Meibohm, B. and H. Derendorf, Pharmacokinetic/pharmacodynamic studies in drug product development. J Pharm Sci, 2002. 91(1): p. 18-31.

7. $\quad$ Romero, K., et al., Pharmacometrics as a discipline is entering the "industrialization" phase: standards, automation, knowledge sharing, and training are critical for future success. J Clin Pharmacol, 2010. 50(9 Suppl): p. 9S-19S.

8. Manolis, E. and R. Herold, Pharmacometrics for regulatory decision making: status and perspective. Clin Pharmacokinet, 2011. 50(10): p. 625-6.

9. Bhattaram, V.A., et al., Impact of pharmacometric reviews on new drug approval and labeling decisions--a survey of 31 new drug applications submitted between 2005 and 2006. Clin Pharmacol Ther, 2007. 81(2): p. 213-21.

10. Vaddady, P.K., R.E. Lee, and B. Meibohm, In vitro pharmacokinetic/pharmacodynamic models in anti-infective drug development: focus on TB. Future Med Chem, 2010. 2(8): p. 1355-69.

11. Pasipanodya, J. and T. Gumbo, An oracle: antituberculosis pharmacokineticspharmacodynamics, clinical correlation, and clinical trial simulations to predict the future. Antimicrob Agents Chemother, 2011. 55(1): p. 24-34.

12. Preston, S.L., et al., Levofloxacin population pharmacokinetics and creation of a demographic model for prediction of individual drug clearance in patients with serious community-acquired infection. Antimicrob Agents Chemother, 1998. 42(5): p. 1098-104.

13. Lee, J.Y., et al., Impact of pharmacometric analyses on new drug approval and labelling decisions: a review of 198 submissions between 2000 and 2008. Clin Pharmacokinet, 2011. 50(10): p. 627-35.

14. Ikawa, K., et al., Pharmacokinetic modeling and dosage adaptation of biapenem in Japanese patients during continuous venovenous hemodiafiltration. J Infect Chemother, 2008. 14(1): p. 35-9.

15. Lodise, T.P., et al., Use of population pharmacokinetic modeling and Monte Carlo simulation to describe the pharmacodynamic profile of cefditoren in plasma and epithelial lining fluid. Antimicrob Agents Chemother, 2008. 52(6): p. 1945-51. 
16. Lodise, T.P., Jr., et al., Comparison of the probability of target attainment between ceftriaxone and cefepime in the cerebrospinal fluid and serum against Streptococcus pneumoniae. Diagn Microbiol Infect Dis, 2007. 58(4): p. 445-52.

17. Rodvold, K.A., et al., Identifying exposure targets for treatment of staphylococcal pneumonia with ceftobiprole. Antimicrob Agents Chemother, 2009. 53(8): p. 3294-301.

18. Lodise, T.P., Jr., et al., Probability of target attainment for ceftobiprole as derived from a population pharmacokinetic analysis of 150 subjects. Antimicrob Agents Chemother, 2007. 51(7): p. 2378-87.

19. Van Wart, S., et al., Population pharmacokinetics and pharmacodynamics of garenoxacin in patients with community-acquired respiratory tract infections. Antimicrob Agents Chemother, 2004. 48(12): p. 4766-77.

20. Noreddin, A.M., et al., Comparative pharmacodynamics of garenoxacin, gemifloxacin, and moxifloxacin in community-acquired pneumonia caused by Streptococcus pneumoniae: a Monte Carlo simulation analysis. Clin Ther, 2007. 29(12): p. 2685-9.

21. Tanigawara, Y., K. Nozawa, and H. Tsuda, Optimal dose finding of garenoxacin based on population pharmacokinetics/pharmacodynamics and Monte Carlo simulation. Eur J Clin Pharmacol, 2012. 68(1): p. 39-53.

22. Noreddin, A.M., D.J. Hoban, and G.G. Zhanel, Comparison of gatifloxacin and levofloxacin administered at various dosing regimens to hospitalised patients with community-acquired pneumonia: pharmacodynamic target attainment study using North American surveillance data for Streptococcus pneumoniae. Int J Antimicrob Agents, 2005. 26(2): p. 120-5.

23. Owens, R.C., Jr., S.M. Bhavnani, and P.G. Ambrose, Assessment of pharmacokinetic-pharmacodynamic target attainment of gemifloxacin against Streptococcus pneumoniae. Diagn Microbiol Infect Dis, 2005. 51(1): p. 45-9.

24. Drusano, G.L., et al., A population pharmacokinetic analysis of the penetration of the prostate by levofloxacin. Antimicrob Agents Chemother, 2000. 44(8): p. 204651.

25. Drusano, G.L., et al., Levofloxacin penetration into epithelial lining fluid as determined by population pharmacokinetic modeling and monte carlo simulation. Antimicrob Agents Chemother, 2002. 46(2): p. 586-9.

26. Sprandel, K.A., et al., Population pharmacokinetic modeling and Monte Carlo simulation of varying doses of intravenous metronidazole. Diagn Microbiol Infect Dis, 2006. 55(4): p. 303-9.

27. Simon, N., et al., Population pharmacokinetics of moxifloxacin in plasma and bronchial secretions in patients with severe bronchopneumonia. Clin Pharmacol Ther, 2003. 74(4): p. 353-63.

28. Zhang, J., et al., Population pharmacokinetic and pharmacodynamic modeling of norvancomycin. Eur J Clin Microbiol Infect Dis, 2008. 27(4): p. 275-84.

29. Acosta, E.P., et al., Oseltamivir dosing for influenza infection in premature neonates. J Infect Dis, 2010. 202(4): p. 563-6.

30. Parrott, N., et al., Development of a physiologically based model for oseltamivir and simulation of pharmacokinetics in neonates and infants. Clin Pharmacokinet, 2011. 50(9): p. 613-23. 
31. Occhipinti, D.J., et al., Pharmacokinetics and pharmacodynamics of two multipledose piperacillin-tazobactam regimens. Antimicrob Agents Chemother, 1997. 41(11): p. 2511-7.

32. Frei, C.R. and D.S. Burgess, Pharmacokinetic/pharmacodynamic modeling to predict in vivo effectiveness of various dosing regimens of

piperacillin/tazobactam and piperacillin monotherapy against gram-negative pulmonary isolates from patients managed in intensive care units in 2002. Clin Ther, 2008. 30(12): p. 2335-41.

33. Goutelle, S., et al., Population modeling and Monte Carlo simulation study of the pharmacokinetics and antituberculosis pharmacodynamics of rifampin in lungs. Antimicrob Agents Chemother, 2009. 53(7): p. 2974-81.

34. Lodise, T.P., Jr., et al., Telavancin penetration into human epithelial lining fluid determined by population pharmacokinetic modeling and Monte Carlo simulation. Antimicrob Agents Chemother, 2008. 52(7): p. 2300-4.

35. Lodise, T.P., et al., Penetration of vancomycin into epithelial lining fluid in healthy volunteers. Antimicrob Agents Chemother, 2011. 55(12): p. 5507-11.

36. Damle, B., M.V. Varma, and N. Wood, Pharmacokinetics of voriconazole administered concomitantly with fluconazole and population-based simulation for sequential use. Antimicrob Agents Chemother, 2011. 55(11): p. 5172-7.

37. Czock, D. and F. Keller, Mechanism-based pharmacokinetic-pharmacodynamic modeling of antimicrobial drug effects. J Pharmacokinet Pharmacodyn, 2007. 34(6): p. 727-51.

38. Schmidt, S., et al., PK/PD: new insights for antibacterial and antiviral applications. Curr Opin Pharmacol, 2008. 8(5): p. 549-56.

39. Budha, N.R., et al., A simple in vitro PK/PD model system to determine time-kill curves of drugs against Mycobacteria. Tuberculosis (Edinb), 2009. 89(5): p. 37885.

40. Stass, H. and A. Dalhoff, The integrated use of pharmacokinetic and pharmacodynamic models for the definition of breakpoints. Infection, 2005. 33 Suppl 2: p. 29-35.

41. Drusano, G.L., et al., Use of preclinical data for selection of a phase II/III dose for evernimicin and identification of a preclinical MIC breakpoint. Antimicrob Agents Chemother, 2001. 45(1): p. 13-22.

42. Turnidge, J. and D.L. Paterson, Setting and revising antibacterial susceptibility breakpoints. Clin Microbiol Rev, 2007. 20(3): p. 391-408, table of contents.

43. Zeitlinger, M.A., et al., Protein binding: do we ever learn? Antimicrob Agents Chemother, 2011. 55(7): p. 3067-74.

44. Barbour, A., F. Scaglione, and H. Derendorf, Class-dependent relevance of tissue distribution in the interpretation of anti-infective pharmacokinetic/pharmacodynamic indices. Int J Antimicrob Agents, 2010. 35(5): p. 431-8.

45. Noreddin, A.M., et al., Pharmacodynamic target attainment potential of azithromycin, clarithromycin, and telithromycin in serum and epithelial lining fluid of community-acquired pneumonia patients with penicillin-susceptible, intermediate, and resistant Streptococcus pneumoniae. Int J Infect Dis, 2009. 13(4): p. 483-7. 
46. Gumbo, T., et al., Isoniazid bactericidal activity and resistance emergence: integrating pharmacodynamics and pharmacogenomics to predict efficacy in different ethnic populations. Antimicrob Agents Chemother, 2007. 51(7): p. 232936.

47. Wiegand, I., K. Hilpert, and R.E. Hancock, Agar and broth dilution methods to determine the minimal inhibitory concentration (MIC) of antimicrobial substances. Nat Protoc, 2008. 3(2): p. 163-75.

48. DeRyke, C.A., J.L. Kuti, and D.P. Nicolau, Reevaluation of current susceptibility breakpoints for Gram-negative rods based on pharmacodynamic assessment. Diagn Microbiol Infect Dis, 2007. 58(3): p. 337-44.

49. Korsan, B., Transparent Trade-offs: A clinical utility index (CUI) openly evaluates a product's attributes - and chance of success. Pharmaceutical Executive, 2005.

50. Matzke, G.R., et al., Drug dosing consideration in patients with acute and chronic kidney disease-a clinical update from Kidney Disease: Improving Global Outcomes (KDIGO). Kidney Int, 2011. 80(11): p. 1122-37.

51. Drusano, G.L., Antimicrobial pharmacodynamics: critical interactions of 'bug and drug'. Nat Rev Microbiol, 2004. 2(4): p. 289-300.

52. Samtani, M.N., et al., Pharmacokinetic-pharmacodynamic-model-guided doripenem dosing in critically ill patients. Antimicrob Agents Chemother, 2010. 54(6): p. 2360-4.

53. American Thoracic, S. and A. Infectious Diseases Society of, Guidelines for the management of adults with hospital-acquired, ventilator-associated, and healthcare-associated pneumonia. Am J Respir Crit Care Med, 2005. 171(4): p. 388-416.

54. Katsube, T., et al., Pharmacokinetic/pharmacodynamic modeling and simulation to determine effective dosage regimens for doripenem. J Pharm Sci, 2010. 99(5): p. 2483-91.

55. Goldie, S.J., et al., Prophylaxis for human immunodeficiency virus-related Pneumocystis carinii pneumonia: using simulation modeling to inform clinical guidelines. Arch Intern Med, 2002. 162(8): p. 921-8.

56. Li, F., et al., Pharmacometrics-based dose selection of levofloxacin as a treatment for postexposure inhalational anthrax in children. Antimicrob Agents Chemother, 2010. 54(1): p. 375-9.

57. European Medicines Agency Committee for Proprietary Medicinal Products (CPMP) Points to consider on pharmacokinetics and pharmacodynamics in the development of antibacterial medicinal products. 2009.

58. European Medicines Agency Committee for Proprietary Medicinal Products (CPMP) Guideline on the clinical evaluation of medicinal products intended for treatment of hepatitis $B 2009$.

59. European Medicines Agency Committee for Proprietary Medicinal Products (CPMP) Guideline on clinical investigation of medicinal products for the treatment of sepsis. 2009.

60. Jonsson, S., et al., Role of modelling and simulation: a European regulatory perspective. Clin Pharmacokinet, 2012. 51(2): p. 69-76. 
61. Rowland, M., C. Peck, and G. Tucker, Physiologically-based pharmacokinetics in drug development and regulatory science. Annu Rev Pharmacol Toxicol, 2011. 51: p. 45-73.

62. Huang, S.M. and M. Rowland, The role of physiologically based pharmacokinetic modeling in regulatory review. Clin Pharmacol Ther, 2012. 91(3): p. 542-9.

63. Barrett, J.S., et al., Physiologically based pharmacokinetic (PBPK) modeling in children. Clin Pharmacol Ther, 2012. 92(1): p. 40-9.

64. Brunner, M., H. Derendorf, and M. Muller, Microdialysis for in vivo pharmacokinetic/pharmacodynamic characterization of anti-infective drugs. Curr Opin Pharmacol, 2005. 5(5): p. 495-9.

65. Chaurasia, C.S., et al., AAPS-FDA Workshop White Paper: microdialysis principles, application, and regulatory perspectives. J Clin Pharmacol, 2007. 47(5): p. 589-603.

66. Heron, M., Deaths: leading causes for 2010. Natl Vital Stat Rep, 2013. 62(6): p. $1-96$.

67. http://www.who.int/topics/tuberculosis/en/, World Health Organization. 2015.

68. Gillespie, S.H. and K. Singh, XDR-TB, what is it; how is it treated; and why is therapeutic failure so high? Recent Pat Antiinfect Drug Discov, 2011. 6(2): p. 7783.

69. $\quad$ http://www.tballiance.org/.

70. Budha, N.R., A PHARMACOKINETICS AND PHARMACODYNAMICS (PK/PD) GUIDED APPROACH TO LEAD OPTIMIZATION OF NITROFURANYLAMIDE ANTI-TUBERCULOSIS AGENTS, in Graduate Health Sciences. May 2009, The University of Tennessee.

71. Vaddady, V.N.R.P.K., PHARMACOKINETIC AND PHARMACODYNAMIC STUDIES OF A NOVEL SPECTINAMIDE SERIES OF ANTITUBERCULOSIS AGENTS, in Graduate Health Sciences. May 2011, The University of Tennessee.

72. van den Boogaard, J., et al., New drugs against tuberculosis: problems, progress, and evaluation of agents in clinical development. Antimicrob Agents Chemother, 2009. 53(3): p. 849-62.

73. Caminero, J.A., et al., Best drug treatment for multidrug-resistant and extensively drug-resistant tuberculosis. Lancet Infect Dis, 2010. 10(9): p. 621-9.

74. Mitnick, C.D., S.C. Appleton, and S.S. Shin, Epidemiology and treatment of multidrug resistant tuberculosis. Semin Respir Crit Care Med, 2008. 29(5): p. 499-524.

75. Casali, N., et al., Evolution and transmission of drug-resistant tuberculosis in a Russian population. Nat Genet, 2014. 46(3): p. 279-86.

76. Mdluli, K., T. Kaneko, and A. Upton, The tuberculosis drug discovery and development pipeline and emerging drug targets. Cold Spring Harb Perspect Med, 2015. 5(6).

77. Borovinskaya, M.A., et al., A steric block in translation caused by the antibiotic spectinomycin. ACS Chem Biol, 2007. 2(8): p. 545-52.

78. Louw, G.E., et al., A balancing act: efflux/influx in mycobacterial drug resistance. Antimicrob Agents Chemother, 2009. 53(8): p. 3181-9. 
79. Balganesh, M., et al., Efflux pumps of Mycobacterium tuberculosis play a significant role in antituberculosis activity of potential drug candidates.

Antimicrob Agents Chemother, 2012. 56(5): p. 2643-51.

80. Ramon-Garcia, S., et al., Functional and genetic characterization of the tap efflux pump in Mycobacterium bovis BCG. Antimicrob Agents Chemother, 2012. 56(4): p. 2074-83.

81. Lee, R.E., et al., Spectinamides: a new class of semisynthetic antituberculosis agents that overcome native drug efflux. Nat Med, 2014. 20(2): p. 152-8.

82. Morris, B.D.a.T., Physiological parameters in laboratory animals and humans. Pharmaceutical Research, 1993. 10: p. 1093-1095.

83. Scheife, R.T., Protein binding: what does it mean? DICP, 1989. 23(7-8 Suppl): p. S27-31.

84. PE, R., Plasma protein binding displacement interactions--why are they still regarded as clinically important? British Journal of Clinical Pharmacology, 1994. 37(2): p. 125-128.

85. Daniel, W.A. and J. Wojcikowski, Lysosomal trapping as an important mechanism involved in the cellular distribution of perazine and in pharmacokinetic interaction with antidepressants. Eur Neuropsychopharmacol, 1999. 9(6): p. 483-91.

86. Kazmi, F., et al., Lysosomal sequestration (trapping) of lipophilic amine (cationic amphiphilic) drugs in immortalized human hepatocytes (Fa2N-4 cells). Drug Metab Dispos, 2013. 41(4): p. 897-905.

87. Daniel, W.A. and J. Wojcikowski, Contribution of lysosomal trapping to the total tissue uptake of psychotropic drugs. Pharmacol Toxicol, 1997. 80(2): p. 62-8.

88. Goldman, S.D., et al., Mechanisms of amine accumulation in, and egress from, lysosomes. Bioanalysis, 2009. 1(8): p. 1445-59.

89. Anderson, N. and J. Borlak, Drug-induced phospholipidosis. FEBS Lett, 2006. 580(23): p. 5533-40.

90. Gonzalez-Juarrero, M., et al., Mouse model for efficacy testing of antituberculosis agents via intrapulmonary delivery. Antimicrob Agents Chemother, 2012. 56(7): p. 3957-9.

91. De Luca, D., et al., Intrapulmonary drug administration in neonatal and paediatric critical care: a comprehensive review. Eur Respir J, 2011. 37(3): p. 678-89.

92. Chono, S., et al., Pharmacokinetic and pharmacodynamic efficacy of intrapulmonary administration of ciprofloxacin for the treatment of respiratory infections. Drug Metab Pharmacokinet, 2007. 22(2): p. 88-95.

93. Vavilin, G.I., et al., [Intrapulmonary administration of antitubercular agents in experimental tuberculosis of the lungs]. Probl Tuberk, 1979(7): p. 52-6.

94. Li, Y.J., M. Petrofsky, and L.E. Bermudez, Mycobacterium tuberculosis uptake by recipient host macrophages is influenced by environmental conditions in the granuloma of the infectious individual and is associated with impaired production of interleukin-12 and tumor necrosis factor alpha. Infect Immun, 2002. 70(11): p. 6223-30.

95. Ernst, J.D., Macrophage receptors for Mycobacterium tuberculosis. Infect Immun, 1998. 66(4): p. 1277-81. 
96. Fenton, M.J., Macrophages and tuberculosis. Curr Opin Hematol, 1998. 5(1): p. 72-8.

97. Podinovskaia, M., et al., Infection of macrophages with Mycobacterium tuberculosis induces global modifications to phagosomal function. Cell Microbiol, 2013. 15(6): p. 843-59.

98. Shaffer, C.L., et al., Using a tritiated compound to elucidate its preclinical metabolic and excretory pathways in vivo: exploring tritium exchange risk. Drug Metab Dispos, 2006. 34(9): p. 1615-23.

99. Yang, S., et al., Pharmacokinetics and disposition study of calf thymus DNA in rats by applying 3H-labeling method. J Pharm Biomed Anal, 2012. 64-65: p. 359.

100. Roffey, S.J., et al., What is the objective of the mass balance study? A retrospective analysis of data in animal and human excretion studies employing radiolabeled drugs. Drug Metab Rev, 2007. 39(1): p. 17-43.

101. Muir, K.T. and R.O. Gomeni, Non-compartmental analysis: Pharmacokinetics in Drug Development, In Pharmacokinetics in Drug Development: Clinical Study Design and Analysis, P.L. Bonate and D.R. Howard, Editors. 2004 AAPS Press: USA.

102. Vogelman, B., et al., In vivo postantibiotic effect in a thigh infection in neutropenic mice. J Infect Dis, 1988. 157(2): p. 287-98.

103. MacKenzie, F.M. and I.M. Gould, The post-antibiotic effect. J Antimicrob Chemother, 1993. 32(4): p. 519-37.

104. Trivedi, A., R.E. Lee, and B. Meibohm, Applications of pharmacometrics in the clinical development and pharmacotherapy of anti-infectives. Expert Rev Clin Pharmacol, 2013. 6(2): p. 159-70.

105. Nielsen, E.I. and L.E. Friberg, Pharmacokinetic-pharmacodynamic modeling of antibacterial drugs. Pharmacol Rev, 2013. 65(3): p. 1053-90.

106. Treyaprasert, W., et al., Pharmacokinetic/pharmacodynamic modeling of in vitro activity of azithromycin against four different bacterial strains. Int J Antimicrob Agents, 2007. 29(3): p. 263-70.

107. Palaci, M., et al., Cavitary disease and quantitative sputum bacillary load in cases of pulmonary tuberculosis. J Clin Microbiol, 2007. 45(12): p. 4064-6.

108. Mostowy, S., et al., The in vitro evolution of BCG vaccines. Vaccine, 2003. 21(27-30): p. 4270-4274.

109. Beste, D.J., et al., Compiling a molecular inventory for Mycobacterium bovis $B C G$ at two growth rates: evidence for growth rate-mediated regulation of ribosome biosynthesis and lipid metabolism. J Bacteriol, 2005. 187(5): p. 167784.

110. Nielsen, E.I., O. Cars, and L.E. Friberg, Pharmacokinetic/pharmacodynamic $(P K / P D)$ indices of antibiotics predicted by a semimechanistic PKPD model: a step toward model-based dose optimization. Antimicrob Agents Chemother, 2011. 55(10): p. 4619-30.

111. Woodcock, J., J.P. Griffin, and R.E. Behrman, Development of Novel Combination Therapies. New England Journal of Medicine, 2011. 364(11): p. 985-987. 
112. Zumla, A.I., et al., New antituberculosis drugs, regimens, and adjunct therapies: needs, advances, and future prospects. Lancet Infect Dis, 2014. 14(4): p. 327-40.

113. Lim, T.P., et al., Quantitative assessment of combination antimicrobial therapy against multidrug-resistant Acinetobacter baumannii. Antimicrob Agents Chemother, 2008. 52(8): p. 2898-904.

114. Tam, V.H., et al., Novel approach to characterization of combined pharmacodynamic effects of antimicrobial agents. Antimicrob Agents Chemother, 2004. 48(11): p. 4315-21.

115. Yuan, Z., et al., Quantitative assessment of combination antimicrobial therapy against multidrug-resistant bacteria in a murine pneumonia model. J Infect Dis, 2010. 201(6): p. 889-97.

116. Blaser, J., In-vitro model for simultaneous simulation of the serum kinetics of two drugs with different half-lives. J Antimicrob Chemother, 1985. 15 Suppl A: p. 125-30.

117. Shim, C.-K. and J.-U. Lee, Comparative study of rifampicin pharmacokinetics administered orally and intravenously in the fasted and non-fasted rats. Archives of Pharmacal Research, 1985. 8(3): p. 177-186.

118. Sopirala, M.M., et al., Synergy testing by Etest, microdilution checkerboard, and time-kill methods for pan-drug-resistant Acinetobacter baumannii. Antimicrob Agents Chemother, 2010. 54(11): p. 4678-83.

119. Bonapace, C.R., et al., Evaluation of antibiotic synergy against Acinetobacter baumannii: a comparison with Etest, time-kill, and checkerboard methods. Diagn Microbiol Infect Dis, 2000. 38(1): p. 43-50.

120. Hurdle, J.G., et al., A microbiological assessment of novel nitrofuranylamides as anti-tuberculosis agents. J Antimicrob Chemother, 2008. 62(5): p. 1037-45.

121. Institute, C.a.L.S., Methods for Dilution Antimicrobial Susceptibility Tests for Bacteria That Grow Aerobically, in Approved Standard-Ninth Edition. 2012.

122. Hsieh, M.H., et al., Synergy assessed by checkerboard. A critical analysis. Diagn Microbiol Infect Dis, 1993. 16(4): p. 343-9.

123. Bonapace, C.R., et al., Comparison of methods of interpretation of checkerboard synergy testing. Diagn Microbiol Infect Dis, 2002. 44(4): p. 363-6.

124. Cappelletty, D.M. and M.J. Rybak, Comparison of methodologies for synergism testing of drug combinations against resistant strains of Pseudomonas aeruginosa. Antimicrob Agents Chemother, 1996. 40(3): p. 677-83.

125. Chadwick, E.G., S.T. Shulman, and R. Yogev, Correlation of antibiotic synergy in vitro and in vivo: use of an animal model of neutropenic gram-negative sepsis. J Infect Dis, 1986. 154(4): p. 670-5. 


\section{VITA}

Ashit Trivedi was born in 1985 in Ahmedabad, India. He was brought up and finished his schooling in 2002 in Mumbai, India. He obtained his Bachelors of Science in Biochemistry in 2005 and Masters of Science in Bioanalytical Sciences in 2007 from Ramnarain Ruia College, University of Mumbai. During his Bachelors and Master's degree, he did multiple internships at Tata Memorial Hospital, Haffkines Research Institute, Wockhardt Hospitals, Animal research center and Lupin Pharmaceuticals. He worked as Research Associate at Macleods Pharmaceuticals, Mumbai and Research Associate in Drug Metabolism and Pharmacokinetics at Lupin Pharmaceuticals, Pune, India. Later, he received another Master's degree in Pharmaceuticals Sciences from Northeastern University, Boston, MA in 2010. During his Masters, he did an internship at Abbott Bioresearch Center in Molecular Pharmacology, Worcester, MA and in Formulations at Vertex Pharmaceuticals, Cambridge, MA in 2009 and 2010, respectively.

Consequently, he joined the PhD Program in Pharmaceutical Science at University of Tennessee Health Science Center in 2010 with Dr. Bernd Meibohm as his major advisor. During his PhD, he was involved with various leadership positions such as Chair-elect of the American Association of Pharmaceutical Scientist (AAPS) Student Chapter at the University of Tennessee in 2012, Chair of the AAPS Student Chapter in 2013, Trainee Chair for the American Conference on Pharmacometrics in 2014 and Student Representative for the Clinical Pharmacology and Translational Research section in AAPS from 2013-2015. He received multiple travel awards and was a recipient of the Graduate Research Award in Pharmacokinetics, Pharmacodynamics and Drug Metabolism and Clinical Pharmacology and Translational Research at the AAPS Annual Meeting in 2014. During this period, he was also a summer intern at Takeda (Millennium) Pharmaceuticals, Cambridge MA in summer of 2014. After completion of his $\mathrm{PhD}$, he will be joining the Clinical Pharmacology group at Amgen, Thousand Oaks, CA as a Scientist. 